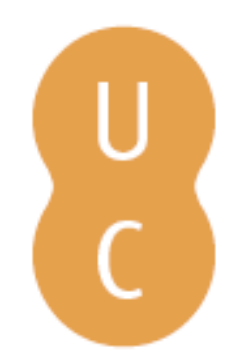

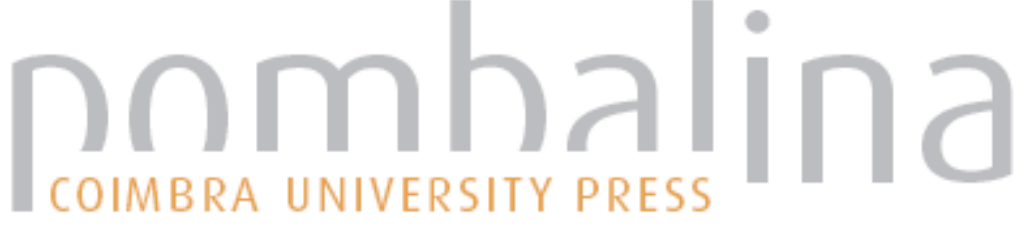

\section{A mobilidade académica e a emigração portuguesa qualificada}

Autor(es): $\quad$ Gomes, Rui Machado (coord.)

Publicado por: Imprensa da Universidade de Coimbra

URL

persistente: URI:http://hdl.handle.net/10316.2/47279

DOI: $\quad$ DOI:https://doi.org/10.14195/978-989-26-1707-7

Accessed : $\quad$ 3-Mar-2020 15:28:48

A navegação consulta e descarregamento dos títulos inseridos nas Bibliotecas Digitais UC Digitalis, UC Pombalina e UC Impactum, pressupõem a aceitação plena e sem reservas dos Termos e Condições de Uso destas Bibliotecas Digitais, disponíveis em https://digitalis.uc.pt/pt-pt/termos.

Conforme exposto nos referidos Termos e Condições de Uso, o descarregamento de títulos de acesso restrito requer uma licença válida de autorização devendo o utilizador aceder ao(s) documento(s) a partir de um endereço de IP da instituição detentora da supramencionada licença.

Ao utilizador é apenas permitido o descarregamento para uso pessoal, pelo que o emprego do(s) título(s) descarregado(s) para outro fim, designadamente comercial, carece de autorização do respetivo autor ou editor da obra.

Na medida em que todas as obras da UC Digitalis se encontram protegidas pelo Código do Direito de Autor e Direitos Conexos e demais legislação aplicável, toda a cópia, parcial ou total, deste documento, nos casos em que é legalmente admitida, deverá conter ou fazer-se acompanhar por este aviso. 


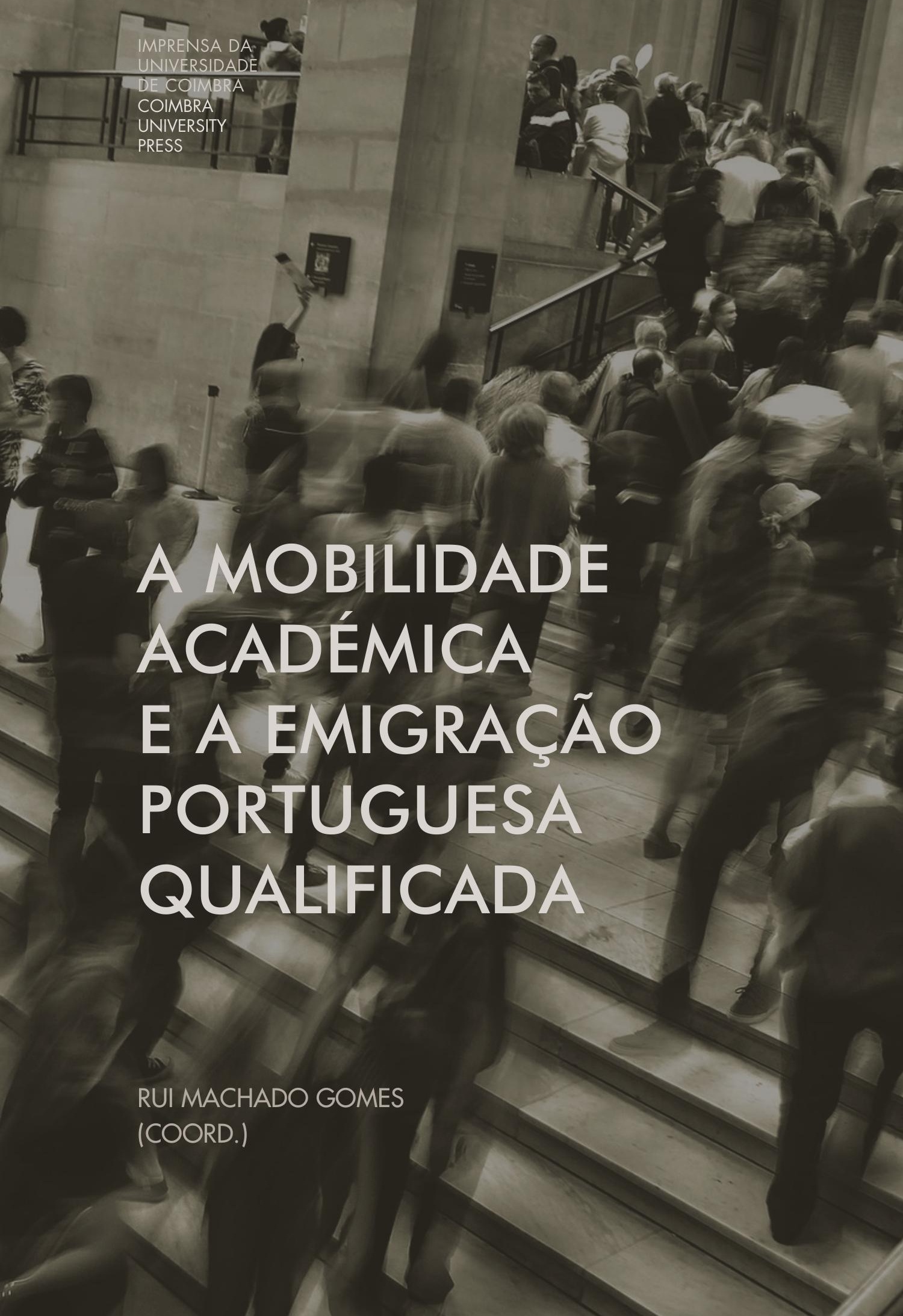


Neste livro são descritas e analisadas opções de mobilidade e emigração individuais, que se incluem numa longa história que vem sendo escrita desde há séculos por muitos portugueses de diferentes gerações e qualificações que resolveram emigrar. As dificuldades de hoje são menores, os percursos são, regra geral, bem-sucedidos e revelam pessoas que encontraram forma de avançar e que tomaram as rédeas do seu destino. Estas opções individuais são, no entanto, também a expressão de que um mal profundo ataca a Europa, fazendo com que os mais qualificados dos países periféricos e semi-periféricos sejam atraídos pelos países centrais, onde estão disponíveis os recursos, deixando os países menos desenvolvidos entregues a uma economia carente de conhecimento e inovação. Ressoa no murmúrio das vozes dos que ouvimos e inquirimos uma experiência que anseia por ser partilhada e compreendida na sua plenitude. 


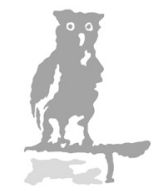

I N

V E

E

S

T

I

G

A

C

$\tilde{A}$

0

$\underbrace{}_{\substack{\text { IMPREISA DA UNIERSIDADE DE COIMBRA } \\ \text { COIMBRA LNIVESITY PRESS }}}$

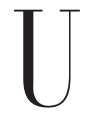




\section{EDIÇÃo}

Imprensa da Universidade de Coimbra

Email: imprensauc@ci.uc.pt

URL: http//www.uc.pt/imprensa_uc

Vendas online: http://livrariadaimprensa.uc.pt

COORDENAÇÃO EDITORIAL

Imprensa da Universidade de Coimbra

CONCEÇÃo GRÁFICA

Imprensa da Universidade de Coimbra

IMAGEM DA CAPA

by Free-Photos

via Pixabay

INFOGRAFIA DA CAPA

Mickael Silva

Pré-IMPRESSÃo

Jorge Neves

PRINT BY

KDP

ISBN

978-989-26-1706-0

ISBN DIGITAL

978-989-26-1707-7

DOI

https://doi.org/10.14195/978-989-26-1707-7

DEPÓSITO LEGAL

460391/19

(C) AGOSTO 2019, IMPRENSA DA UNIVERSIDADE DE COIMBRA

A mobilidade académica e a emigração portuguesa qualificada / coord. Rui Machado

Gomes. - (Investigação)

ISBN 978-989-26-1706-0 (ed. impressa)

ISBN 978-989-26-1707-7 (ed. eletrónica)

I - GOMES, Rui, 1955-

CDU 314 
IMPRENSA DA

UNIVERSIDADE

DE COIMBRA

COIMBRA

UNIVERSITY

PRESS

A MOBILIDADE

ACADÉMICA

E A EMIGRAÇÃO

PORTUGUESA

QUALIFICADA

RUI MACHADO GOMES

(COORD.) 
(Página deixada propositadamente em branco) 


\section{Í N D I C E}

Introdução . . . . . . . . . . . . . . . . . . . . . . . . . . . . 7

A FUGA DE CÉREBROS EM PERSPETIVA COMPARADA

A Emigração Portuguesa Qualificada: Êxodo ou Diáspora? . . . . . . . . . . 11 RUI GOMES et al.

A Produção Social do Indivíduo que Emigra:

uma Análise a partir de Retratos Sociológicos. . . . . . . . . . . . . . 43

JOÃO TEIXEIRA LOPES et al.

Knowledge Diasporas: Moving Frontier of Development . . . . . . . . . . . 57

JEAN-BAPTISTE MEYER

Brain Drain-Brain Gain: an International Perspective . . . . . . . . . 73

WENDY HANSEN

VELHAS E NOVAS EMIGRAÇÕES

A Nova Emigração e a Relação com a Sociedade Portuguesa:

Perfis e Estratégias dos Emigrantes Mais e Menos Qualificados . . . . . . . . 91 PEDRO CANDEIAS et al.

A Emigração Portuguesa: da Ausência à Redescoberta dos Movimentos

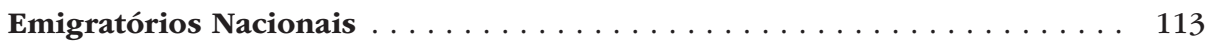

JOSÉ CARLOS MARQUES

As Qualificações como Passaporte?

Processos de (Re)Produção de Mobilidades na Saúde.

JOANA SOUSA RIBEIRO 
(Página deixada propositadamente em branco) 


\section{N T R O D U Ç ̃̃ O}

A fuga de cérebros refere-se à transferência de capital humano com elevados níveis de educação e competências dos países menos desenvolvidos para os países mais desenvolvidos. A saída de profissionais altamente qualificados limita deste modo a rentabilização dos investimentos educativos realizados, criando condições favoráveis à sua reutilização pelos países mais desenvolvidos.

A emigração qualificada tem sido analisada segundo dois modelos contrastantes: por um lado, o modelo do êxodo que põe em primeiro plano a ideia de que os mais competentes se veem obrigados a um exílio que lhes permita obter um posto de trabalho e uma remuneração correspondentes à sua formação; por outro lado, o modelo da diáspora que sublinha os benefícios mútuos retirados das trocas interculturais abertas pela circulação de saberes promovida pelas elites académicas, científicas e culturais cosmopolitas.

Sendo Portugal um dos países europeus com maior emissão de emigrantes qualificados, este é um debate que atravessa atualmente a sociedade portuguesa. A conferência realizada em setembro de 2015 na Faculdade de Letras da Universidade do Porto visou aprofundá-lo de modo informado, tornando públicos os resultados de um projeto financiado pela FCT que analisou a fuga de cérebros em Portugal nos últimos anos. Este exercício foi feito a partir dos grandes números e das biografias de portugueses que emigraram para a Europa na última década.

No primeiro caso, demos a conhecer as respostas a um questionário administrado em 2014 a mais de 1000 portugueses qualificados que optaram nos últimos anos pela emigração no espaço europeu. Quais os fatores que afetam as decisões de migração? Quais os modos de integração no mercado de trabalho 
europeu? Quais as expetativas de regresso? Estas foram algumas das perguntas que vimos respondidas.

No segundo caso, partilhámos os percursos biográficos de mais de 50 portugueses que escolheram viver e trabalhar fora de Portugal. São retratos de jovens mulheres e homens que contam histórias de indivíduos e famílias, de opções pessoais e fluxos coletivos, de afetos e amizades, de sucessos e fracassos, de fim de sonhos e recomeço de projetos. Em todos eles existe um traço comum: resistir à perda de valor criado pelo investimento do país, dos pais e dos próprios na educação. Alguns dos entrevistados marcaram presença numa mesa-redonda com associações de graduados portugueses no espaço europeu.

Mas a conferência serviu também para construir pontes analíticas entre modos de ver a fuga de cérebros em diferentes latitudes e numa perspetiva comparada. Qual é a visão dos países de acolhimento? Qual é a visão dos países emissores? Qual a interpretação da fuga de cérebros vista a partir da América Latina? Dois conferencistas convidados abriram pistas para este debate.

Finalmente, a conferência estabeleceu o diálogo com outras investigações recentemente concluídas, quer analisando os movimentos emigratórios portugueses mais gerais, quer interpretando os fluxos específicos de certas profissões com um impacto social muito evidente (académicos, cientistas, enfermeiros, etc.).

Neste livro são descritas e analisadas opções individuais, também elas parte de uma longa história que vem sendo escrita desde há séculos por muitos portugueses de diferentes gerações e qualificações. As dificuldades de hoje são menores, os percursos são, regra geral, bem-sucedidos e revelam pessoas que encontraram forma de avançar e que tomaram as rédeas do seu destino. As mesmas opções individuais são, no entanto, também a expressão de que um mal profundo ataca a Europa, fazendo com que os mais qualificados dos países periféricos sejam atraídos pelos países centrais, onde estão disponíveis os recursos, deixando os países menos desenvolvidos entregues a uma economia carente de conhecimento e inovação. Ressoa no murmúrio das vozes dos que ouvimos e inquirimos uma experiência que anseia por ser partilhada e compreendida na sua plenitude. 


\section{A FUGA DE CÉREBROS \\ EM PERSPETIVA COMPARADA}


(Página deixada propositadamente em branco) 
RUI GOMES et al. ${ }^{1}$

https://orcid.org/0000-0002-3793-6369

\section{A EMIGRAÇÃO PORTUGUESA QUALIFICADA: ÊXODO OU DIÁSPORA?}

\section{Enquadramento e objetivos}

O presente texto apresenta o projeto de investigação BRADRAMO - Brain Drain And Academic Mobility From Portugal to Europe, relevando os seus objetivos e interrogações iniciais, a estratégia metodológica escolhida, os resultados obtidos e as principais conclusões a que a pesquisa conduziu.

Este projeto, financiado por fundos nacionais através da Fundação para a Ciência e a Tecnologia (FCT/MEC) e cofinanciado pelo Fundo Europeu de Desenvolvimento Regional (FEDER) através do COMPETE - Programa Operacional Fatores de Competitividade (POFC), envolveu uma equipa multidisciplinar de 13 investigadores com formação em diversas áreas das ciências sociais (sociologia, ciências da educação e economia), tendo estado ativo entre janeiro de 2013 e

${ }^{1}$ Autores: Rui Machado Gomes (CES/FCDEF - Universidade de Coimbra); João Teixeira Lopes (IS/FL - Universidade do Porto); José Pedro Silva (IS - Universidade do Porto); Rafaela Ganga (IS - Universidade do Porto); Henrique Vaz (CIIE/FPCEUP - Universidade do Porto); Luísa Cerdeira (IE - Universidade de Lisboa); Belmiro Cabrito (IE - Universidade de Lisboa); Dulce Magalhães (IS/FLUP - Universidade do Porto); Maria Lourdes Machado-Taylor (CIPES - Centro de Investigação de Políticas do Ensino Superior); Paulo Peixoto (CES/FE - Universidade de Coimbra); Rui Brites (ISEG - Universidade de Lisboa); Sílvia Silva (FL - Universidade do Porto/FE - Universidade de Coimbra); Tomás Patrocínio (IE Universidade de Lisboa).

Este artigo é resultado do projeto de investigação "Êxodo de Competências e Mobilidade Académica de Portugal para a Europa" (PTDC/IVC-PEC/5049/2012), financiado por fundos nacionais através da Fundação para a Ciência e a Tecnologia (FCT/MEC) e cofinanciado pelo Fundo Europeu de Desenvolvimento Regional (FEDER) através do COMPETE - Programa Operacional Fatores de Competitividade (POFC). 
setembro de 2015. A pesquisa desenvolvida incidiu sobre a emigração portuguesa qualificada ${ }^{2}$ para o espaço europeu.

O ponto de partida para a realização desta investigação foi a constatação da intensificação dos fluxos emigratórios portugueses nos anos imediatamente anteriores ao seu início, com destaque para o ano de 2011. Olhando apenas para o volume das saídas, a vaga emigratória que se seguiu à crise financeira de 2008 e, em especial, à imposição de um programa de reajustamento estrutural iniciado em 2011 sob a égide da chamada "Troika" constituída pela Comissão Europeia, Banco Central Europeu e Fundo Monetário Internacional, só é comparável ao cenário que se registava nos últimos anos do Estado Novo: entre 2010 e 2015, o número de pessoas que saiu de Portugal foi sempre superior a 100.000, atingindo os $134.624 \mathrm{em} 2014^{3}$.

Por outro lado, o peso dos trabalhadores qualificados no fluxo de saída aumentou significativamente. Assim, entre 2001-2002 e 2010-2011, a emigração de portugueses qualificados registou um aumento de 87,5\%. Nesse período, o peso dos trabalhadores qualificados no conjunto de todos os emigrantes subiu de 6,2\% para 9,9\%, atingindo os 11\% em 2015 (Gomes et al., 2015). É certo que a informação disponível sobre a emigração portuguesa qualificada apresenta lacunas importantes. Ainda assim, estes números evidenciam uma tendência importante de aumento das saídas de trabalhadores qualificados do país em anos recentes, podendo ainda estar subavaliados, como nos mostram as estatísticas de alguns dos países que mais emigrantes portugueses recebem. Por exemplo, de acordo com estatísticas oficiais do Reino Unido, 21,5\% dos emigrantes portugueses com mais de 16 anos possuíam, em 2011, qualificações de nível superior.

As implicações futuras desta saída em grande escala de capital humano do país não são ainda totalmente claras. Existem várias teses que procuram explicar as consequências desse fenómeno, porém, os caminhos apontados são frequentemente diversos.

2 Para efeitos da investigação desenvolvida, definimos emigração qualificada como a emigração de indivíduos detentores de um diploma do ensino superior ou de experiência profissional equivalente.

3 Dados disponibilizados pelo Observatório da Emigração e disponíveis em http:// observatorioemigracao.pt/np4/1315/ (consultado a 27 de junho de 2017). 
O primeiro destes modelos teóricos é o do brain drain: uma vez que o capital humano não é aproveitado na sociedade ou país onde foi gerado, perde-se, no médio e no longo prazo, o investimento realizado na sua criação e as externalidades dele resultantes. Investigações prévias apontam para efeitos negativos no crescimento económico e na formação de capital humano no país de origem (Miyagiwa, 1991; Haque \& Kim, 1995). Assim, o retorno do investimento na educação pode-se perder devido ao efeito da emigração de recursos humanos, medido através das perdas de retorno de capital ou de potenciação de desenvolvimento (Rosenbaum et al., 1990).

A segunda tese é a do brain drain benéfico: uma vez que a emigração de indivíduos qualificados resulta em rendimentos individuais mais elevados, o número de pessoas capazes de investir na sua educação e na educação dos seus filhos aumentará, o que terá um efeito positivo na taxa de educação dos países em desenvolvimento (Mountford, 1997). No entanto, os resultados deste tipo de abordagem não são conclusivos. Se alguns estudos a confirmam (Beine et al., 2003; 2008; Docquier et al., 2008), outros sugerem que os ganhos obtidos não compensam o efeito de brain drain (Heuer, 2011).

De acordo com a tese da fertilização cruzada a partir da mobilidade das elites, os movimentos circulares e frequentemente transitórios de profissionais altamente qualificados são benéficos para os países de origem e de destino, uma vez que potenciam a troca de conhecimento e de competências e os projetos temporários.

O modelo da circulação de "cérebros" através da criação de redes defende que o aumento da circulação de pessoas e conhecimento é inevitável num contexto de globalização, independentemente do nível de desenvolvimento dos países. Isto articula-se com as redes de transferência de tecnologia e conhecimento do país de destino para o país de origem e que são resultado da crescente transnacionalização das esferas científica e empresarial. Segundo esta abordagem, estas redes são vantajosas para o desenvolvimento dos países de origem.

Finalmente, o modelo do brain drain latente, articulado com a mobilidade formativa, postula que as saídas do país relacionadas com a formação e a educação, previsivelmente temporárias, podem-se tornar permanentes com a inserção no mercado de trabalho de países mais desenvolvidos ou menos 
afetados pelo desemprego jovem (Pizarro, 2005). No entanto, outras investigações sugerem que um período de estudo fora seguido de uma experiência de trabalho no país de destino pode produzir um benefício a médio prazo, no momento de regresso ao país de origem (Johnson \& Regets, 1998).

Perante a multiplicidade de abordagens e conceções, a investigação desenvolvida teve como propósito colocar à prova cada um destes modelos teóricos sobre a emigração qualificada, procurando alguma inovação em termos teóricos e metodológicos: primeiro, ao recusar os pressupostos globalizantes sobre a teoria do capital humano e ao analisar o conjunto de fatores que geram a repulsão e a atração, antevendo-se assim que a emigração possa ser gerada por fatores que ultrapassam a diferença entre as remunerações; e segundo, uma vez que se admite que o sistema de emprego internacional depende não só do efeito independente do jogo da oferta e da procura, tornando também necessário analisar as trajetórias biográficas, no sentido de compreender as razões e os destinos da emigração.

Com estes propósitos em mente, e tendo ainda em conta as já referidas limitações da informação estatística disponível sobre emigração portuguesa qualificada, partiu-se para a pesquisa com as seguintes questões fundamentais: 1) Quais são as modalidades, causas e caraterísticas do brain drain português na última década?; 2) Qual foi a evolução do stock e dos fluxos?; 3) Quais são as formas de articulação entre as diferentes modalidades do êxodo de profissionais portugueses qualificados e os processos de migração internacional? 4) Quais são as formas de articulação entre o brain drain e os fluxos crescentes de mobilidade académica?

\section{Metodologia}

Uma vez que o brain drain é um fenómeno multifacetado, o desenho metodológico segue a natureza relacional do objeto social, articulando várias dimensões de análise. Realizou-se um estudo comparativo de quatro casos, representando diferentes tipos de emigração qualificada: a) migração para um país europeu para o exercício de profissões nos sistemas científico ou de ensino superior; b) migração de longo prazo para um país europeu para 
trabalhar nos segmentos primário ou secundário do sistema de emprego; c) mobilidade estudantil europeia do $1 .^{\circ}, 2 .^{\circ}$ ou $3 .^{\circ}$ ciclo do ensino superior conducente à inserção no segmento primário ou secundário do mercado de trabalho; d) mobilidade e circulação transitória ou pendular através de redes europeias de ciência, produção, serviços ou cultura. Procurou-se compreender cada um destes casos e, ao mesmo tempo, encontrar fatores e processos de comparação, translação e transferência, permitindo fazer generalizações que não se baseiam na probabilidade estatística e na representatividade, mas antes na profundidade, intensidade e densidade da análise.

Assim, a partir de cada caso e dentro de cada caso, combinou-se procedimentos de natureza qualitativa e quantitativa, explicação e compreensão, dedução e indução, enquadrados num diálogo constante entre teoria e prática.

O recurso a uma panóplia relativamente alargada de técnicas de recolha de informação permitiu a operacionalização dos propósitos antes assumidos, bem como a comparação das práticas vividas, experienciadas, narradas e declaradas dos atores envolvidos nestes fluxos migratórios, possibilitando a triangulação da informação.

A seleção dos quatro casos seguiu a interseção dos seguintes princípios estruturantes basilares: 1) caraterísticas temporais da mobilidade: permanente ou temporária, de longo prazo ou transitória; 2) posição social no sistema de emprego: segmento primário ou secundário do mercado de trabalho; 3) perfil funcional do sistema de emprego: académicos e cientistas, outras profissões altamente qualificadas; e 4) tipo de mobilidade: direta (depois da entrada no sistema de emprego do país de origem), indireta ou latente (depois de um período de estudos no país de destino).

Em cada um destes casos, a abordagem iniciou-se com uma pesquisa exploratória baseada na análise de fontes secundárias, tanto documentais como estatísticas, articuladas com conversas informais com informadores privilegiados das organizações que lidam com estes fluxos e atores.

Assumindo-se uma estratégia mista e multilateral, articulando a pesquisa extensiva com uma análise em profundidade, intensiva, recorreu-se a técnicas quantitativas e qualitativas de recolha de informação: entrevistas com grupos focais, inquéritos por questionário e histórias de vida, traduzidas nos retratos sociológicos. 
A primeira fase foi a realização de grupos focais para cada um dos diferentes casos em análise (Barbour \& Kitzinger, 1999). Devido à sua natureza intersubjetiva e partilhada (Krueger, 1998), o recurso a esta técnica foi particularmente útil para, antes da administração do inquérito por questionário, identificar fatores de push e pull, bem como fatores de reskilling e deskilling. Isto revelou-se especialmente valioso, uma vez que a revisão do estado de arte apontou para fatores muito gerais. Deste modo, foi possível construir indicadores e dimensões mais precisas para o inquérito.

As entrevistas foram feitas por videoconferência, usando o software de chamadas Skype, ultrapassando, desta forma, as fronteiras geográficas que estão inerentes ao universo de estudo do projeto, bem como as dificuldades de reunião dos entrevistados num mesmo espaço físico, próprias da técnica utilizada.

A seleção dos entrevistados foi realizada com base na técnica de amostragem bola-de-neve, iniciada com um apelo através de um formulário de intenção de participação que foi divulgado pelos contactos pessoais dos investigadores e por contactos institucionais com ligação a portugueses em mobilidade. Esta lista inicial de possíveis entrevistados foi, de resto, o ponto de partida para os contactos posteriores de participação.

A escassez de estudos sistemáticos sobre fluxos migratórios associados à mobilidade académica torna especialmente relevante, de um ponto de vista metodológico, uma abordagem inicial transversal, mais adequada a um esforço de mapeamento da representatividade do fenómeno. Foi precisamente essa escassez que determinou, para o questionário, a definição de uma amostra não-probabilística intencional (Almeida \& Pinto, 1996), que, articulada com outros instrumentos de pesquisa, contribui, gradualmente, para a compreensão não só da extensão do fenómeno, mas também das suas caraterísticas intrínsecas.

Deste modo, o questionário escolhe deliberadamente um público dominante - dotado de elevadas competências académicas - ao mesmo tempo que contém as diversas situações expressas nos estudos de caso desenvolvidos que, de certo modo, determinam uma categorização prévia que garante a comparabilidade com o instrumento do inquérito. Esta comparabilidade permite-nos discriminar os traços determinantes na identificação do fenómeno. Do mesmo modo, a estrutura do questionário, para além de incluir as variá- 
veis independentes que caraterizam a população-alvo, procura elencar um conjunto de escalas que abordam os seguintes tópicos: 1) Fatores push e pull; 2) Fatores percebidos como cruciais para a decisão de migrar; 3) Deskilling e reskilling; 4) Brain gain e brain waste; e 5) Mobilidade social e cultural, sendo importante compreender até que ponto a decisão de migrar baseada, na sua fase inicial, em razões relacionadas com a formação e o emprego, se transforma (ou não) em mobilidade social e cultural.

Dos resultados provisórios produzidos pela análise dos dados recolhidos através do inquérito por questionário, bem como das suas limitações e das pistas por eles fornecidas, emergiram as linhas orientadoras que enquadraram a preparação dos guiões para a realização dos retratos sociológicos (Lahire, 2002), com especial foco na explicação das contradições que se revelam na interseção da administração do inquérito por questionário, a análise exploratória e os resultados dos focus group.

Procedeu-se ainda a uma análise estatística multivariada dos dados obtidos através do inquérito por questionário, o que permitiu a construção de perfis-tipo dos emigrantes, cada um deles definindo um tipo de relação particular com o fenómeno em estudo. A partir daqui foram selecionados os indivíduos e grupos para a construção dos retratos sociológicos. A preparação do guião foi acompanhada pela preocupação em compreender como é que os atores envolvidos nos fluxos migratórios analisados estruturam, através das suas vidas, disposições favoráveis à migração e em perceber a tensão entre disposições e situações múltiplas em que os principais contextos desencadeiam o desejo de mobilidade.

Os retratos sociológicos assumem a existência de indivíduos multissocializados, agentes plurais que, através das suas trajetórias, adquiriram uma multiplicidade de disposições, muitas vezes contrastantes e até contraditórias, que, de certo modo, refletem a complexidade das sociedades contemporâneas e a natureza multidimensional dos projetos e constrangimentos associados a estes fluxos migratórios.

A triangulação final permitiu confrontar práticas e discursos ou, noutros termos, o vivido com o experienciado (a memória do passado), o narrado (especialmente visível nos retratos), o compartilhado (destacado nos grupos focais) e o declarado (mostrado no inquérito). 


\section{Principais resultados 4}

\section{Resultados dos focus group}

Os focus group permitiram, por um lado, enquadrar e preparar a recolha de informação quantitativa através da aplicação de inquéritos e, por outro lado, identificar especificidades relacionadas com cada um dos quatro estudos de caso a desenvolver no âmbito do projeto.

De uma forma geral, os focus group possibilitaram caraterizar projetos de vida; mapear e tipificar trajetórias de vida (familiar, formação, emprego); identificar estratégias de rentabilização do capital escolar nos projetos de vida; e dar conta dos mecanismos de naturalização (ato pensado, repentino, fatores desencadeadores, enquadramento familiar/social) que possam ser vistos como efeitos socializadores da decisão de emigrar.

Selecionados e agrupados tendo em conta o estudo de caso a que mais se adequavam, considerando, igualmente, a diversidade de sexo, idade, país e profissão, foram criados sete focus group, num total de 27 pessoas. Adicionalmente, e por impossibilidade de reunir as pessoas, foram realizadas cinco entrevistas individuais, duas online e três presenciais, com o mesmo guião de entrevista. As entrevistas foram transcritas integralmente e posteriormente analisadas recorrendo ao software de análise qualitativa MaxQda, tendo-se procedido à análise de conteúdo e, por outro lado, à quantificação dos indicadores dela resultantes.

Através dos quadros seguintes é possível uma primeira análise, em extensão, das dimensões das entrevistas: i) fatores de "deskilling" e de "reskilling" nos países de destino; ii) fatores de atração e de repulsão em Portugal e no país de destino; iii) formas de integração no país de destino; iv) relações com Portugal; e v) tipo de inclusão no sistema de emprego do país de destino.

\footnotetext{
${ }^{4}$ Para mais informações, incluindo as principais conclusões, consultar www.bradramo.pt.
} 
QUADRO 1: Fatores de deskilling e de reskilling nos países de destino

\begin{tabular}{|c|c|c|c|c|}
\hline & \multirow{3}{*}{$\begin{array}{c}\mathbf{N} \\
16 \\
\end{array}$} & \multirow{3}{*}{$\begin{array}{l}\% \\
59,3\end{array}$} \\
\hline & & & & \\
\hline \multirow{9}{*}{$\begin{array}{l}\text { Emigrou por } \\
\text { deskilling, } \\
\text { reskilling ou } \\
\text { upskilling }\end{array}$} & \multirow{3}{*}{ Upskilling } & Não & & \\
\hline & & Sim & 11 & 40,7 \\
\hline & & Total & 27 & 100,0 \\
\hline & \multirow{3}{*}{ Reskilling } & Não & 24 & 88,9 \\
\hline & & Sim & 3 & 11,1 \\
\hline & & Total & 27 & 100,0 \\
\hline & \multirow{3}{*}{ Deskilling } & Não & 26 & 96,3 \\
\hline & & Sim & 1 & 3,7 \\
\hline & & Total & 27 & 100,0 \\
\hline \multirow{6}{*}{$\begin{array}{l}\text { Perspetiva de } \\
\text { carreira }\end{array}$} & \multirow{3}{*}{ Continuidade } & Não & 24 & 88,9 \\
\hline & & Sim & 3 & 11,1 \\
\hline & & Total & 27 & 100,0 \\
\hline & \multirow{3}{*}{ Progressão } & Não & 21 & 77,8 \\
\hline & & Sim & 6 & 22,2 \\
\hline & & Total & 27 & 100,0 \\
\hline \multirow{3}{*}{$\begin{array}{l}\text { Inserção ou não na } \\
\text { área de formação } \\
\text { de origem }\end{array}$} & \multirow{3}{*}{$\begin{array}{l}\text { Trabalho fora da } \\
\text { área de formação }\end{array}$} & Não & 22 & 81,5 \\
\hline & & Sim & 5 & 18,5 \\
\hline & & Total & 27 & 100,0 \\
\hline
\end{tabular}

Através do Quadro 1 é possível constatar a maior percentagem de entrevistados que registaram upskilling no seu processo migratório (40,7\%), o que se traduz numa melhoria das qualificações obtidas. De notar também a compatibilidade entre a formação académica e o trabalho exercido. Apesar de as perspetivas de carreira não apontarem, à partida, para uma situação de continuidade e progressão (embora mais progressão do que continuidade), como foi possível constatar numa análise mais detalhada das entrevistas, tal não significa um descontentamento ou insatisfação com a situação profissional. Pelo contrário. Mesmo em situações em que os entrevistados se encontram a realizar tarefas abaixo das suas qualificações, a perceção do reconhecimento profissional é algo patente.

No que concerne aos fatores push e pull (Quadro 2) é de notar que não foram enunciados quaisquer fatores de repulsão no país de destino. Os fatores profissionais (remuneração, carreira ou progressão) são os mais referidos (63\%), seguindo-se as oportunidades de emprego e os fatores pessoais e familiares $(44,4 \%$, respetivamente). 
QUADRO 2: Fatores de atração e de repulsão em Portugal e no país de destino

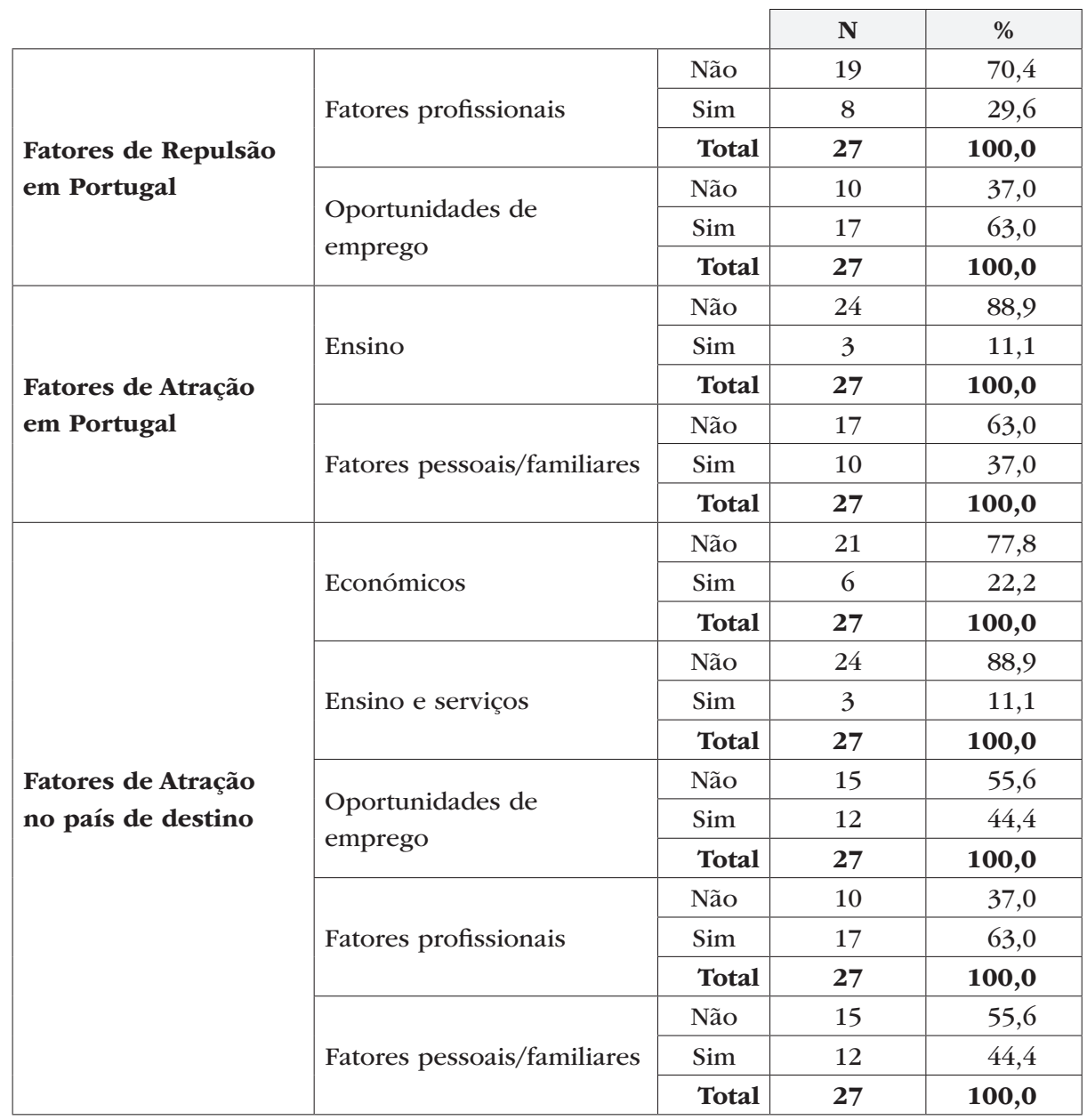

Relativamente a Portugal são os fatores pessoais e familiares que se destacam no domínio da atração. Estes são, de resto, dos maiores motivos que concorrem com as opções de mobilidade tomadas, exercendo um grande peso na possibilidade de regresso. Contudo, as oportunidades de emprego (63\%) e os fatores profissionais $(29,6 \%)$ em Portugal são dimensões que exercem grande repulsão do país.

Desta forma, a duração da emigração destaca-se como permanente ou de longo prazo (44\%), coincidente com os dados que obtivemos posteriormente 
no inquérito por questionário, assim como nos retratos sociológicos. Há que salientar ainda a dimensão transitória (33\%) da emigração.

Na dimensão respeitante às relações com Portugal (Quadro 3) são avaliados não só o lugar de Portugal no quotidiano no país de destino (redes de amigos, colegas de trabalho, contactos com família em Portugal), como também os indicadores de pertença e a ação como facilitadores ou não da emigração de outros.

\section{QUADRO 3: Relações com Portugal}

\begin{tabular}{|c|c|c|c|}
\hline & \\
\hline & & $\mathbf{N}$ & $\%$ \\
\hline \multirow{3}{*}{ Influência na emigração de outros } & Não & 17 & 63,0 \\
\hline & Sim & 10 & 37,0 \\
\hline & Total & 27 & 100,0 \\
\hline \multirow{3}{*}{ Atividades realizadas em Portugal } & Não & 17 & 63,0 \\
\hline & $\operatorname{Sim}$ & 10 & 37,0 \\
\hline & Total & 27 & 100,0 \\
\hline \multirow{3}{*}{ Viagens esporádicas a Portugal (menos de 2 vezes por ano) } & Não & 24 & 88,9 \\
\hline & $\operatorname{Sim}$ & 3 & 11,1 \\
\hline & Total & 27 & 100,0 \\
\hline \multirow{3}{*}{ Viagens frequentes a Portugal ( 2 ou mais vezes por ano) } & Não & 9 & 33,3 \\
\hline & $\operatorname{Sim}$ & 18 & 66,7 \\
\hline & Total & 27 & 100,0 \\
\hline \multirow{3}{*}{ Identidade emigrante } & Não & 23 & 85,2 \\
\hline & Sim & 4 & 14,8 \\
\hline & Total & 27 & 100,0 \\
\hline \multirow{3}{*}{ Identidade portuguesa } & Não & 7 & 25,9 \\
\hline & Sim & 20 & 74,1 \\
\hline & Total & 27 & 100,0 \\
\hline \multirow{3}{*}{ Amigos de outros países } & Não & 10 & 37,0 \\
\hline & Sim & 17 & 63,0 \\
\hline & Total & 27 & 100,0 \\
\hline \multirow{3}{*}{ Amigos portugueses } & Não & 9 & 33,3 \\
\hline & Sim & 18 & 66,7 \\
\hline & Total & 27 & 100,0 \\
\hline
\end{tabular}

No que concerne à rede de amigos, é visível tanto a presença de amigos de origem portuguesa (66,7\%), como de outros países (63\%). Quanto à identidade, resiste a identidade de português $(74,1 \%)$ mais do que a identidade de 
emigrante (14,8\%). Conforme veio a ser posteriormente confirmado, o autorreconhecimento como cidadão europeu, ou cidadão do mundo, vivendo numa "bolha internacional" é algo mais proeminente do que a identificação como emigrante. A saudade das pessoas, da comida, dos costumes, do clima leva a que Portugal esteja presente no imaginário destes emigrantes qualificados. Por conseguinte, as viagens a Portugal são, na maioria dos casos, frequentes $(66,7 \%)$, sendo muitas vezes aproveitadas para diversos consumos e procura de serviços (cabeleireiro, médico, etc. - 37\%).

\section{Resultados do inquérito 5}

Este é um projeto que conta histórias de percursos individuais de mulheres e homens portugueses que decidiram prosseguir as suas vidas fora de Portugal. No entanto, as histórias singulares decorrem num quadro social mais geral. Os percursos individuais realizam-se em condições que não foram escolhidas, antes constituíram dados de partida para as opções de cada um. Na verdade, a decisão de emigrar apresenta caraterísticas estruturais que constituem a exterioridade do fenómeno e que limitam ou ampliam os efeitos das decisões individuais.

Essas condições estruturais foram caraterizadas através de um questionário online administrado entre maio e outubro de 2014, junto de uma amostra intencional, não aleatória, de cidadãos portugueses que estavam ou tivessem estado em mobilidade ou emigrados num país europeu nos últimos 6 anos, com habilitações académicas do ensino superior, ou que tivessem exercido uma atividade profissional correspondente a esse nível académico. Foi com base nas respostas a este questionário que se caraterizou o perfil estrutural da emigração qualificada portuguesa.

5 Resultados publicados no livro "Fuga de cérebros: retratos da emigração portuguesa qualificada" (2015). 


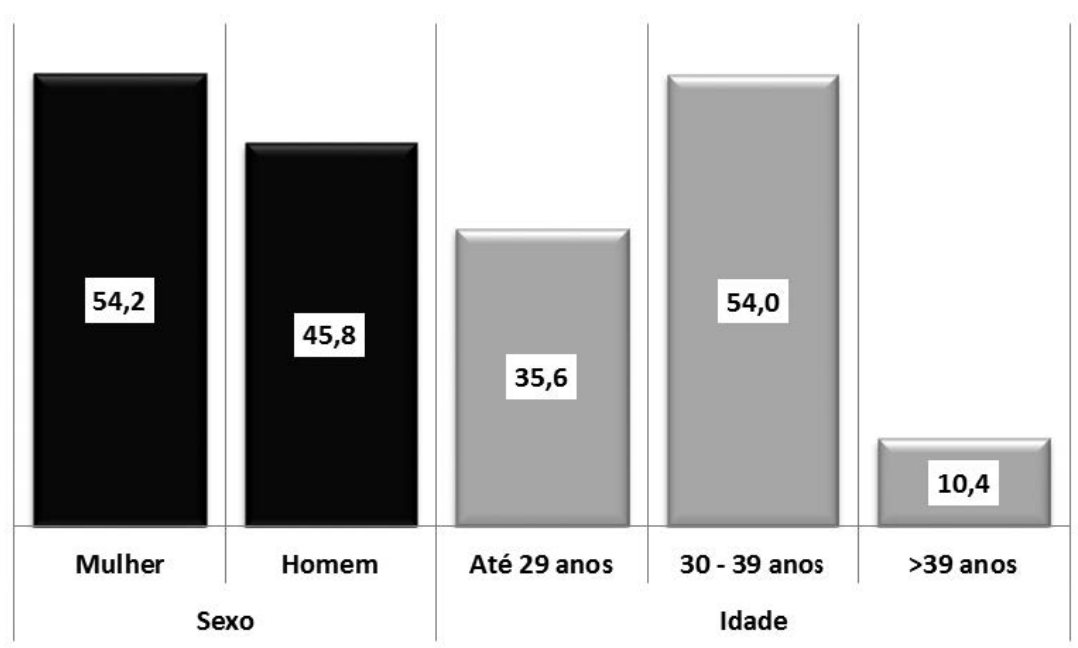

Considerando a amostra de 1011 respondentes, verificamos que ela é ligeiramente feminizada $(54,2 \%)$, o que, desde logo, se apresenta como novidade nos perfis emigratórios portugueses, tradicionalmente masculinizados, refletindo decerto a crescente presença maioritária das mulheres no ensino superior e, por consequência, nas profissões qualificadas.

Por outro lado, em termos etários, destaca-se a juvenilidade da amostra (apenas 10,4\% tem mais de 39 anos), traduzindo não só o prolongamento das transições e da moratória juvenil forçada - para a vida adulta, para um emprego estável, para uma família de destino, para uma habitação própria - como também as particulares dificuldades de encontrar no mercado de trabalho português uma saída para as suas qualificações (cerca de $65 \%$ tem pelo menos o mestrado, em particular nas áreas das ciências, matemáticas e informática, seguido das engenharias e ciências sociais), a par de uma inserção facilitada em redes transnacionais de mobilidade. 


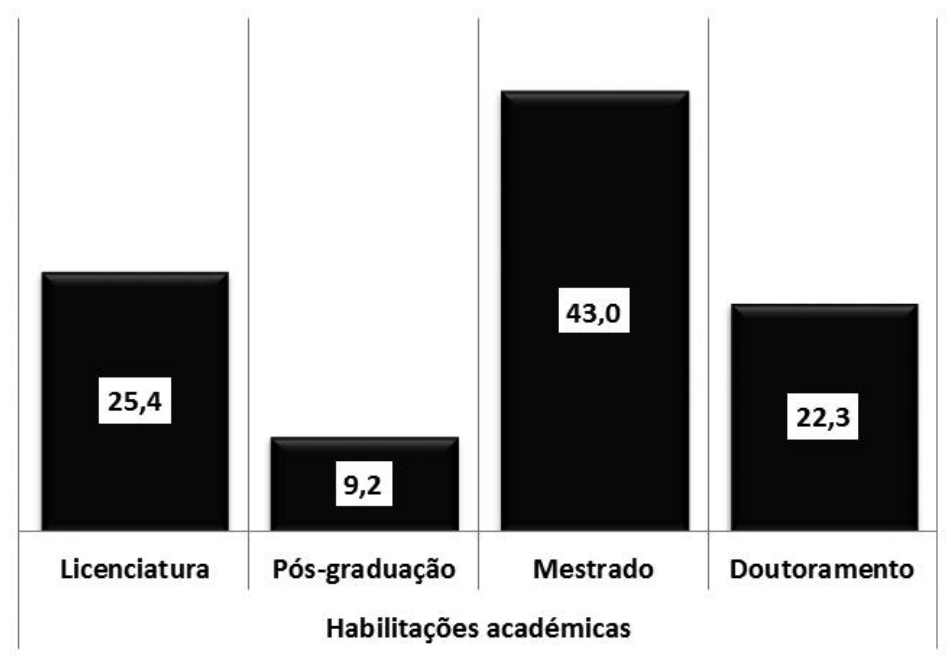

A composição interna das qualificações da amostra revela que uma maioria de inquiridos $(74,5 \%)$ têm cursos pós-graduados - 43\% têm um mestrado, $22,3 \%$ são doutorados e 9,2\% concluíram uma pós-graduação - possuindo os restantes $25,4 \%$ da amostra apenas o grau de licenciado.

A amostra revela uma clara sobrerrepresentação dos sujeitos com mestrado e doutoramento, visto que na população residente em Portugal, até aos 44 anos, os valores são bastante inferiores: 1,7\% concluiu um doutoramento, $11,4 \%$ o mestrado e $86,9 \%$ a licenciatura. A tendência detetada nesta amostra parece refletir que a emigração qualificada dos últimos anos acentuou a saída dos titulares de graus académicos mais elevados e especializados.

Em 2014, apenas 16,5\% da população portuguesa com 15 anos ou mais possuía pelo menos um curso superior. No grupo etário entre os 25 e os 34 anos, onde se enquadra boa parte da nossa amostra, tal percentagem subia para 28\%, de acordo com dados da OCDE para 2012.

Estamos, portanto, na presença de contingentes de jovens e jovens adultos que usufruíram plenamente dos tardios processos de democratização escolar em Portugal e da implementação sistemática de um sistema público de I\&D. 
Qual o ano do último período de emigração?

GRÁfiCo 3: Ano da última saída de Portugal (\%)

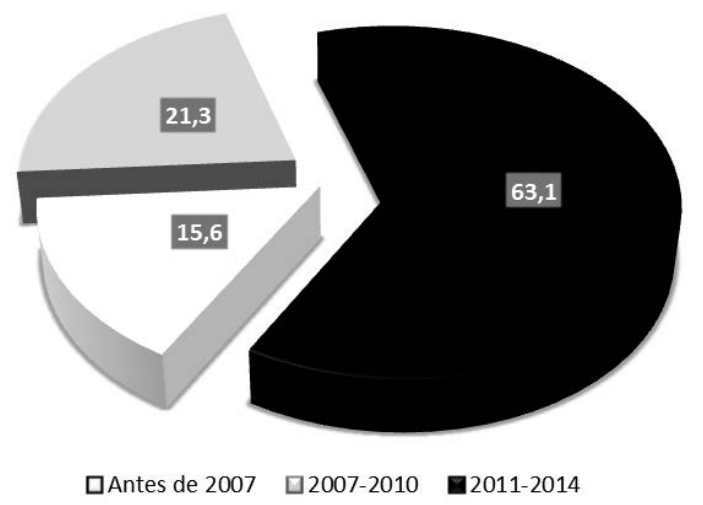

Cerca de 4/5 da amostra saíram de Portugal no deflagrar da crise ou mesmo depois da sua eclosão, uma vez que apenas 15,6\% abandonou o país antes de 2007. Sabemos que a incorporação dos impactos de uma conjuntura tão intensa não é imediata, mas os números das saídas mostram bem como 2008 é o grande detonador: mais de 20 mil emigrantes, contra apenas 7890 no ano anterior (Pordata).

Qual o país de residência atual?

GRÁfICO 4: País de residência atual (\%)

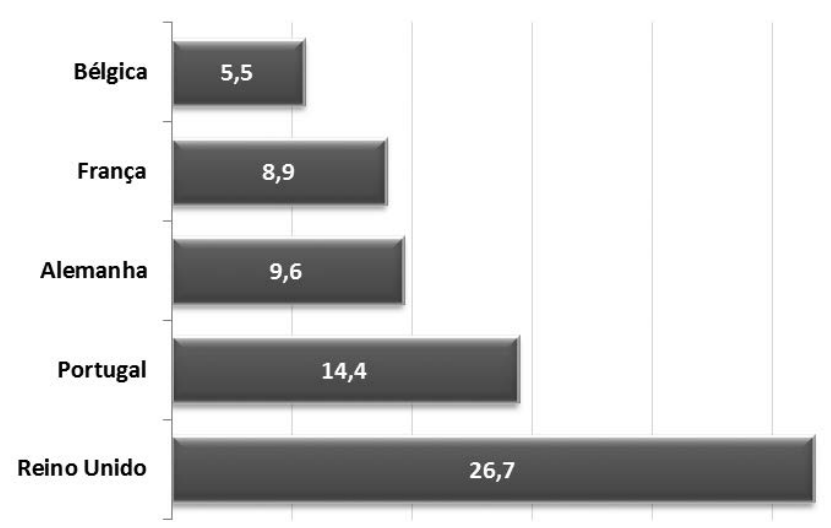


Se observarmos o atual país de residência, percebemos a importância do Reino Unido (26,7\%) e de outros países do centro europeu (Alemanha, França e Bélgica), mas também a circunstância de uma fatia não negligenciável viver em Portugal no momento de administração do questionário, o que se relacionará ou com um regresso potencialmente bem-sucedido (depois de acumularem credenciais, experiências e capital social no estrangeiro) ou com uma mera transição para outros destinos.

Qual a situação perante o trabalho, antes e depois da emigração? Qual o rendimento mensal líquido, antes e depois de emigrar?

GRÁFICO 5: Situação perante o trabalho antes e após a migração (\%)

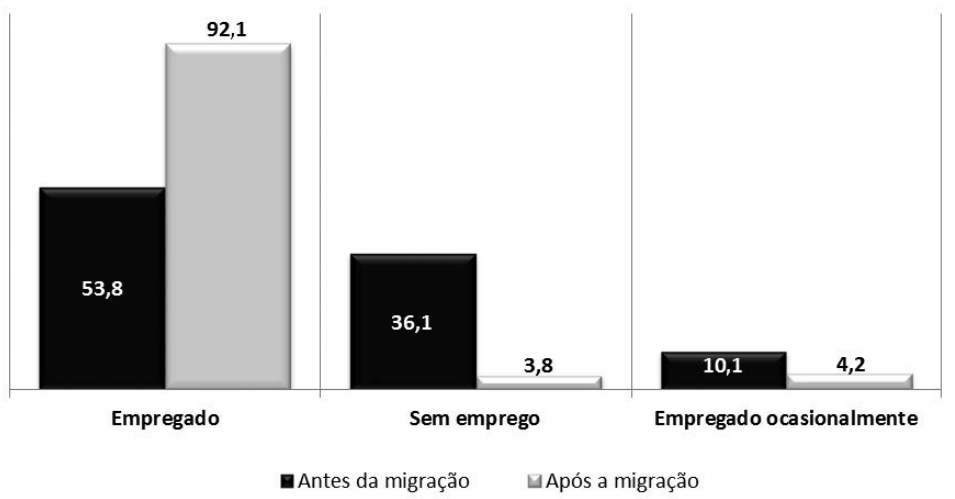

GRÁFICO 6: Rendimento mensal líquido antes e após a migração (\%)

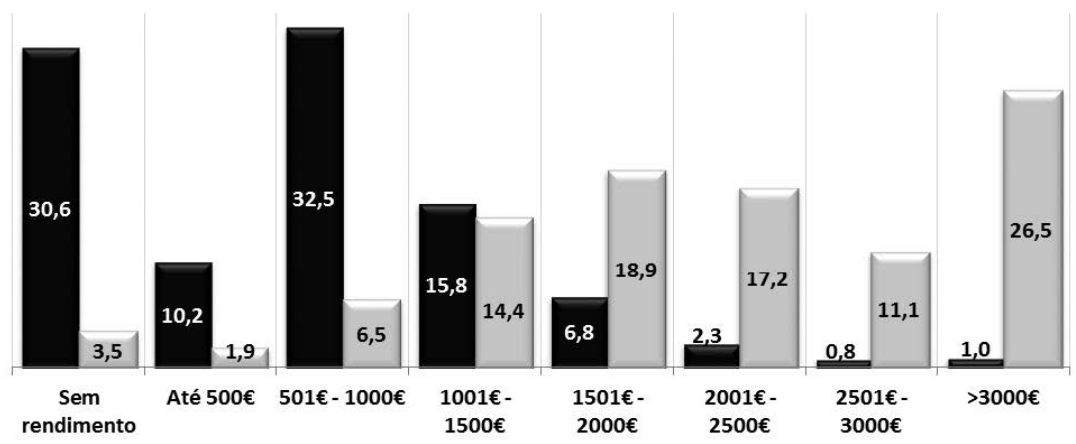


Constata-se, de igual modo, que a saída tem um efeito notório no emprego: apenas 3,8\% estão desempregados no destino, quando em Portugal tal percentagem superava os 36\%, grosso modo análogo às taxas de desemprego nestes escalões etários.

O rendimento mensal líquido também apresenta valores bastante contrastantes: antes da saída mais de 70\% auferia menos de 1000 euros, no destino mais de $50 \%$ recebe um montante superior a 2000 euros e $26,5 \%$ recebe acima de 3000 euros.

Qual a área científica de formação inicial e da formação mais elevada?

GRÁFICO 7: Área científica de formação inicial e da mais elevada (\%)

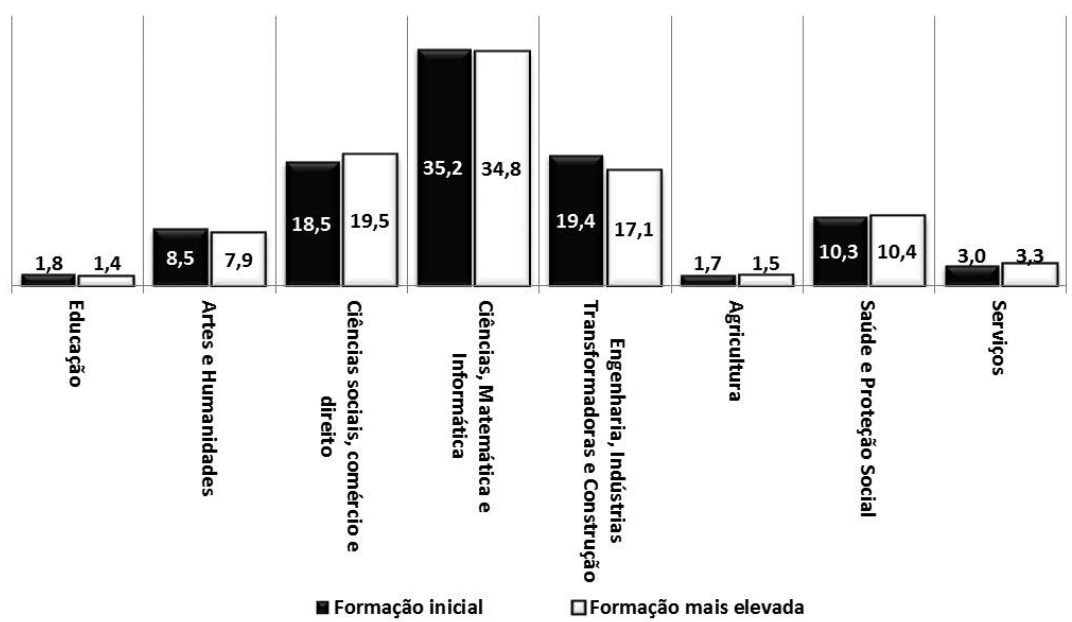

Os inquiridos mostram uma forte coerência entre a área de formação inicial e a formação mais elevada, concentrando-se nas ciências, matemáticas e informática (cerca de 1/3), seguido das ciências sociais, comércio e direito e, com números próximos, engenharia, indústrias transformadoras e construção. Não existem, por isso, processos de reconversão académica, antes uma lógica de fileira, com o aprofundamento da formação inicial. 
GRÁFICO 8: Correspondência entre o trabalho exercido e a formação académica antes e após a migração (\%)

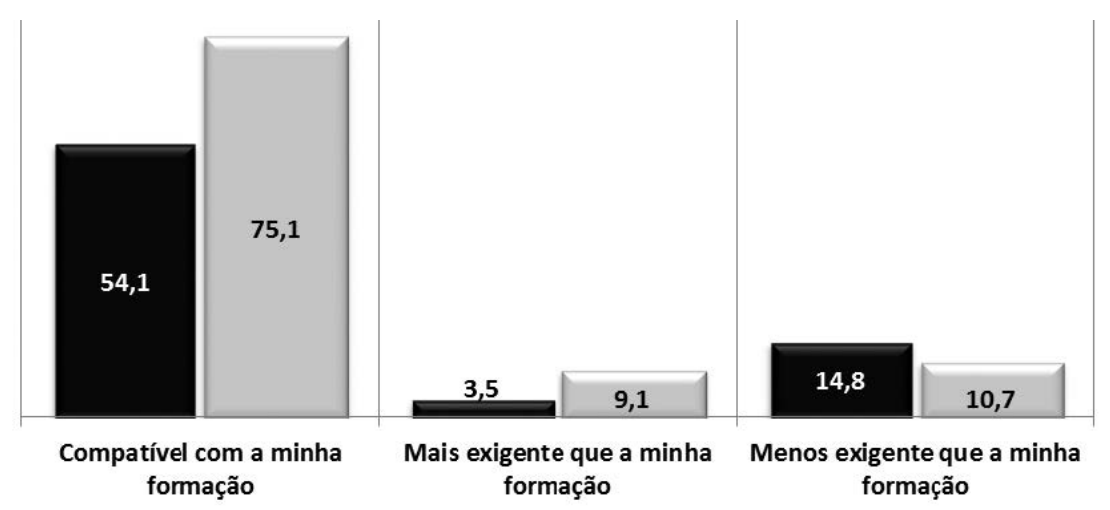

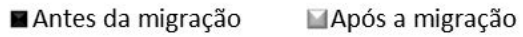

Considerando que a maior parte dos respondentes exercia funções profissionais compatíveis com a sua formação académica, mesmo antes de emigrar, facilmente se constata que em Portugal esse reconhecimento formal de competências e de recursos organizacionais não encontrava uma clara correspondência nos níveis de remuneração, tampouco nas possibilidades de carreira.

Também cresce o número dos que declaram que o trabalho no país de destino é mais exigente do que a formação académica recebida e diminui a perceção de trabalhar em funções abaixo das qualificações, o que se ligará, porventura, a acrescidas oportunidades de carreira e de formação. 
Quais as razões para a emigração?

GRÁFICO 9: Razões para a emigração (\%)

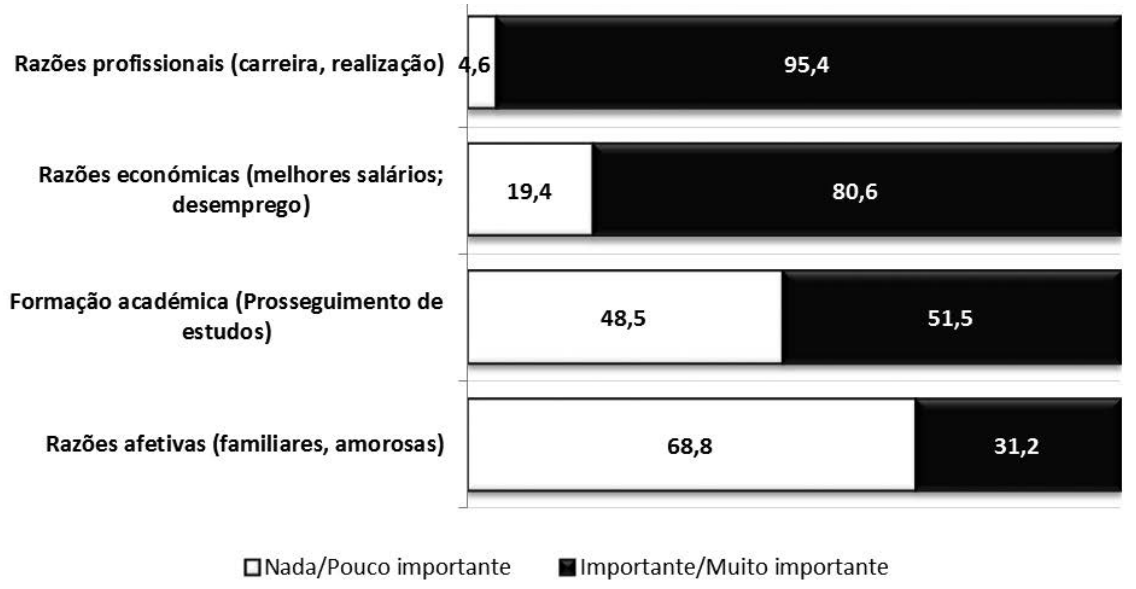

A decisão de emigrar tem nas razões profissionais e económicas o seu principal impulso: prosseguir uma carreira em que se sintam realizados profissionalmente surge para $95,4 \%$ dos inquiridos como a razão principal que os leva a emigrar. Porém, as razões salariais e a situação de desemprego ou de subemprego também revelam um peso muito importante na decisão de emigrar (80,6\%). Bastará observar que o desemprego e o subemprego atingiam $46,2 \%$ da amostra para se perceber o peso relativo desta razão. Embora as razões afetivas assumam alguma importância, quer a reunificação familiar quer a presença de redes amicais nos países de destino são claramente secundárias na hierarquia de motivos que originam a emigração.

Quando aprofundamos as razões profissionais que conduzem à decisão de emigrar verificamos que a valorização das qualificações académicas no país de destino constitui o principal fator de atração ( $90 \%$ de concordância), acompanhado pelo reconhecimento de que a realização profissional não tem condições para se concretizar em Portugal (51\%).

Por outro lado, a discriminação de alguns indicadores económicos revela-nos o impacto relativo na decisão de emigrar: em primeiro lugar a crise económica como fator de repulsão (88\%), depois a desadequação remuneratória no país de origem (65\%), seguida de muito perto pela insatisfação com 
o estatuto socioeconómico em Portugal (63\%) e a perceção de insegurança e instabilidade que o decréscimo de rendimentos provoca. Simetricamente regista-se a perceção de adequação salarial (78\%) e a maior disponibilidade de empregos nos países de destino como os principais indicadores económicos que levaram à emigração.

As experiências de mobilidade académica noutros países surgem como o fator de impulso mais importante entre as razões académicas (77\%), bem como o reconhecimento da valorização da área de estudos no país de destino (66\%). Estes indicadores revelam bem como a mobilidade académica e o cálculo custo/benefício realizado pelos estudantes durante os programas de mobilidade contribuem para transformar o brain drain latente numa decisão mais firme de emigração para países europeus do centro.

Merece também destaque o facto de, ao contrário dos processos de emigração tradicionais, os emigrantes qualificados não terem nas redes familiares, de amizade ou afetivas um impulso muito importante para a decisão de emigrar. Menos de 30\% dos inquiridos afirmam terem optado por um país onde já estavam inseridos familiares ou amigos.

Por último, na escolha dos países de destino não é indiferente a natureza do pacto social que neles vigora, sendo escolhidos países em que o estado social e a participação cívica se encontram plenamente consolidados (61\%). Em sentido inverso, reconhecem os inquiridos (69\%) que as políticas de restrição ao estado social não são temporárias em Portugal e que não têm repercussões tão graves e evidentes nos países em que se encontram atualmente (49\%).

\section{A decisão de emigrar é de curto, médio ou longo prazo?}

Um dos aspetos que pode determinar a perda de capital humano no país de origem é a duração do período de emigração. A maioria dos inquiridos refere que a mobilidade foi inicialmente projetada como solução transitória, mas a experiência entretanto vivida mudou os planos para uma perspetiva de emigração de médio $(30,4 \%)$ ou de longo prazo $(62,9 \%)^{6}$.

\footnotetext{
${ }^{6}$ No âmbito deste estudo considera-se que a "emigração de médio prazo" inclui a expetativa de residência fora de Portugal por um período entre 2 e 5 anos e a "emigração de longo prazo" inclui a expetativa de residência fora de Portugal por 6 ou mais anos.
} 
A maioria dos inquiridos projeta-se numa emigração para "toda a vida" no atual país de residência ou em outros países europeus (61,7\% e 68,9\% respetivamente), embora a perceção de uma crise prolongada esteja também associada à decisão de ficar mais anos a trabalhar fora de Portugal e à expetativa de regressar depois de consolidado o percurso profissional $(42,9 \%)$.

GRÁfICO 10: Expetativas em relação ao futuro (\%)

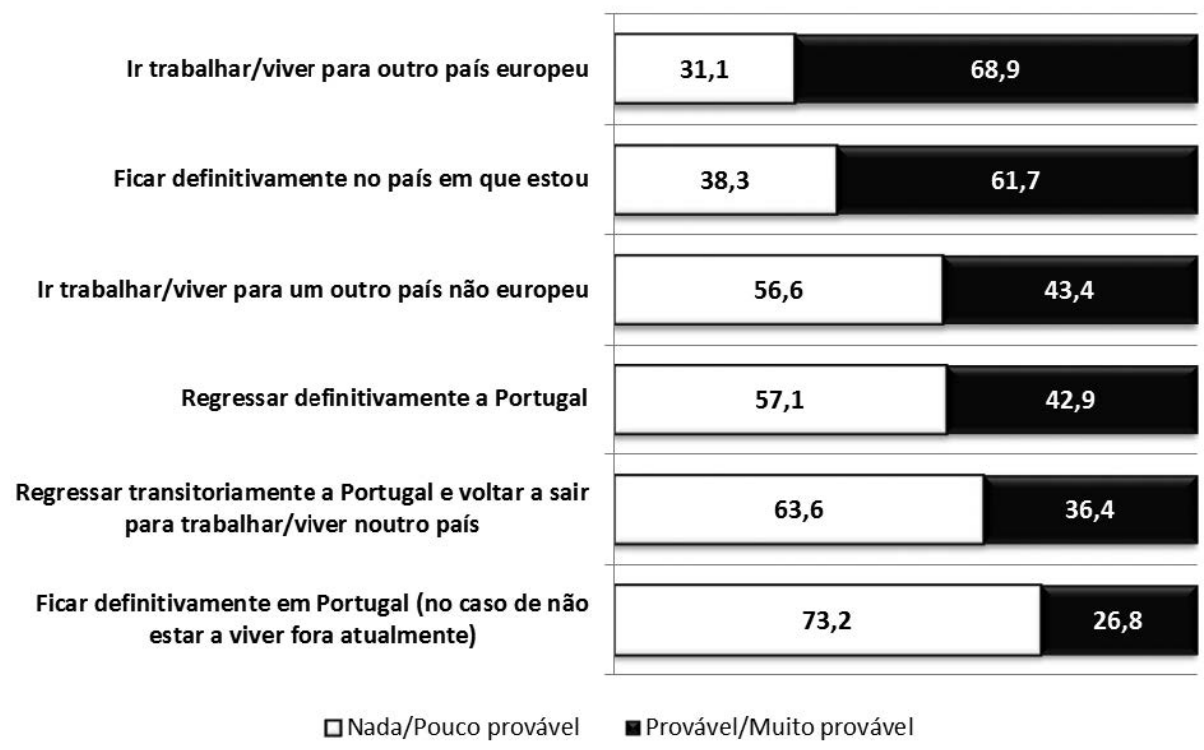

\section{Resultados das entrevistas - Retratos Sociológicos}

Os retratos sociológicos surgem como dispositivo metodológico capaz de resgatar uma dupla pluralidade nas trajetórias individuais: por um lado, a pluralidade das disposições internas, tendo em conta a sua génese, a sua desigual "força" e sistematicidade; por outro lado, a pluralidade contextual, externa, associada à multiplicidade de processos, agências e contextos de socialização ou modos da vida, percebendo os detalhes das variações intraindividuais, como cada indivíduo se desdobra em compromissos e 
metamorfoses múltiplas pelos diferentes domínios de ação. É neste âmbito que Lahire (2002) propõe os retratos sociológicos como um dispositivo metodológico.

Pretendeu-se, pois, alcançar três grandes objetivos: i) apreender o património plural de disposições que forma o habitus (Bourdieu, 1983) destes sujeitos; ii) relacionar sistemas de desigualdades de origem com desigualdades de percurso; iii) fomentar a reflexividade biográfica.

Saliente-se, contudo, que, nesta pesquisa, os retratos foram sempre orientados para a(s) experiência(s) migratória(s). Não se trata de uma mera história de vida, antes do delinear de um percurso que desemboca na emigração.

Antecipando um número que permitisse dar conta da diversidade dos percursos biográficos, mas que fosse ao mesmo tempo revelador de uma certa unidade em aspetos decisivos e marcantes para o percurso migratório; e tendo em consideração as limitações do projeto, o objetivo passou por se entrevistarem 12 indivíduos por cada um dos quatro perfis-tipo estabelecidos desde o início do projeto.

No total foram entrevistadas 53 pessoas, resultando em 53 retratos sociológicos de portugueses qualificados que emigraram para outros países europeus.

Ao selecionar os entrevistados dos contactos obtidos, além da diversidade em relação ao sexo e idade, dentro de cada perfil-tipo, procurou-se também ter em conta a diversidade do país de acolhimento e da área profissional. Ainda assim, existe a predominância de alguns países em detrimento de outros, reflexo dos contactos reunidos, mas também do maior peso de emigrantes qualificados em determinados países, de acordo com as estimativas oficiais.

De forma a dar conta da grande diversidade de percursos migratórios, que refletem os diferentes projetos de vida dos seus protagonistas; dos múltiplos pontos de partida e de chegada sociais e geográficos, com pontos de passagem intermédios igualmente diversificados; dos diferentes níveis de sucesso ou insucesso, e vários graus de satisfação ou insatisfação com a situação pessoal e profissional vivida durante a mobilidade apresenta-se de seguida uma breve síntese da análise feita aos retratos em cada perfil-tipo. 
Perfil-tipo: migração para um país europeu para o exercício de profissões nos sistemas científico ou de ensino superior

Os retratos neste grupo registam os percursos de jovens investigadores portugueses que escolheram trabalhar no sistema científico de vários países europeus.

A maior parte dos retratados emigraram para prosseguir estudos avançados de doutoramento e pós-graduação, sendo as oportunidades de mobilidade potenciadas por processos formais de recrutamento das instituições de investigação e ensino superior europeias. As trajetórias são frequentemente de mobilidade múltipla, com durações muito variáveis, o que dificulta a distinção analítica entre mobilidade e migração.

A mobilidade académica não é entendida pela maioria como uma fatalidade ou uma consequência direta da crise económica, mas antes como uma estratégia de carreira, num país da semiperiferia científica, económica e cultural europeia. Embora alguns declarem que existe o desafio aliciante de transformar a capacidade das diásporas científicas para transferir conhecimento e tecnologias, reconhecem também que as instituições nacionais e europeias fazem muito pouco para o concretizar.

Passando por "transições profissionais" e "transições experimentais" (Guerreiro \& Abrantes, 2007) até à vida adulta, estes jovens, que ocupam funções de prestígio, bem remuneradas e altamente competitivas, e têm progressões rápidas na carreira, vivenciam o trabalho académico como um continuum, numa "cultura de horário prolongado". Neste contexto, a conciliação entre trabalho profissional e vida pessoal torna-se difícil, acabando essas duas esferas da vida por se imbricarem.

As experiências de trabalho decorrentes do processo migratório são perspetivadas de um modo diferente, porque os investigadores têm em regra um contrato de trabalho, efetuam descontos e sentem-se inseridos no mercado laboral enquanto fazem o doutoramento ou o pós-doutoramento.

A questão profissional é a que parece mais determinante para sair ou simplesmente para ficar no país em que se teve uma experiência de mobilidade. Em alguns casos, devido à especificidade das especializações que se querem aprofundar e para as quais não haverá resposta suficiente em Portugal; nou- 
tros, é a precariedade das opções oferecidas no mercado português que leva as pessoas a procurarem percursos fora do território nacional.

As orientações das políticas públicas para a ciência, traduzidas no subfinanciamento da prática científica, afastaram definitivamente a crença na possibilidade de optar por um percurso que passe pelo país de origem, quer no curto quer no longo prazo, porque se admite que a recuperação das condições anteriores apenas seja possível dentro de uma a duas décadas.

Ainda que se admita estar perante um mercado global, no qual o investimento numa carreira no exterior pode ter reflexos positivos no país - porque o conhecimento e a tecnologia tendem a circular -, impera a perceção generalizada de que Portugal fica sempre a perder, desde logo porque não rentabiliza o investimento efetuado na formação dos quadros que emigram.

Perfil-tipo: migração de longo prazo para um país europeu para trabalhar nos segmentos primário ou secundário do sistema de emprego

Os retratos deste grupo têm como pano de fundo a experiência laboral e a inserção profissional, quer antes quer depois da experiência migratória.

Sobressai neste grupo de retratos uma perceção negativa da evolução da situação socioeconómica do país e uma crítica revoltada aos governos que não sabem aproveitar a sua maior riqueza, a mão-de-obra altamente qualificada e, pelo contrário, incentivam a sua exportação para outros países, revelando-se incapazes de criar estímulos ao retorno. As alternativas e os apoios aos jovens que saem do ensino superior são consideradas ausentes mas necessárias. A criação de condições para a retoma da atividade económica, o tratamento justo dos cidadãos e a criação de condições que apoiem a maternidade são medidas apresentadas por jovens que pertencem a uma geração que se sentiu impelida a sair de um país que não os soube aproveitar.

Há, por isso, nestes retratos, um murmúrio de revolta. Para este grupo, a emigração surge menos como opção do que como necessidade.

Regressar ou não regressar? Para uns, o regresso é pensado de modo temporário ou distante - de férias ou na reforma; para outros, o regresso está circunscrito ao campo dos desejos e depende das condições necessárias para que a realização profissional possa ser alcançada em Portugal. 
Por outro lado, as questões familiares assumem um papel importante. O enraizamento profissional e a integração dos filhos no país de acolhimento tornam cada vez mais distante o regresso. Com o passar dos anos, a ideia de não voltar para um país onde se tem cada vez menos ligações familiares, e de ficar onde estão os filhos e onde estarão os netos, está muito presente nesta nova emigração.

A emigração assume-se, assim, como um fenómeno estrutural e não mais conjuntural. E a decisão de regressar é continuamente adiada. O regresso apenas é pensado a longo prazo, não sendo equacionado, por exemplo, construir casa em Portugal ou enviar remessas.

Mesmo em situações de menor sucesso no país de acolhimento - contrariando as expetativas de ascensão social - esta é uma situação considerada passageira e encarada como algo que poderá rapidamente ser ultrapassado, uma expetativa que se funda não só na contraposição da situação atual com a situação que teria de ser enfrentada se a emigração não tivesse ocorrido, mas também na noção de que a formação académica é um fator de sucesso. É por isso relevante constatar o desejo transversal de investir na aprendizagem da língua do país de acolhimento e de fazer cursos de formação, no sentido de aumentar as oportunidades de uma melhor inserção profissional.

No geral, a identidade nacional, o "ser português", torna-se muitas vezes exaltada. As saudades dos familiares e dos amigos que se deixaram, mas também do país em si - as pessoas, a cultura, a hospitalidade, a comida, o sol, a praia - são elementos que se recordam com nostalgia e que representam, de alguma forma, o que de bom tem o país e que o distingue dos outros.

É também através dos consumos que a identidade nacional é fortemente atualizada: a procura de produtos portugueses de consumo diário; a compra de produtos alimentares (bacalhau, café, etc.), fazem com que as referências visuais e emocionais estejam mais presentes.

Perfil-tipo: mobilidade estudantil europeia que conduz à inserção nos segmentos primário ou secundário do sistema de emprego

Uma das primeiras dimensões a salientar neste perfil-tipo prende-se com a constatação de uma disseminação nas instituições de ensino superior da 
oferta de incentivos à mobilidade estudantil. Estas oportunidades formativas permitiram-lhes uma comparação entre os sistemas científicos do país de destino e o português, mas também o conhecimento de pessoas (professores, colegas, amigos) que se revelariam de crucial importância na decisão de emigrar.

A maior parte dos entrevistados considera que a sua formação de base, em Portugal, os preparou cientificamente para as mais elevadas exigências, mas são unânimes em reconhecer o défice nas concretizações.

Importa igualmente realçar que uma parte destes sujeitos teve experiências profissionais em Portugal durante a sua formação superior, o que, se em parte contribuiu para acentuar disposições favoráveis à conciliação entre esferas de vida (trabalho, estudo, família), desvendou por outro lado as dificuldades de progressão profissional no nosso país.

Ao contrário do que se poderia supor, nem todos usufruem de estatutos profissionais estáveis. Alguns experimentam situações de indefinição contratual e precariedade. Ainda assim, tanto pelos rendimentos auferidos, claramente superiores aos expetáveis para idênticas funções em Portugal, como pela satisfação que revelam nas ocupações exercidas, tal questão não se mostra, por enquanto, limitadora do potencial de otimismo. É certo que pertencem a uma "geração adaptável", socializada no pressuposto de que já não há carreiras fixas e previamente asseguradas, ideias tão propagadas pelos mais variados aparelhos ideológicos. Daí que, desde que a valorização intrínseca do trabalho ("gostar do que se faz") e um certo padrão de consumo e de qualidade de vida estejam assegurados, não se levantem problemas existenciais.

É claro que o tempo jogará os seus dados e produzirá os seus efeitos. Estamos em presença de entrevistados que deixaram Portugal há relativamente pouco tempo. Mas muitos admitem prosseguir trajetórias de inserção profissional noutros países e nenhum encara um regresso rápido a Portugal. Esta é, aliás, uma das pistas interpretativas mais marcantes deste conjunto de retratos. Apesar de desejarem em termos abstratos o regresso a Portugal, nenhum coloca essa opção no futuro próximo e todos condicionam tal decisão a muitos fatores: encontrar um emprego estável em Portugal; regressar apenas para o ambiente cosmopolita de grandes cidades, nunca para pequenas urbes; 
voltar só depois de os filhos serem crescidos; ou, apenas, se o/a namorado/a também conseguir uma colocação.

Em geral, estes sujeitos olham com ceticismo para Portugal; desconfiam da qualidade das suas elites e em particular dos políticos; desprezam o imediatismo das decisões e a ausência de apostas estratégicas na qualificação, na inovação, no desenvolvimento sustentável, na diversificação produtiva, no investimento em sistemas sólidos de I\&D. Por acharem que nada vai mudar a curto e médio prazo, mais facilmente se veem a prosseguir viagem, particularmente nos casos em que a situação profissional é precária, do que a voltar para o sombrio futuro português.

Perfil-tipo: mobilidade e circulação transitória ou pendular através de redes europeias de ciência, produção, serviços ou cultura

Os retratos deste perfil-tipo revelam vidas em trânsito, quer pela sua constante mobilidade espacial, quer porque expressam projetos de vida em transição. É esta condição dúplice que lhes dá a ambiguidade própria de uma experiência "amarga como muitas, mas, como poucas, libertadora", nas palavras de Eduardo Lourenço, que conhece bem a vivência de longos anos no estrangeiro.

As experiências de vida que captamos nestes retratos são construídas a partir de um novo tipo de nomadismo que as sociedades contemporâneas facilitaram por força da compressão do espaço-tempo do mundo. São histórias de pessoas que já passaram por várias experiências de emigração, incluindo breves períodos de regresso a Portugal, embora quase nunca se revejam na figura do emigrante. Desde logo, porque encontram no espaço europeu uma casa comum, mas também porque têm a experiência de uma emigração transitória. A transitoriedade não significa porém o desejo de regresso próximo a Portugal nem um nomadismo de exclusão; pelo contrário, assumem a busca constante da inclusão através de novos itinerários, novas formas de ver o trabalho, diferentes ritmos de vida e formas inusuais de superar obstáculos.

Neste universo em que impera a flexibilidade imposta ou procurada, há os que ganham, os que perdem e os que resistem. Entre os que ganham, predominam as narrativas de vida que põem em primeiro plano a vocação e a realização profissional como forma de obter a realização pessoal. Entre 
os que perdem, o trabalho é apresentado como uma forma instrumental de garantir os meios de subsistência necessários à construção de um projeto de vida. Entre os que resistem, a vida é descentrada do trabalho, surgindo as dimensões expressivas e reflexivas da vida como um valor maior para a realização pessoal.

A dificuldade maior ou menor em criar uma linha condutora para a vida verifica-se em todos os casos. A mudança pendular de emprego e até de funções dificulta muitas vezes a integração evidente em qualquer tipo de carreira. Embora a relação salarial obtida no estrangeiro seja mais atrativa do que em Portugal, a sua continuidade não é sempre um dado seguro.

A flexibilidade espacial põe muitas vezes os emigrantes transitórios e pendulares numa encruzilhada em que não se trata apenas de mudar de emprego, de cidade ou de país, mas de pôr toda a vida em mobilidade. Ir e vir, estar hoje numa cidade portuguesa e amanhã numa cidade estrangeira, obriga a uma constante mediação cultural e não apenas de lugar. O multilocalismo é certamente um enriquecimento para quem o vive, mas cria também dificuldades de identidade com as pessoas e os locais. O conceito de local propriamente dito passa a ser polivalente.

As noções de pertença e identidade deixam de estar vinculadas a um território concreto e a processos locais. A ideia de cultura própria deixa de fazer sentido para quem tem experiências alargadas de aprendizagem e de trabalho translocal. O sentido plural das culturas é facilmente assumido, embora o modo de gerir a pluralidade passe na maior parte dos casos pela multiplicação de localismos.

As condições comparativamente mais compensadoras de Estado social nos países de acolhimento sobrelevam quaisquer considerações nostálgicas de pertença nacional. Neste contexto, o regresso a Portugal é visto como uma impossibilidade ou como uma decisão para a reforma.

\section{Notas conclusivas}

A realização sequencial de focus group, de inquéritos por questionário e de retratos sociológicos permitiu uma leitura ampla e intensa do fenómeno 
abordado. O caráter eclético da metodologia seguida foi fundamental para consolidar os resultados obtidos.

A pesquisa concretizada por meio dos focus group permitiu verificar uma forte presença das mulheres nos fluxos da emigração portuguesa qualificada. Permitiu ainda dar conta do caráter rejuvenescido dos fluxos e do peso muito significativo dos que possuem um grau superior à licenciatura. Nesse contexto não é de estranhar a predominância de perfis pessoais onde imperam os solteiros e aqueles que não têm filhos. As razões profissionais destacaram-se como as que mais contribuíram para a saída de Portugal e encontrou-se uma tendência muito forte para a sua inserção profissional na área de formação, e, em contraste com a tendência geral dominante na inserção profissional dos jovens europeus, em situação de upskilling e com perspetivas de progressão na carreira muito significativas.

A falta de oportunidades de emprego em Portugal revelou-se desde as primeiras recolhas de informação como um claro fator de repulsão, motivando a fuga para o estrangeiro. No confronto de fatores de atração, os fatores pessoais e familiares, ainda que motivem a permanência em Portugal, são menos decisivos que os fatores profissionais na emigração para os países de destino. Neste contexto, os focus group revelaram uma tendência acentuada para que as formas de integração nos países de destino se concretizem sob a perspetiva de uma permanência de longo prazo.

A mobilidade é, em múltiplos sentidos, um fator estruturante que enquadra a fuga de cérebros em Portugal, salientando-se três caraterísticas: a) as experiências prévias de mobilidade académica são um fator claramente estruturante da emigração; b) os que saem divergem do estereótipo e das práticas do emigrante tradicional, encaixando-se em perfis identitários estruturados pela mobilidade; c) as oportunidades revestem-se de uma grande dinâmica, tornando a circulação por vários empregos e países um traço marcante dos fluxos da emigração portuguesa qualificada.

Num país com uma vasta comunidade emigrante, os portugueses com o ensino superior emigrados em países da OCDE eram, nos Censos de 2011, apenas cerca de $10 \%$ do total de portugueses emigrados nesses países. Mas este grupo de portugueses qualificados alcança a mais elevada taxa de crescimento em 10 anos (87,5\%). Países como o Reino Unido e a Alemanha 
apresentam valores bem mais elevados para ambos os indicadores, superiores a $20 \%$.

Os questionários administrados a uma amostra não probabilística de 1011 indivíduos confirmam e reforçam estas tendências. Revelam ainda o sentido mais imediato das razões profissionais enquanto justificação da fuga, pois se antes de emigrarem 36\% dos inquiridos não tinham emprego, após a emigração, nos países de destino, 92\% estão empregados. A isto deve acrescentar-se o facto de, antes da experiência migratória, cerca de 1/3 não ter qualquer rendimento em Portugal, com outro terço a ter um rendimento mensal líquido de entre 500 e 1000 euros. Confrontando esta situação com a realidade após a experiência migratória, verifica-se uma enorme diferença, pois um pouco mais de $1 / 4$ dos inquiridos auferem no país onde estão emigrados um salário mensal líquido superior a 3000 euros e uma proporção da mesma ordem de grandeza (também um pouco mais de 1/4) aufere entre 2000 e 3000 euros líquidos mensais.

Os retratos sociológicos realizados conferem densidade e dão rostos humanos a estes dados. Mostram, entre outras, e para lá da diversidade de experiências individuais, regularidades transversais que vale a pena destacar: o reconhecimento da qualidade da formação académica obtida em Portugal e a sua importância para a inserção no país de destino; a ausência das condições e das perspetivas que poderiam motivar o regresso, marcado por expetativas pessoais que apontam para uma permanência longa nos países de destino; a recusa de uma identidade emigrante e a adoção de práticas que corroboram a expetativa de que o regresso é pouco mais que uma miragem.

Considerando as hipóteses teóricas, conclui-se estarmos perante um fenómeno de fuga de cérebros e não de circulação de elites. Os fluxos tendem a ser fortemente assimétricos (com saldos muito negativos entre entradas e saídas), intensos, permanentes e de longo prazo. A emigração transitória é tendencialmente baixa e as redes, formais e informais, são residuais. Por outro lado há uma mobilidade latente que se constitui como uma alavanca para a saída. Experiências de mobilidade académica fomentam o fenómeno da fuga de cérebros. E mesmo aqueles que não emigram no período imediato à mobilidade académica ficam com uma forte predisposição latente para sair. 


\section{Referências bibliográficas}

AlmeIDA, J., \& Pinto, J. (1996). A investigação nas ciências sociais. Lisboa: Ed. Presença.

BARBOUR, R., \& Kitzinger, J. (1999). Developing focus group research: politics, theory and practice. London: Sage Publications.

BEINE, M., Docquier, F., \& Rapoport, H. (2003). Brain Drain and LDC's Growth: Winners and Losers. (IZA Discussion Paper No. 819). Bonn: The Institute for the Study of Labour (IZA).

BEINE, M., Docquier, F., \& Rapoport, H. (2008). Brain Drain and Human Capital Formation in Developing Countries: Winners and Losers. The Economic Journal, 118(528), 631-652.

BOURDIEU, P. (1983). Questões de Sociologia. Rio de Janeiro: Marco Zero.

DocQuIER, F., Faye, O., \& Pestieau, P. (2008). Is Migration a Good Substitute for Education Subsidies? Journal of Development Economics, 86(2), 263-276.

GOMES, R. (coord.) (2015). Fuga de cérebros: retratos da emigração portuguesa qualificada. Lisboa: Bertrand.

GUERrEIRO, M. D., \& Abrantes, P. (2007). Transições Incertas. Os jovens perante o Trabalbo e a Família. Lisboa: Comissão para a Igualdade no Trabalho e no Emprego.

HAQUE, N., \& Kim, S. (1995). Human Capital Flight: Impact of Migration on Income and Growth. Imf Staff paper, 42(3), 577-607.

HEUER, N. (2011). Working Paper in Economic and Finance No.7. Tubingen: University of Tubingen.

JOHNSON, J., \& Regets, M. (1998). International Mobility of Scientists and Engineers to the US - Brain Drain or Brain Circulation? NSF Issue Brief, No. 98-316..

KRUEGER, R. (1998). Developing questions for focus groups. Thousand Oaks: Sage Publications.

LAHIRE, B. (2002). Portraits Sociologiques. Dispositions et variations individuelles. Paris: Nathan.

MiYAgIWA, K. (1991). Scale Economies in Education and the Brain Drain Problem. International Economic Review, 32, 743-759.

MOUNTFORD, A. (1997). Can a Brain Drain be Good for Growth in the Source Economy? Journal of Development Economics, 53(2), 287-303. 
PIZARRO, J. (2005). Globalizados, pero restringidos. Una visión latinoamericana del mercado global de recursos humanos calificados. Santiago de Chile: Centro Latinoamericano y Caribeño de Demografía.

Rosenbaum, J., Kariya, T., Settersten, R., \& Maier, T. (1990). Market and Network Theories of the Transition from High-School to Work: Their Application to Industrial Societies. Annual Review of Sociology, 16, 263-299. 
JOÃO TEIXEIRA LOPES et al. ${ }^{1}$

https://orcid.org/0000-0001-6891-7411

\section{A PRODUÇÃO SOCIAL DO INDIVÍDUO QUE EMIGRA: UMA ANÁLISEA PARTIR DE RETRATOS SOCIOLÓGICOS}

\section{Socialização e migrações: a questão da escala}

Qualquer fenómeno social pode ser estudado através de várias escalas e, preferencialmente, articulando níveis de observação. O presente texto privilegia o que poderíamos considerar a "produção social do indivíduo que decide emigrar", centrando-se nos processos e contextos de socialização que, ao longo do percurso biográfico, originam disposições sociais migratórias, conetadas ou não com processos de mobilidade social e/ou cultural, através de uma análise qualitativa, assente em 52 retratos sociológicos, metodologia proposta por Bernard Lahire (2002) e por nós atualizada (Lopes, 2014). Assim, partimos de uma amostra intencional, não aleatória, de cidadãos portugueses que estavam ou estiveram em mobilidade ou emigrados num país europeu nos últimos 6 anos, com habilitações académicas do ensino superior, ou que tivessem exercido uma atividade profissional correspondente a esse nível académico.

\footnotetext{
${ }^{1}$ Autores: João Teixeira Lopes (IS/FL - Universidade do Porto); José Pedro Silva (IS - Universidade do Porto); Rafaela Ganga (IS - Universidade do Porto); Rui Gomes (CES/ FCDEF - Universidade de Coimbra); Henrique Vaz (CIIE/FPCEUP - Universidade do Porto); Luísa Cerdeira (IE - Universidade de Lisboa); Belmiro Cabrito (IE - Universidade de Lisboa); Dulce Magalhães (IS/FLUP - Universidade do Porto); Maria Lourdes Machado-Taylor (CIPES - Centro de Investigação de Políticas do Ensino Superior); Paulo Peixoto (CES/ FE - Universidade de Coimbra); Rui Brites (ISEG - Universidade de Lisboa); Sílvia Silva (FL - Universidade do Porto/FE - Universidade de Coimbra); Tomás Patrocínio (IE - Universidade de Lisboa).

Este artigo é resultado do projeto de investigação "Êxodo de Competências e Mobilidade Académica de Portugal para a Europa" (PTDC/IVC-PEC/5049/2012), financiado por fundos nacionais através da Fundação para a Ciência e a Tecnologia (FCT/MEC) e cofinanciado pelo Fundo Europeu de Desenvolvimento Regional (FEDER) através do COMPETE - Programa Operacional Fatores de Competitividade (POFC).
} 
Esta análise insere-se num projeto vasto sobre as migrações portuguesas incluídas no fenómeno da "fuga de cérebros" ("Brain drain"). Nesse projeto, os diferentes níveis ou escalas de observação são cruzados, pelo que remetemos para outras publicações (Gomes, 2015) a evidência desse exercício.

\section{Metodologia: Perfis-tipo e retratos sociológicos}

A revisão da literatura permitiu a construção de perfis-tipo dos migrantes qualificados, de acordo com a definição de um tipo particular de relação com o fenómeno em estudo e com as hipóteses teóricas avançadas, cruzando quatro grandes princípios estruturantes: i) caraterísticas temporais da mobilidade: permanente ou temporária, de longo prazo ou transitória; ii) posição social no sistema de emprego: segmento primário ou secundário do mercado de trabalho; iii) perfil funcional no sistema de emprego: académicos e cientistas, outras profissões altamente qualificadas; iv) tipo de mobilidade: direta (depois de ter entrado no sistema de emprego do país de origem), indireta ou latente (após um período de estudo no país de acolhimento).

Os quatro perfis-tipo construídos são os seguintes:

i. migração para um país europeu para o exercício de profissões no sistema científico ou no ensino superior;

ii. migração de longo prazo para um país europeu para trabalhar no segmento primário (equivalente às qualificações académicas) ou secundário (abaixo das qualificações académicas) do sistema de emprego;

iii. mobilidade estudantil europeia, que conduz à inserção nos segmentos primário ou secundário do sistema de emprego do país em que é feita a formação;

iv. mobilidade e circulação transitória ou pendular através de redes europeias de ciência, produção, serviços ou cultura.

Em função destas categorias selecionaram-se os indivíduos a serem retratados, numa relação de 13 indivíduos por cada perfil-tipo, num total de 52 retratos. 
Os retratos sociológicos surgem como dispositivo metodológico capaz de resgatar uma dupla pluralidade nas trajetórias individuais: por um lado, a pluralidade das disposições internas, tendo em conta a sua génese, a sua desigual "força" e sistematicidade; por outro lado, a pluralidade contextual, externa, associada à multiplicidade de processos, agências e contextos de socialização ou modos de vida. Dito de outro modo: somos indivíduos plurais em contextos também eles plurais. Bernard Lahire (2002) apresenta-nos uma grande teoria capaz de corresponder à pluralidade e complexidade contemporâneas. $\mathrm{Na}$ genealogia da teoria da prática, este autor francês desenvolveu uma série de pesquisas que lhe permitiram propor um programa assente no ator plural, exposto a princípios de socialização múltiplos, diferentemente atualizado ao longo do seu percurso e fortemente relacionado com os domínios de atividade, as situações e os contextos.

Lahire (1998) chega a propor o abandono do conceito de habitus ${ }^{2}$, substituindo-o pela noção de património individual de disposições, onde se salientam, precisamente, repertórios de disposições, com géneses diferentes, graus de ativação distintos e forças diferenciadas.

$\mathrm{Na}$ verdade, um amplo trabalho de pesquisa tem demonstrado que as disposições se transferem sob um determinado número de condições. Como já referimos, existem situações que as ativam, mobilizando-as, enquanto outras as adormecem ou inibem. As próprias disposições têm graus desiguais de robustez, em íntima articulação com a sua génese (o modo particular como num determinado indivíduo o processo de socialização - sempre plural, mais ou menos contraditório e acionado por múltiplos agentes, inclusive no próprio meio familiar - se exerceu). Importa, deste modo, perceber os detalhes das variações intraindividuais, como cada indivíduo se desdobra em compromissos e metamorfoses múltiplas pelos diferentes domínios de ação.

É neste âmbito que Lahire (2002) propõe os retratos sociológicos como um dispositivo metodológico. A ideia não consiste em conceber um indivíduo isento de constrangimentos sociais, dessocializado ou fragmentado. Pelo

2 O conceito de habitus, tal como foi proposto por Pierre Bourdieu, diz respeito a um conjunto de visões do mundo e disposições para a ação coerente e inculcado, que, decorrendo do posicionamento e da trajetória do indivíduo no espaço social, estrutura as suas práticas sociais (Bourdieu, 1997). 
contrário, pretende-se analisar a sua produção social, em termos de complexidade. Afinal, o indivíduo é multissocializado e multideterminado, corpo socializado e socializador que reflete no seu percurso a arquitetura invisível das forças sociais, desenvolvendo modos de relação consigo próprio e com os contextos e situações onde se move. Essa forma de produção de si incorpora os mais pesados constrangimentos sociais e nada deve às teorias encantadas e ilusórias do livre-arbítrio. Lahire (2002) refere-se a este processo como sendo o da constituição das pregas singulares do social, advogando a autonomia e a pertinência complementares de uma escala de observação e de um nível de análise que os sociólogos não podem abandonar, sob pena de se tornarem analiticamente míopes.

Contudo, a escala de observação individual não exclui as demais: a um nível meso, encontram-se os quadros de interação e as instituições (Lopes \& Costa, 2014); a um nível macro e estrutural, estão as posições no espaço social. De certa forma, o "interior" não é mais do que um "exterior" no estado dobrado. Diz Lahire (2013, p. 16): “Não há para os indivíduos qualquer existência possível fora do tecido social (...) as fibras desse tecido, que se cruzam e entrecruzam, são constitutivas de cada indivíduo", formando, assim, uma espécie de coeficiente de singularidade. Ora, é esse coeficiente que aqui se pretende estudar: é objetivo deste artigo apreender os contextos de origem, consolidação e ativação da disposição para emigrar.

Importa salientar que, nesta pesquisa, os retratos foram sempre orientados para a(s) experiência(s) emigratória(s) dos sujeitos - não se trata de uma mera história de vida, antes do delinear de um percurso que desemboca na emigração.

\section{Uma sociografia a partir dos retratos}

Em primeiro lugar, apenas quatro dos entrevistados têm uma idade superior a 40 anos, o que mostra bem a juvenilidade da amostra: no geral, os entrevistados fazem parte dessa categoria designada de "adultez emergente" ou "jovens adultos", aprisionados no prolongamento sociológico da juventude por viverem dificuldades nos trânsitos entre ciclos de vida e passagens insti- 
tucionais (Ferreira \& Pais, 2010), amiúde não completando as transições (para a vida adulta, para o trabalho contratualizado, para uma família de destino).

Por outro lado, provêm, na sua maioria, de famílias com médio ou alto capital escolar, o que indica como forte a possibilidade de a emigração se efetuar como evitamento de processos de desclassificação social, particularmente acentuados em períodos de crise económica e social, permitindo manter ou melhorar níveis de vida, pela procura no estrangeiro de empregos mais ou menos correspondentes à formação académica. Esta, por sua vez, é elevadíssima, uma vez que 34 dos entrevistados possuem mestrado e/ou doutoramento.

Finalmente, destacaríamos, neste ponto, a escolha esmagadora de países do centro europeu, mostrando como a transferência de capital humano altamente qualificado consolida posições geopolíticas anteriores de centralidade (centro e norte da Europa) e periferia (Portugal) - muitos habitam em cidades-região fortemente integradas em sistemas urbanos de cariz transnacional.

\section{Coerências, dissonâncias, ruturas}

Comecemos por analisar a distribuição dos percursos em termos de coerência, heterogeneidade disposicional ou mesmo de rutura biográfica. De certo modo, esta análise implica uma opção artificial, se pretendermos que a classificação dos casos seja mutuamente exclusiva. Raros são os percursos que formam um património individual de disposições totalmente unificado e confirmado, contexto após contexto de socialização, ciclo de vida após ciclo de vida, incorporando a mesmidade e operando uma radical economia da contradição e da dissonância. Em todos os retratados existe algum coeficiente de diversidade disposicional, até pela multiplicidade de papéis sociais exercidos e pela plêiade de experiências vividas numa pluralidade de mundos da vida.

Deste modo, consideraremos, em termos de análise, que existe coerência disposicional quando se conjugam, mobilizam e reforçam quadros e experiências de socialização, favoráveis ou desfavoráveis, face à decisão (efetivamente tomada) de emigrar. No primeiro caso, a emigração surgirá com paixão, ou pelo menos fortemente incrustada no percurso biográfico, nas suas múltiplas 
MAPA 1: Presença dos emigrantes portugueses qualificados nas cidades de destino

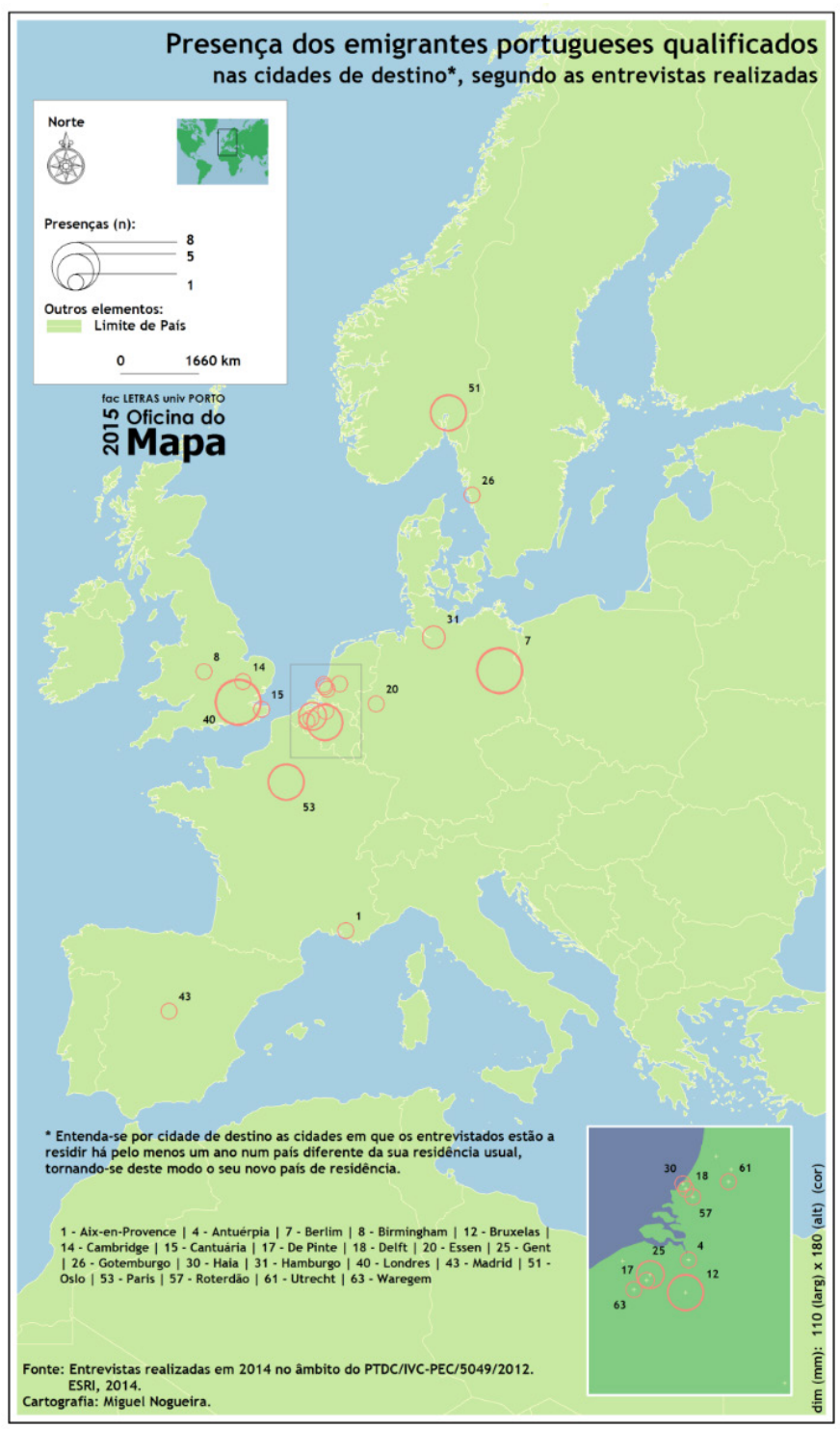


instâncias. No caso de uma coerência desfavorável, a emigração assoma com sofrimento, desgosto e/ou rejeição.

Nos casos de heterogeneidade, assistiremos a uma luta entre forças com graus diferentes de intensidade, em que as disposições mais arreigadas (porque mais precocemente interiorizadas e/ou porque mais ativa e sistematicamente mobilizadas) levam a que $o$ ator oscile, hesite ou viva com ambiguidade a sua decisão. Em percursos em que esta heterogeneidade se radicalize, poderemos encontrar situações de rutura biográfica que obrigam a escolhas, muitas vezes por inflexão de percurso, ou à resolução de impasses com maior ou menor grau de ativação de mecanismos e recursos de reflexividade.

QUADRO 1: Casos de coerência/heterogeneidade/rutura disposicional ao longo do percurso que culmina na decisão de emigrar

\begin{tabular}{|c|c|c|c|}
\hline \multicolumn{2}{|c|}{ Coerência disposicional } & \multirow{2}{*}{$\begin{array}{c}\text { Heterogeneidade } \\
\text { disposicional }\end{array}$} & $\begin{array}{c}\text { Rutura } \\
\text { biográfica }\end{array}$ \\
\hline Ana Baião & $\begin{array}{c}\text { Desfavorável } \\
\text { à emigração }\end{array}$ & Joana Batista & Manuela Alcobia \\
\hline Carlos Mesquita & & Bruno Azenha & Carlos Barradas \\
\hline Joana Antunes & Ana Taborda & Eleonora Rodrigues \\
\hline Francisco Fernandes & & Carina Faustino & \\
\hline Joana Campos & & João Sousa & \\
\hline Tiago Franco & & & \\
\hline Sónia Machado Costa & & \\
\hline Yara Reis & & & \\
\hline Alexandra Faria & & & \\
\hline Ângela Relógio & & & \\
\hline Alexandra Veríssimo & & & \\
\hline Liliana Silva & & & \\
\hline Inês Cabrito & & & \\
\hline Marisa Reis & & & \\
\hline Rita Rodrigues & & & \\
\hline Duarte Pinto & & & \\
\hline Ana da Costa & & & \\
\hline Sara Lopes & & & \\
\hline Pedro Alves & & & \\
\hline João Pais & & & \\
\hline
\end{tabular}




\begin{tabular}{|c|c|c|c|}
\hline \multicolumn{2}{|c|}{ Coerência disposicional } & \multirow{2}{*}{$\begin{array}{l}\text { Heterogeneidade } \\
\text { disposicional }\end{array}$} & \multirow{2}{*}{$\begin{array}{c}\text { Rutura } \\
\text { biográfica }\end{array}$} \\
\hline $\begin{array}{c}\text { Favorável } \\
\text { à emigração }\end{array}$ & $\begin{array}{l}\text { Desfavorável } \\
\text { à emigração }\end{array}$ & & \\
\hline \multicolumn{4}{|l|}{ Raquel Antunes } \\
\hline \multicolumn{4}{|l|}{ Amílcar Guedes } \\
\hline \multicolumn{4}{|l|}{ Firmino } \\
\hline \multicolumn{4}{|l|}{ Adriana Pereira } \\
\hline \multicolumn{4}{|l|}{ Rui C. Gomes } \\
\hline \multicolumn{4}{|l|}{ Elsa Razborsek } \\
\hline \multicolumn{4}{|l|}{ Sofia Maia } \\
\hline \multicolumn{4}{|l|}{ Nuno Saraiva } \\
\hline \multicolumn{4}{|l|}{ Sandra Antunes } \\
\hline \multicolumn{4}{|l|}{ Diana Lourenço } \\
\hline \multicolumn{4}{|l|}{ Ana Ribeiro } \\
\hline \multicolumn{4}{|l|}{ Ana Almeida } \\
\hline \multicolumn{4}{|l|}{ Cristina Nunes } \\
\hline \multicolumn{4}{|l|}{ Hugo Meneses } \\
\hline \multicolumn{4}{|l|}{ Susana Vieira } \\
\hline \multicolumn{4}{|l|}{ Pedro Barros } \\
\hline \multicolumn{4}{|l|}{ Eva Fernandes } \\
\hline \multicolumn{4}{|l|}{ Helena Sousa } \\
\hline \multicolumn{4}{|l|}{ Elisa Santos } \\
\hline \multicolumn{4}{|l|}{ Carolina Henriques } \\
\hline \multicolumn{4}{|l|}{ Fernando Carvalho } \\
\hline Vítor Martins & & & \\
\hline
\end{tabular}

Como se constata, são apenas sete os casos de heterogeneidade disposicional. Esta concentração, algo surpreendente face aos quadros teóricos de partida, demonstra a cumulatividade de certos processos sociais. Um deles reside no treino de competências de autonomia, num mútuo reforço entre família e escola. Progenitores desejosos de formarem filhos capazes de ativarem disposições contrárias a situações de dependência, libertando-os parcialmente das condições sociais de origem, em vários casos declinantes (ainda que relativamente privilegiadas), encontram em certos estabelecimentos escolares ou mesmo em programas de educação não-formal dispositivos de aprendizagem favoráveis a tal treino. 
A aquisição da autonomia processa-se por ensaios, tentativa e erro, retificação e experimentação. Neste sentido, a capacidade de agência é fortemente treinada, uma vez que os entrevistados vão revelando como aprenderam a lidar reflexivamente com os seus percursos, confrontando-se com constrangimentos vários, mas também com matrizes de escolhas e possibilidades. Um dos traços marcantes transversais a este perfil prende-se com o exercitar de projetos de mobilidade (turística, juvenil, académica, profissional), ela própria geradora de competências e disposições emancipatórias face às origens sociais.

Por outro lado, a aprendizagem relativamente precoce de disposições cosmopolitas (em cursos de línguas, viagens, programas juvenis de cooperação...), favorece claramente a decisão de emigrar para destinos densamente urbanizados, onde os entrevistados encontram atmosferas sociais e culturais que valorizam os recursos humanos qualificados no setor "quaternário" da criação simbólica e estética e nos serviços que lidam com o processamento e a difusão de informação, nas suas mais variadas formas.

Estes percursos lidam bem com as lógicas competitivas de acumulação de capital social, em particular capital social de tipo inclusivo, através do qual se articulam papéis sociais diversificados (profissional, amigo, consumidor, espetador...) localizando e otimizando recursos multilocalizados (Putnam, 2002).

Os casos de heterogeneidade, por seu lado, evidenciam o choque entre diferentes dimensões da vida na construção da disposição para a mobilidade, demonstrando, assim, a complexidade e pluralidade presentes em cada indivíduo. Para além disso, eles revelam ainda que, se a emigração trouxe consigo a possibilidade de satisfazer certas ambições, ela tem também custos produtores de um certo mal-estar. Em alguns dos casos de heterogeneidade observados, os sujeitos encontram-se numa situação profissional consideravelmente mais satisfatória do que aquela que conheciam em Portugal. Não obstante, deteta-se a expressão de um certo sofrimento, provocado por um sentimento de perda - ou, pior ainda, de abandono - de laços com pessoas significativas que ficaram em Portugal que, ainda que não seja suficientemente forte para que se lamente a decisão de emigrar, gera alguma ambiguidade. 
QUADRO 2: Contextos de ativação do processo migratório nos percursos de heterogeneidade

\begin{tabular}{|c|c|c|c|c|}
\hline Família & Profissão & $\begin{array}{c}\text { Aprendizagem } \\
\text { formal }\end{array}$ & Amigos & $\begin{array}{c}\text { Formação } \\
\text { social }\end{array}$ \\
\hline & Joana Batista & Joana Batista & Joana Batista & Joana Batista \\
\hline & Bruno Azenha & & & Bruno Azenha \\
\hline & Ana Taborda & & & Ana Taborda \\
\hline & Carina Faustino & & Carina Faustino & Carina Faustino \\
\hline & João Sousa & João Sousa & & João Sousa \\
\hline & Mafalda Costa & Mafalda Costa & & Mafalda Costa \\
\hline Catarina Gomes & Catarina Gomes & & & \\
\hline
\end{tabular}

Apesar da pressão da "formação social" (o eclodir e agudizar da crise a partir de 2008), as esferas social e afetiva jogam a sua importância na singularidade de cada percurso.

Será interessante, contudo, atentarmos mais detalhadamente nos raros casos de rutura biográfica.

QUADRO 3: Fatores e processos de rutura biográfica

\begin{tabular}{|l|l|l|}
\hline \multicolumn{1}{|c|}{$\begin{array}{c}\text { Momentos } \\
\text { (ciclo de vida) }\end{array}$} & \multicolumn{1}{|c|}{$\begin{array}{c}\text { Contextos } \\
\text { (eclosão) }\end{array}$} & \multicolumn{1}{c|}{$\begin{array}{c}\text { Mudanças } \\
\text { (disposicionais) }\end{array}$} \\
\hline $\begin{array}{l}\text { Entrada na idade } \\
\text { adulta (Daniel } \\
\text { Barradas) }\end{array}$ & $\begin{array}{l}\text { Relação afetiva (Daniel } \\
\text { Barradas) }\end{array}$ & $\begin{array}{l}\text { Sedimentação de disposições } \\
\text { cosmopolitas (Daniel Barradas) }\end{array}$ \\
\hline $\begin{array}{l}\text { Maternidade (3 } \\
\text { filhos) (Manuela } \\
\text { Alcobia) }\end{array}$ & $\begin{array}{l}\text { Contexto profissional (seu e } \\
\text { do marido); crise económica } \\
\text { (Manuela Alcobia) }\end{array}$ & $\begin{array}{l}\text { Reconstrução da carreira } \\
\text { profissional (Manuela Alcobia) }\end{array}$ \\
\hline $\begin{array}{l}\text { Relação amorosa } \\
\text { (Eleonora } \\
\text { Rodrigues) }\end{array}$ & $\begin{array}{l}\text { Inadaptação do companheiro } \\
\text { a Londres e risco de rutura } \\
\text { da relação (Eleonora } \\
\text { Rodrigues) }\end{array}$ & $\begin{array}{l}\text { Regresso a Portugal, permanência } \\
\text { temporária do casal em casa de } \\
\text { familiares e recomeço de vida } \\
\text { autónoma em Espinho (Eleonora } \\
\text { Rodrigues) }\end{array}$ \\
\hline
\end{tabular}

No percurso de Daniel Barradas existem linhas de continuidade. Uma família com algum capital escolar e focada na escolarização dos filhos favoreceu a sua dedicação aos estudos e a prossecução de hábitos de leitura e de prática musical, que o levaram a seguir estudos musicais, contra vontade, 
e depois design gráfico, em Lisboa. Tudo parecia encaminhado para uma internacionalização pela porta grande, em Nova Iorque, mas fez a escolha "menos lógica", rumando à Noruega, a convite do namorado que acabara de conhecer. A partir daí, o contacto com a realidade laboral norueguesa, em vários empregos ligados ao design, a inserção em redes "gay" e as inúmeras situações de abertura à diversidade consolidaram fortes disposições cosmopolitas. Regressou a Portugal com o namorado, devido a ter resvalado para uma situação de subemprego, mas a crise de 2008 fá-lo regressar à Noruega, onde encontrou novo relacionamento que resultou mais tarde em casamento. Hoje, mesmo não se sentindo profissionalmente seguro, não vislumbra qualquer possibilidade ou desejo de regresso, dada a proteção social que a Noruega lhe oferece. Esta perceção vincada de um regresso improvável, associada à idade madura, torna-o nostálgico, o que mostra bem como as disposições cosmopolitas podem coexistir com inclinações saudosistas.

No caso de Manuela Alcobia, a disposição para emigrar resulta de uma situação de rutura, produzindo ela própria reajustamentos subsequentes. Antes de partir, Manuela estava empregada há treze anos num hospital público, trabalhando como técnica de saúde para diagnóstico genético. No entanto, a impossibilidade de progressão na sua carreira na função pública, a que não são indiferentes as políticas de austeridade adotadas em Portugal, associada à instabilidade no trabalho do marido, com salários em atraso, obrigaram-na a optar entre a emigração ou um ajustamento do estilo de vida face à nova realidade económica familiar. Escolhendo a primeira opção, toda a família emigrou para Londres de forma planeada. No Reino Unido vivem com boas condições financeiras, mas com algum sofrimento pelos laços deixados em Portugal. Manuela retrocedeu - momentaneamente, pelo menos - do ponto de vista da carreira e do reconhecimento profissional e reconhece ter agora menos espaço para ser criativa no trabalho. Por outro lado, gosta do papel que a confiança tem nas relações laborais e considera estarem reunidas melhores condições para ajudar os três filhos a construir um futuro.

Finalmente, Eleonora Rodrigues, com 31 anos, é natural de Lisboa e vive em Espinho. Tanto o pai (bacharel da Escola do Comércio) como a mãe (12. ${ }^{\circ}$ ano) nasceram em Angola, para onde as respetivas famílias tinham ido viver. Após uma passagem de 3 anos pelo Brasil, iniciada quando Eleonora tinha 
apenas três meses, o casal conheceu uma situação difícil quando, já em Portugal, a empresa de importação/exportação que entretanto fundara faliu. Aos 16 anos, Eleonora vivia e estudava em Coimbra com a irmã mais velha, quando os pais se mudaram para Leiria por razões profissionais. Tal contribuiu para que adquirisse desde cedo uma certa autonomia. Licenciou-se em Comunicação Organizacional na Escola Superior de Educação de Coimbra e fez Erasmus em Istambul, experiência rica em novas aprendizagens e sociabilidades e decisiva para reforçar a vontade de conhecer o mundo. Terminada a licenciatura, e depois de alguns estágios não remunerados e trabalhos precários, conseguiu uma ambicionada experiência profissional internacional através do programa INOV Contacto: um estágio de 9 meses no Brasil, na área de assessoria e gestão de eventos. De volta a Portugal, conheceu o atual companheiro e foi viver para Espinho, terra natal dele. Trabalhou 9 meses como assistente de marketing e de direção, seguindo-se uma curta experiência como vendedora de máquinas Bimby. Face à precariedade da vida profissional de ambos, e apesar de alguma resistência dele, o casal emigrou para Londres em janeiro de 2013, destino escolhido pela língua inglesa e por ele ter um casal amigo em Inglaterra. Eleonora encontrou trabalho, orientado para o mercado brasileiro, como Advertising Sales Executive; mas descobriu que o seu chefe - um português - pagava salários inferiores aos trabalhadores oriundos de Portugal, Espanha e América Latina. Para além disso, o companheiro não se adaptou a Londres, o que gerou um mal-estar emocional. Três meses depois da chegada e com a sua relação em risco, o casal decidiu voltar a Portugal, vivendo temporariamente em casa dos pais dele. Eleonora encontrou um estágio profissional de um ano, sem qualquer possibilidade de continuidade, voltado para o mercado brasileiro. Manifesta descontentamento com o elitismo do ensino superior, a precariedade do mercado de trabalho e as políticas públicas de emprego. Voltar a emigrar é uma hipótese que não descarta.

\section{Notas conclusivas}

Antes de mais, importa referir uma surpresa na análise dos resultados: não esperávamos encontrar tantos casos de coerência disposicional favorável à 
emigração. Insistimos num ponto: não estamos a falar de percursos monolíticos, nem de indivíduos despojados de pluralidade (de princípios de socialização, papéis e experiências sociais ou mesmo patrimónios de disposições). Contudo, parece claro que a emigração surge como consequência de um reforço entre disposições favoráveis à autonomia, emancipação e cosmopolitismo (contacto precoce com o universo das viagens e das diferenças culturais), a influência de outros significativos nos processos de socialização (pais, familiares, professores, amigos) e, em muitos trajetos, a vivência de experiências de mobilidade estudantil (Erasmus). Esta conjugação é acicatada quer pela vontade de concretizar aspirações e projetos (em que frequentemente se cruzam motivos amorosos e profissionais), quer pela constatação de uma ausência de contextos de ativação de disposições e competências qualificadas em Portugal. A dissociação entre percursos académicos bem-sucedidos e altamente qualificados e o mercado de trabalho nacional, incapaz de absorver estes recursos, gera um efeito de procura de realização profissional num contexto internacional, o qual passa a ser percebido como um mercado global.

Os casos de heterogeneidade evidenciam a potencial colisão entre diferentes esferas da vida, jogando com a força que cada uma delas desempenhava na singularidade dos percursos.

Finalmente, as trajetórias de rutura denotam bifurcações biográficas, com reajustamentos significativos. Num caso, evidencia o predomínio de lógicas afetivas (Carlos Barradas), noutro a recusa em aceitar uma abrupta queda social (Manuela Alcobia).

Esta é uma síntese possível, resultado do olhar comparativo entre trajetos. Contudo, gostaríamos que ela não descartasse a ideia da multiplicidade de casos e de percursos, percebendo como, em cada indivíduo, se cruzam de forma singular, única e irrepetível múltiplas influências socializadoras, processos e dinâmicas sociais, experiências e momentos. Assim, importa ainda sublinhar a potencialidade do retrato sociológico enquanto dispositivo metodológico, não sendo displicente afirmar que este dispositivo metodológico permite captar, por um lado, a complexidade das sociedades contemporâneas, através da análise transversal e comparativa e, por outro lado, a natureza plural dos projetos de vida, através da prática de uma sociologia ao nível do indivíduo. 


\section{Referências Bibliográficas}

AA.VV. (17 de maio de 2011). Memorando da troika anotado. Público. Disponível em http://www.publico.pt/economia/memorando-da-troika-anotado

BEINE, M., Docquier, F., \& Rapoport, H. (2008). Brain Drain and Human Capital Formation in Developing Countries: Winners and Losers. The Economic Journal, 118(528), 631-652.

BOURDIEU, P. (1997). Razões Práticas - Sobre a Teoria da Acção. Oeiras: Celta.

FERreIRA, V. S., \& Pais, J. M. (2010). Tempos e Transições de Vida: Portugal ao Espelho da Europa. Lisboa: Imprensa de Ciências Sociais.

LAHIRE, B. (1998). L'Homme pluriel. Les ressorts de l'action. Paris: Nathan.

LAHIRE, B. (2002). Portraits Sociologiques. Paris: Nathan.

LAHIRE, B. (2013). O Singular Plural. Cadernos do Sociófilo, Quarto Caderno, 16-26.

LOPES, J. T. (2014). Retratos sociológicos: dispositivo metodológico para uma sociologia da pluralidade disposicional. In L. L. Torres, \& J. A. Palhares, Metodologia de Investigação em Ciências Sociais da Educação. V. N. de Famalicão: Húmus.

LOPES, J. T., \& Costa, A. F. (2014). Estrutura, contexto e agência nos percursos desiguais dos estudantes do ensino superior: Fatores e processos de sucesso e insucesso. In A. F. Costa, J. T. Lopes, \& A. Caetano, Percursos de Estudantes no Ensino Superior (pp. 203-210). Lisboa: Editora Mundos Sociais.

MALHEIROS, J. (31 de março de 2011). JANUS.NET e-journal of International Relations, 2(1), 133-142. Disponível em: http://.ual.pt/janus.net/pt_vol2_n1_(Consultado em: 31 novembro 2013).

MATTOO, A., Neagu, I. C., \& Özden, C. (2005). Brain Waste? Educated Immigrants in the U.S. Labor Market. World Bank Policy Research Working Paper No. 3581). Washington, DC: World Bank.

PIRES, R. P., Pereira, C., Azevedo, J., Santo, I. E., \& Vidigal, I. (16 de Março de 2015). Portuguese Emigration Factbook 2014. Obtido de Observatório da Emigração: http://www.observatorioemigracao.pt/np4/1269 
JEAN-BAPTISTE MEYER ${ }^{1}$

https://orcid.org/0000-0002-5442-8323

\section{KNOWLED GE D I S PORAS:}

\section{MOVING FRONTIER OF DEVELOPMENT}

\section{Introduction}

Today, the diaspora appears as a possible asset for the development of many countries. In this vision, reconnection with high-skilled expatriate human resources has acquired a particular momentum. However, this focus outside of the national territory suffers from a lack of tools to translate itself into a tangible contact and actual mobilization. Evidence brought from the CIDESAL project, about Latin-American diasporas, reveals the experimental works and reflections attempted in this direction. Migration trends' evolution, occurring at the global as well as the regional level, points to the reinforcing process of diaspora constitution. It deserves to be followed and sometimes managed, requiring information gathering and the shaping of adequate instruments $^{2}$. The chapter looks at both inputs and offers basic principles for a fertile relationship between diasporas and countries.

\footnotetext{
${ }^{1}$ Jean-Baptiste Meyer is a senior researcher at IRD. He coordinated the international project "CIDESAL", Creation of Knowledge Diasporas Incubators for Latin America - with the purpose of concretely strengthening network links for effective developments.

2 Parts of this text have been produced for the introductory note - "a pragmatic approach to diasporas"- and conclusive remarks - "digital humanities and transnational governance" of the book: Meyer J-B. (ed.) (2015). Diaspora: Towards the New Frontier. Paris/Montevideo: IRD/UDELAR editions, http://www.observatoriodiasporas.org
} 


\section{Ancient concept, new evidence and fashionable reference}

The word "diaspora" until recently sounded like an original form of exotic organization, something like a myth attached to some kind of exceptional society. When we started using it to describe contemporary patterns of societal relationships during the 1990s (Sheffer, 1986; Cohen, 1997; Meyer et al. 1997), we were first received with surprise, then often with strong skepticism (Gaillard \& Gaillard, 2003, Lowell \& Gerova, 2004). Surprisingly, in one single decade, what was once a vision has become a conventional view. Doubts quickly vanished under convergent evidence and the term 'diaspora' imposed itself as a major concept to describe a globalizing world in a socio-historical perspective (Dufoix 2008, Gamlen, 2014).

After the paradigm shift announced in the late 1990s (Meyer \& Charum 1995; Khadria, 2001), the emerging migration-development nexus has heavily referred to the expatriates' connection as a positive asset (Faist, Fauser, \& Kivisto, 2011). Interest has quickly developed from international cooperation agencies, finding a promising opportunity for effective North-South transfers, relieved from exogenous or tied aid problems.

The recent awareness of the diasporas' importance and resources (IRD/ Barré et al. 2003; World Bank/Kuznetsov, 2006; MAE/OECD, 2012) soon faced policy issues and the question of feasibility (EPFL, 2010; UNCTAD, 2012; MAE /OECD, 2012; Diaspora Matters, 2012; IOM/MPI, 2012). The very titles of the publications from these agencies highlight their concern about instrumental answers to the challenge of engaging the diasporas in development processes $^{3}$. After the inflation of expectations that diasporic initiatives and resources

\footnotetext{
3 (Emphasis in bold from the author) "Scientific diasporas: How can developing countries benefit from their scientists and engineers abroad?", (Barré, et al. 2003); "Diaspora networks and the international migration of skills: how countries can draw on their talent abroad" (Kuznetzov, 2006); "an action-oriented toolkit to assess good practices of skilled migrants and scientific diasporas" (EPFL, 2010); "Harnessing remittances and diaspora knowledge to build productive capacities" (LDCs UNCTAD annual report, 2012); "Harnessing the skills of migrants and diasporas to foster development: policy options" (MAE/OECD, 2012); "Global, Diaspora strategies toolkit: harnessing the power of global diasporas" (Diaspora matters 2012); "Developing a road map for engaging diasporas in development: a handbook for policy makers and practitioners in home and host countries" (IOM-MPI, 2012).
} 
could help set up capacities in developing countries, the policy concern has become today essentially pragmatic.

How can diasporas be used for creative purposes, in development perspectives? This is today's big question, as pointed out by previous endeavours mentioned above. However, we suggest a different approach. Instead of focusing on political, organizational and management proposals, it appears necessary to turn towards a more fundamental approach. It assumes that diasporas, as transnational entities, require a kind of post-state governance. And it looks for new tools appropriate for this.

In Latin America today, diasporas receive extensive political attention. Like in many parts of the world, they are essentially perceived as extensions of national constituencies. To represent this, central administrations often symbolically stretch the national territory to include the diaspora within a new division, in addition to the traditional ones. For instance, in Argentina, it is the $23^{\text {rd }}$ Province (Provincia veintitrés), while in Uruguay, there is the $20^{\text {th }}$ Department (Departamento Veinte). It is a proper way to epitomize an entity which is impossible to circumscribe and to try to deal with it in a juridically satisfactory manner. But it is also a denial of the intrinsic extraterritoriality of the diaspora. It is a semantic inclusion within traditional borders of something which remains actually beyond, by definition. It is, thus, an illusory shortcut to translate what the countries are actually trying to reach: their new frontier.

\section{From old myth to new prospects}

For the historian Arnold Toynbee, the diaspora is the normal step between the ending nation-state system and the advent of a world society (Toynbee, cited in Dufoix, Guerassimoff, \& Tinguy, 2010). In such a perspective, the current expansion of national policies through diasporic networks may be interpreted as an attempt to adapt locally bounded entities to purely global challenges. The concept of frontier - from American history (Turner, 1893; White, 1991) - deserves to be imported here since it grasps the double dimension of both elusive limits and mobilizing dynamics, through which collective identity is maintained, updated and developed. 
However, is the diaspora discourse of today a performative myth like the frontier speech of the past? In order to go beyond simply rhetorical arguments which cannot, alone, sustain collective action for long, there is a definite need for means and investments. This is where all the policy documents referred to above come into the picture. They try to operationalize the objective of diaspora engagement and mobilization. Public policy aims and programmes are thus listed and, sometimes, implemented. A handbook collecting best practices recorded in many different contexts is proposed, providing governments with a standard scheme of activities development (IOM/MPI 2012). Isomorphism, derived from the transposition of national experiences produced somewhere, to other countries and settings, is even noticed (Gamlen, 2014), with obvious risks of irrelevant organization.

In fact, the implementation of a diaspora strategy collides with the limits of traditional public policy, within nation-state borders. For instance, how can a government plan actions with the country's expatriates when no - or only a few - statistics and knowledge about them depend on its own services? How can a reach out policy be actually designed and organized if most of these expats are not well identified and located? How can actions be proposed to them if their skills and abilities are not well defined and expressed in accordance with their potential partners' objectives? Lastly, where can shared activities be organized and take place if there is no common space for interaction?

\section{Pragmatic leap}

Traditional international cooperation may partly overcome some of these limitations. Information exchange, profiling and matching exercises, distant communication devices, etc. have, for instance, been developed in this context by both origin and host countries together in co-development programs. Multilateral agencies have also gained momentum with their unrivalled ability to deal with the dispersal of diasporic communities (IOM's MIDA programme, EU African Diaspora project, for example). However, there is an important constraint over these attempts: information remains essentially subordinated 
to national settings, not only for data collection but also for its very definition, production and access; and space is bounded by sovereignties with impossible overlap, making transnational interaction dynamics virtually impossible, if no substitute is found for an effective meeting place.

Every diaspora project today is confronted with this contradiction: national conditions for a transnational purpose. Countries remain "containers" and "methodological nationalism paradigm" still rules the world (Beck, 2006; Glick Schiller, 2009). To escape from these enclosures and proceed towards a new frontier, information and space should no longer depend on nation-states' borders. The CIDESAL project created devices that were less state dependent in order to produce these new conditions. It focused on three countries with precocious diaspora policies: Argentina, Uruguay and Colombia, and drew lessons from their history. It explored new information sources, channels and indicators. It experimented with original instruments to open room for co-actions of distant potential partners.

In doing so, a mix of social and engineering sciences was used. History, anthropology, sociology, economics, demography, geography, communication, information science and technology were mobilized. Six teams from public and private organizations have been involved for five years, in four countries. The results of these efforts are some paths opened in the open field of cosmopolitanism that this book presents. Following the pragmatic approach of former explorers, in search of new tools, it is a genuine attempt of actual "realistic cosmopolitanism", in line with Ulrich Beck's vision at the eve of the millennium. These concrete steps in the wild west translate utopia into credible options.

\section{Taking the new context into account}

Today, geopolitical and technological transformations have substantially modified the conditions for the mobilisation of the diasporas. Recurring socio-economic challenges in the North and rapid growth of opportunities in certain regions of the South have generated new dynamics. These have in turn led to emerging countries eventually becoming poles of attraction 
(see other chapters in this volume). In Latin America, for example, the economies now require an influx of skills and calling on the diaspora has thus become more pressing and more specific. In Uruguay, the diaspora is invited to fill in particular shortages in qualified employee profiles that are not exclusively intellectual, such as those of skilled trades or technicians (Lema, 2015). Neighboring Argentina presses for the return of its researchers through repatriation programmes that are heavily advertised (Luchilo, 2015). Brazil offers mobility grants to attract senior and junior academic personnel from abroad to its universities and laboratories. For these countries and others, the diaspora is explicitly called upon to participate in training their human resources that are required for current developments more than ever before.

In contrast to the past when pro-active re-insertion programmes scarcely expressed a specific and constructed demand, those of today are based on needs that are more clearly identified and have better data-mining tools. The dynamics of the emergence of these countries on the one hand and the ad hoc activation of the diaspora on the other are, therefore, complementary in the same way as the findings of the case studies of China and India, which are often cited.

\section{Evolving migration from Latin America}

Like most regions in the world, migration to and from Latin America has significantly increased. Recent OECD data show that countries of this organization received in 2010 50\% more migrants than they used to only 10 years before, with a total of 15439162 persons. Interestingly, the pattern of geographical orientation has moved from North America to other attractive regions: mainly Europe but also South America itself. In particular, Spain and Portugal have seen a tremendous increase of their immigrants from this region, from 693000 to 1936000 and 66550 to 150 000, respectively. Such an increase, over 100\%, is much more than that experienced during the same period by any other receiving country, in particular big ones like Canada and the United States of America. The 
locus of emigration within the region also shifted from the North to the South, with a diminishing relative part of Central America and the Caribbean while the one of Andean countries and those from the southern cone expanded (see figure 1).

FIGURE 1: Evolution of Latin American emigration per sub-region of origin

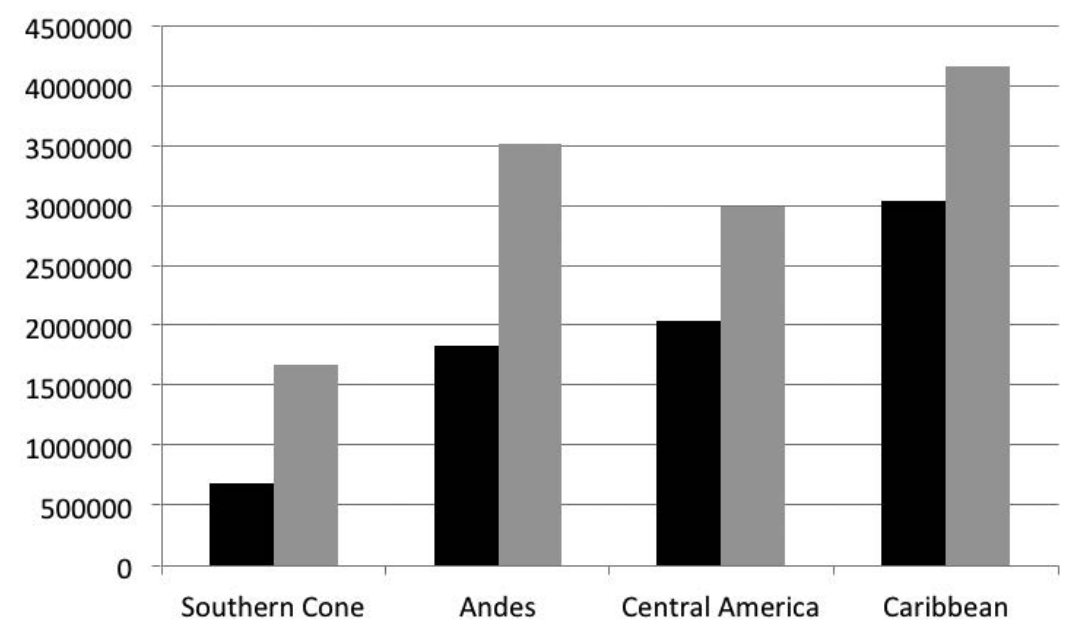

As for all regions, the skills component of the migrant populations has increased: a quarter/one fourth had a higher education degree in 2010 and represented $8 \%$ of the people with the same educational level at home. Such a rate is above all the ones of other developing regions except sub-Saharan Africa. It varies excessively among countries. The Caribbean islands have exceptional proportions ( $50 \%$ and over) while Brazil shows, on the other hand, a uniquely low rate of professionals abroad, though higher than in 2000 (from 1.8 to 2.6\%). Argentina essentially holds a highly skilled diaspora (40\% of all migrants having a university degree). Interestingly enough, these two countries have also become magnets for human resources from their neighbors and remote parts of the world as well.

Argentina and Brazil immigrant populations today are quite different (see figure $2 \mathrm{a}$ and $2 \mathrm{~b}$ ). 
FIGURE 2a and 2b: Main origin countries of immigrants to Argentina (a) and Brazil (b)
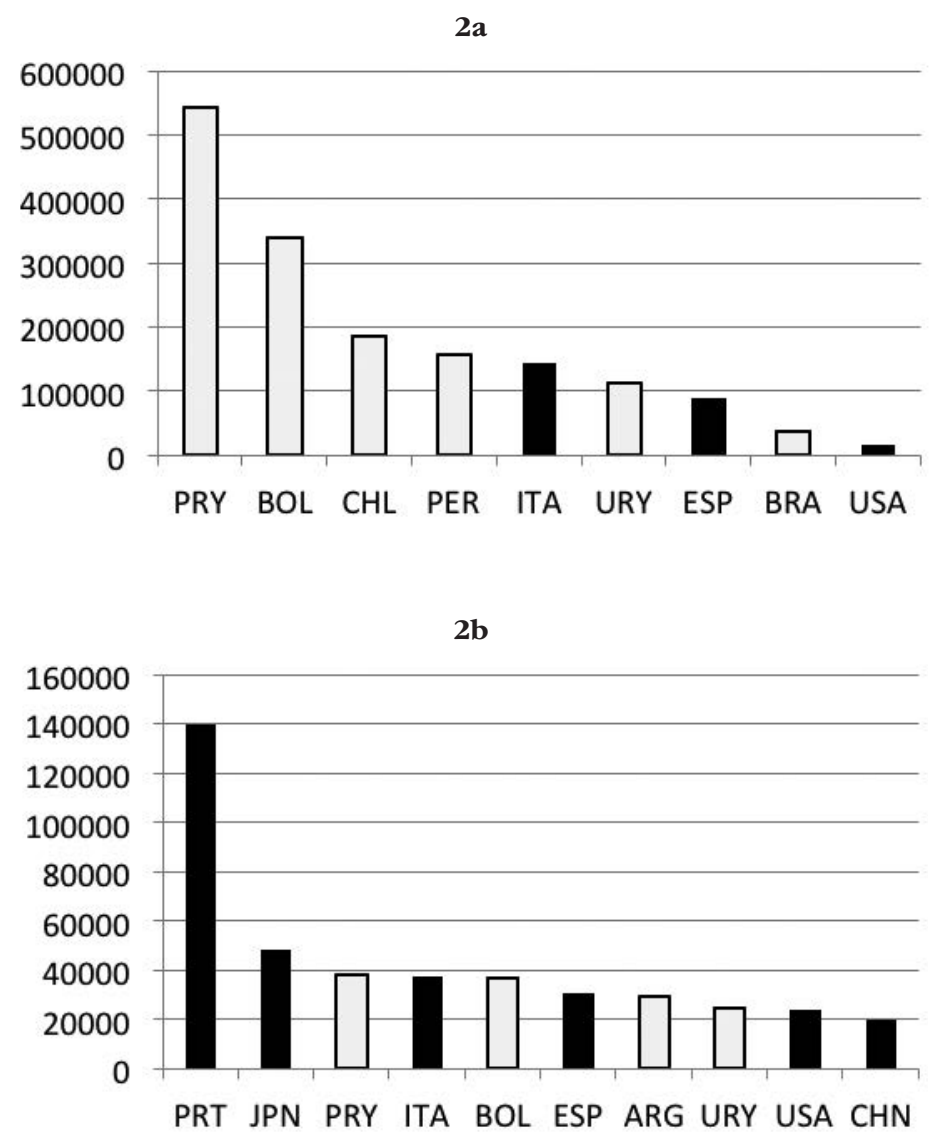

While Argentina basically attracts neighboring populations, people migrating to Brazil come from very different locations. If the traditional European contacts of Argentina (Italy and Spain) are expectedly reasonably well represented, the outstanding part of Portuguese migrants in Brazil is a clear demonstration of an exceptional link between both poles of the migration system.

When looking at the skills component of these populations, there are interesting differences (see figures $3 a$ and $3 b$ ). 
FIGURE 3a and 3b: Argentina and Brazil, skilled migrants population per country of origin

$3 a$

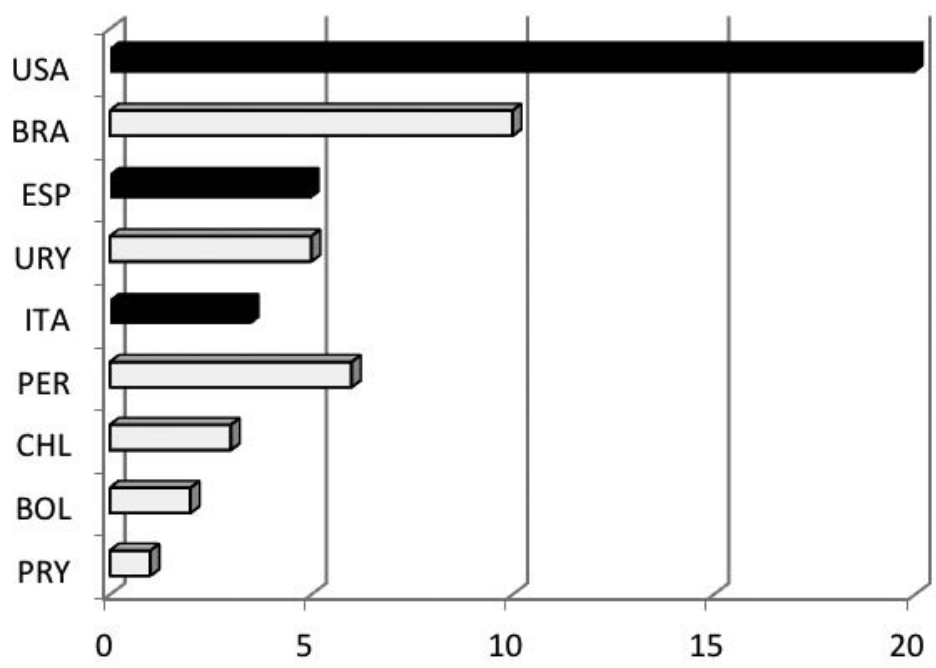

$3 b$

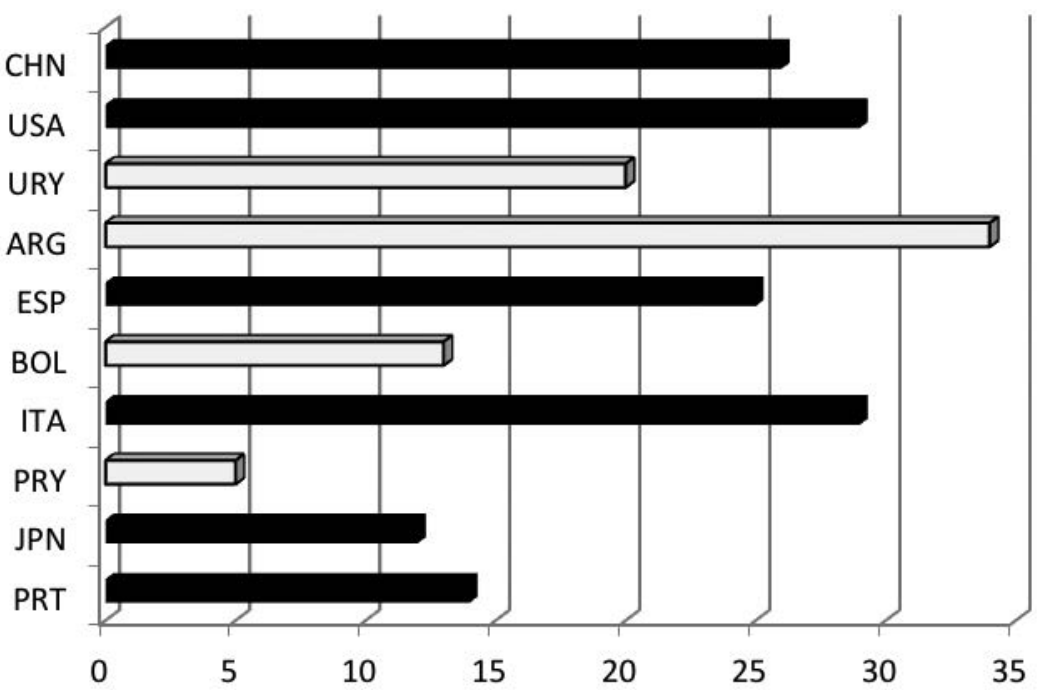

While migrants in Brazil are often highly skilled, it is much less the case for Argentina. Moreover, skilled migrants in Argentina principally come from highly developed countries, or emerging neighbors. Meanwhile, Brazil recei- 
ves skilled migrants from all sorts of countries. Its main source of migrants (Portugal and Japan) - highly developed - have rather a below average proportion of professionals among their emigrants to Brazil.

A clear picture of these mobility and diaspora exchanges between Europe and Latin America, especially the Southern Cone, is evidenced/shown by the intensive circulation going on and which recent years have significantly expanded, in both directions.

\section{New features of diasporas}

Today, the diaspora is also better known than before. Its dimensions and the diversity of its components are not without some surprises. The Latin American Observatory of diasporas (MICAL) has revealed that the previously visible parts of them - composed of the well-established so-called 'homeland associations' - represent only a small fraction of the highly skilled expatriate populations who maintain an effective professional link with their countries of origin (Meyer, 2015).

In short, it appears that the new form of the diaspora link is more often at individual level and direct, without going through an association or a formal collective entity. Despite being dispersed and fragmented, this new form of diaspora linkage is particularly productive because it signifies its presence by its results in terms of scientific and technical cooperation.

The fragmented character of the diaspora adapts well to the current configurations of the Internet, with a web 2.0 more favourable to individual interactions through blogs and microblogs or small, focused, reactive groups, such as those enabled by social networks with exchange of multimedia contents appropriate for facilitating the transnational co-existence of migrants with their diverse backgrounds (Blanco, 2015).

It would not be trivial to observe that computer scientists originating from India who shuttled between Bangalore and Silicon Valley - paragons of the innovative action of the diasporas - were among the first to tap massively into the blogosphere. This enabled them to exchange technical information, market signals, job opportunities and strategic guidance. Such remote inte- 
raction could eventually make it possible to overcome a limitation of the earliest diaspora networks: that of communication by mailing lists to begin with, and later on through the website of the association. While the first frequently choked, by excessive "noise", the real actions under way (Pellegrino, 2015), the second, too hierarchical (top-down from the website to the members or occasional visitors), lacked spontaneous initiatives to spread adequately (Caplan 2015).

\section{Diaspora incubators}

After several years of accumulated experience and many examples of networks, it was possible to identify the need for support systems for the creation, development and continuity of diaspora links. The idea of diaspora incubators condenses this function of support, which can reassure the home countries as well as many other actors (host countries, international agencies, NGOs, decentralized cooperation and institutions). This idea arises from the fact that if the associative structures of the diasporas of knowledge are entities that are often self-organized, their enhancement, as well as the emergence of other convergent actors and initiatives, would require consequential support. The communities concerned with the diaspora link must invest in it in order to capitalize on the cross-fertilizations that it generates.

As with the incubation of innovative enterprises, the role of linking heterogeneous actors is essential. A review of several hundred diaspora networks carried out in the middle of the first decade of the $21^{\text {st }}$ century made it possible to rationalize past experiences and to conceptualize the functions that were required for such incubators (Meyer \& Wattiaux, 2006; Meyer, 2011). This conceptualization is derived from the socio-economic actor-network theory which postulates four operations for successful innovation processes (Latour, 2005): problematization (convergence of meaning), mobilization (involvement of actors), enrolment (definition of the network) and interessment (consolidation of the link). These have been transposed into four operational functions, which were tested during the project entitled Creation of Knowledge Diasporas Incubators for Latin America (CIDESAL). 
The first consisted of finding the actors in the first place, the active members of the diaspora. New techniques of semi-automatic research were developed to identify and locate them. Here it was a question of overtaking the traditional methods of location and storage in under utilized databases, as revealed by previous experiences (CALDAS, SANSA, MIDA, etc.). Very often they affected only a fraction of the expatriate populations, those who had already been incorporated within the ambit of associational and diplomatic communities. The data collected by these traditional methods rapidly became outdated because of the relative volatility of the diaspora. In contrast, the instruments being currently used aim at updating the information in a more continuous and detailed fashion (Meyer, 2015; Turner et al., 2015).

The second function was concerned with the area of communications. It was necessary to get in touch with the expatriates and to convince them to join in reinsertion efforts. This exercise could not be undertaken in a massive and indiscriminate way but rather with the involvement of the actors at an early stage in the definition of the kinds of relationship that they intended to have with their partners. The tools used enabled this introduction which was both broad and specific. Platforms of digital exchange offered places where these first links could be established (Blanco 2015).

The third function is not wholly distinguishable from the preceding one. It was that of constructed interaction through individual and targeted partnerships. The detailed description of the skills of the diasporas, which is feasible today, makes it possible to match them to the specific requests or projects of the country and of its communities (Turner et al. 2015). To do so, it is necessary to organize these projects and requests. The constitution of strategic alliances in the home country to bring about the conformity of actions with the diaspora could also be achieved through digital platforms (Blanco 2015).

Finally, the last function is that of sustainable involvement of the actors in a productive or simply creative relationship. The engagement of expatriates with their home countries is not easy because they have, by their position abroad, already been captured by many other networks, in particular those from highly knowledge-intensive regions where they pursue their main activities. The challenge is thus of stabilizing their interests for engagement with their home countries by the countries showing commitments towards 
their diasporas. Symbolic or substantial incentives and compensations, national programmes ostensibly promoting their participation and facilitating their working remotely, offering equivalent and even better conditions or benefits compared with what are offered to individuals, are some of the options that constitute possibilities of sustainably engaging these much sought-after human resource communities. The host countries also have an important role to play in these efforts, in fuelling these dynamics from which they too can benefit, by partially allowing and encouraging their highly qualified immigrants to engage in collaborative projects, particularly by reinforcing their infrastructures of better communication and interaction (Caplan, 2015).

\section{Principles for policy}

People of the Diasporas are not subjects who can be governed as an extra-territorial extension of the national population. They form a civil society with several allegiances which, as a result, requires a special kind of governance founded on several unique principles.

The first is that of pluralism. Diasporas are heterogeneous and have multiple identity-based affiliations which cannot be reduced to a monolithic representation. Their contacts in the home countries should also be pluralistic for projects which are naturally diverse and varied. Experience has showed that any attempt at bureaucratic monopolization of the diaspora fails rapidly.

The second principle is that of horizontality. The world of knowledge is essentially that of peers, of equals, among whom relationships are not hierarchical. This form of relationship is favorable to reactive exchanges on complex themes. The collegiality between the diaspora and the home community deserves to be maintained and cultivated.

A third principle resides in the idea of flexibility. The geographic, as well as the professional and social, mobility of actors is important. Their roles should be able to evolve and the networks integrate these changes. We observed, for example, that the proponents of cooperation are very often circular migrants, that is, people who were part of the diaspora and then returned and could eventually leave again. 
There are two ways to apply these three principles and make them work: organization on the one hand and technology on the other. The constitution of a multipartite structure where actors and representatives of Diasporas and home communities can operate forms part of the first; installing platforms for remote multilateral interactive exchanges belongs to the second. The contribution of home and host countries in setting up tools that converge towards these two modes - that are often combined - is determinant. This articulation of organizational and technological options for the development of new entities - the contemporary Diasporas - is a techno-political approach. It is the combination of tools provided by programs in the digital humanities and a transnational governance founded on the participation and empowerment of non-state actors that can enable this development and shape these new world relationships.

\section{Bibliography}

BARRÉ, R., Hernandez, V., Meyer, J-B., \& Vinck, D. (Eds') (2003). Scientific Diasporas/ Diasporas scientifiques. Paris: IRD editions.

BECK, U. (2006). The Cosmopolitan Vision. Cambridge: Polity Press.

BLANCO, A. (2015). Diasporic knowledge networks incubators. In J-B. Meyer (Ed.), Diaspora: Towards the New Frontier. Paris/Montevideo: IRD/UDELAR editions.

CAPLAN, C. (2015). Diasporas' associations and networks. In J-B. Meyer (Ed.), Diaspora: Towards the New Frontier (pp. 185-212). Paris/Montevideo: IRD/UDELAR editions.

COHEN, R. (1997). Global Diasporas. London: UCL Press.

DIASPORA MATTERS (2012). Global Diaspora strategies toolkit: harnessing the power of global diasporas. Dublin.

DUFOIX, S. (2008). Diasporas. University of California Press.

DuforX, S., Guerassimoff, C., \& Tinguy, A. (Eds.) (2010). Loin des yeux, près du cour; les États et leurs expatriés. Paris: Fondation nationale des sciences politiques.

EPFL (2010). An Action-oriented Toolkit To Assess Good Practices of Skilled Migrants and Scientific Diasporas. Lausanne: École Polytechnique Fédérale de Lausanne. 
FAIST, T., Fauser, M., \& Kivisto, P. (Eds.) (2011). The Migration-Development Nexus, a Transnational Perspective. Basingstoke: Palgrave/Macmillan.

GAILlARD, J., \& Gaillard, A-M. (2003). Can the Scientific Diaspora Save African Science? Retrieved from: http://www.scidev.net/global/migration/opinion/can-the-scientific-diaspora-save-african-science.html (Accessed: January 15 2015)

GAMLEN, A. (2014). Diaspora Institutions and Diaspora Governance. International Migrations Review, 48(s1), S180-217.

GLICK SCHILLER, N. (2009). A global perspective on transnational migration: theorizing migration without methodological nationalism. COMPAS Working Paper No. 09-67). Retrieved from: https://www.compas.ox.ac.uk/fileadmin/files/Publications/ working_papers/WP_2009/WP0967\%20Glick\%20Schiller.pdf (Accessed: January 15 2015).

IOM/MPI (2012). Developing a Road Map for Engaging Diasporas in Development, a Handbook for Policy Makers and Practitioners in Home and Host Countries. Geneva, Washington DC: International Organisation for Migrations and Migration Policy Institute.

KHADRIA, B. (2001). Shifting Paradigms of Globalization: the Twenty-first Century Transition Towards Generics in Skilled Migration from India. International Migration, 29(5), 45-71.

KUZNETSOV, Y. (Ed.) (2006). Diaspora Networks and the International Migration of Skills. Washington, DC: World Bank Institute.

LATOUR, B. (2005). Reassembling the social: an introduction to actor-network theory. Oxford and New York: Oxford University Press.

LEMA, F. (2015). Highly qualified Uruguayan migration: connection experiences. In J-B. Meyer (Ed.), Diaspora: Towards the New Frontier. Paris/Montevideo: IRD/UDELAR editions.

LOWELl, L., \& Gerova, S. (2004). Diasporas and Economic Development: State of Knowledge. Georgetown: Institute for the Study of International Migration. Retrieved from: http://siteresources.worldbank.org/INTPROSPECTS/Resources/334934 -1322593305595/8287139-1327608098427/LowellDiaspora.pdf (Accessed: 15 January 2015)

LUCHILO, L. (2015). Argentine return and linkage policies: shifts and continuities. In J-B. Meyer (Ed.), Diaspora: Towards the New Frontier. Paris/Montevideo: IRD/UDELAR editions. 
MAE/OECD (2012). Harnessing the skills of migrants and diasporas to foster development: policy options. Paris: French Ministry of Foreign Affairs.

MEYER, J-B. (2011). A Sociology of Diaspora Knowledge Networks. In T. Faist, M. Fauser, \& P. Kivist (Eds.), The Migration-Development Nexus, a Transnational Perspective. (pp. 159-182), Basingstoke: Palgrave/Macmillan.

MEYER, J-B. (Ed.) (2015). Diaspora: Towards the New Frontier. Paris/Montevideo: IRD/ UDELAR editions.

MEYER, J-B. (2015). The web of science: a new window to watch mobility. In J-B. Meyer (Ed.), Diaspora: Towards the New Frontier. Paris/Montevideo: IRD/UDELAR editions.

MEYER, J-B., Bernal, D., Charum, J., Gaillard, J., Granés, J., Leon, J., Montenegro, A., Morales, A., Murcia, C., \& Narvaez Berthelemot, N. (1997). Turning Brain Drain into Brain Gain: The Colombian Experience of the Diaspora Option. Science, Technology and Society,2(2), 285-315.

MEYER J-B., \& Charum, J. (1995). La fuite des cerveaux est-elle épuisée? Paradigme perdu et nouvelles perspectives. Cahiers des Sciences Humaines, 31(4), 1003-1017.

MEYER, J-B., \& Wattiaux, J-P. (2006). Diaspora Knowledge Networks: Vanishing Doubts and Increasing Evidence. International Journal on Multicultural Societies, 8(1), 4-24.

PELlEGRINO, V. (2015). A story of many stories, the Caldas network. In J-B. Meyer (Ed.), Diaspora: Towards the New Frontier. Paris/Montevideo: IRD/UDELAR editions. SHEFFER, G. (1986). A New Field of Study: Modern Diasporas in International Politics. In G. Sheffer, Modern Diasporas in International Politics. London: Croom Helm. TURNER, F. J. (1893). The Significance of the Frontier in American History. New York: Henry Holt and Company.

TURNER, W., Garcia Flores, J., \& Saint-Léger, M. (2015). Computer supporting diaspora knowledge networks: a case study in managing distributed collective practices. In J-B. Meyer (Ed.), Diaspora: Towards the New Frontier. Paris/Montevideo: IRD/ UDELAR editions.

UNCTAD (2012). Harnessing Remittances and Diaspora Knowledge to Build Productive Capacities. In UNCTAD, Least developed countries report. Geneva: United Nations Conference on Trade and Development.

WHITE, R. (1991). "It's Your Misfortune and None of My Own": A New History of the American West. Norman: University of Oklahoma Press. 


\section{BRAIN DRAIN-BRAIN GAIN : \\ AN INTERNATIONAL PERSPECTIVE}

\section{Introduction}

Recent data and indicators will be presented to help place discussions of brain drain-brain gain in current context, in Portugal and on the international scene. Cost and benefit analyses of brain drain-brain gain remain a challenge as does the need to move the development of measures and understanding of human resources in S\&T higher on the priority list of policy makers and data collection agencies. Examples of efforts, developments and obstacles will be given.

\section{The setting}

Context is everything, so it is useful to look at some science and techno$\operatorname{logy}(\mathrm{S} \& \mathrm{~T})$ indicators to remind us of the situation here in Portugal, as well as that of its neighbours and competitors.

Overall, Portugal's R\&D expenditures have been declining since 2009 (OECD, 2014). The OECD data suggests that this decline could put Portugal's capacity to innovate at risk. For example, if we look at $R \& D$ expenditures by

1 Wendy Hansen has been a Senior Policy Analyst, Industry and Science Policy at Industry Canada. She joined MERIT (Maastricht University) as a Senior Research Associate in May 1997 to continue her research on knowledge workers. As a UNU-MERIT research affiliate, her research focuses on knowledge workers, in particular scientists and engineers, and falls in a range of S\&T policy issues. 
sector, Portugal shows the higher education sector with a substantial 39\% share compared with only $24 \%$ for the EU-28 overall.

FIGURE 1: R\&D expenditure by sector, Portugal and the EU-28, 2012
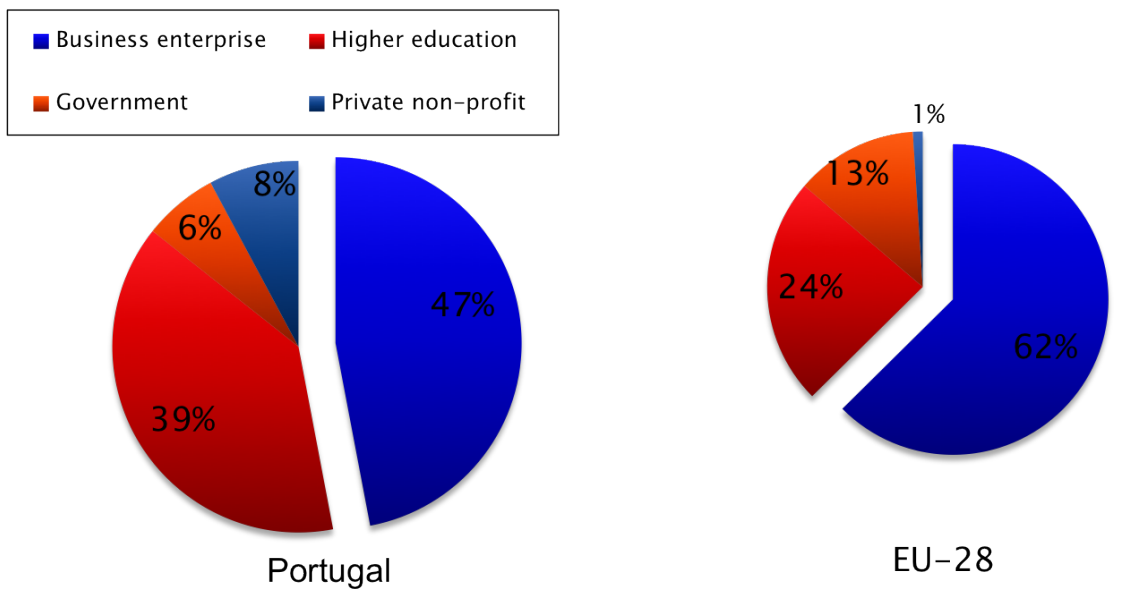

$\mathrm{EU}-28$

Source: Based on Figure 1.24, OECD Economy Surveys: Portugal 2014, OECD, 2014.

This is not good news given the fact that a large share of $R \& D$ is taking place in universities which reportedly have weak linkages with industry. In Portugal, for example, the number of new high-tech firms coming out of academia is low. At the same time, many of the PhDs choose to stay in the university environment rather than entering the private sector. If the universities are losing top talent to overseas destinations, then the picture may become even bleaker for the business enterprise sector.

In Portugal, business expenditures on R\&D, the BERD, are only $0.7 \%$ of GDP compared to the EU-28 with 1.24\%. Only Italy and Spain (each with $0.69 \%$ ) generate lower BERD/GDP than Portugal, among the countries examined. 
FIGURE 2: Business expenditures on R\&D as a percent of GDP, selected countries, 2012

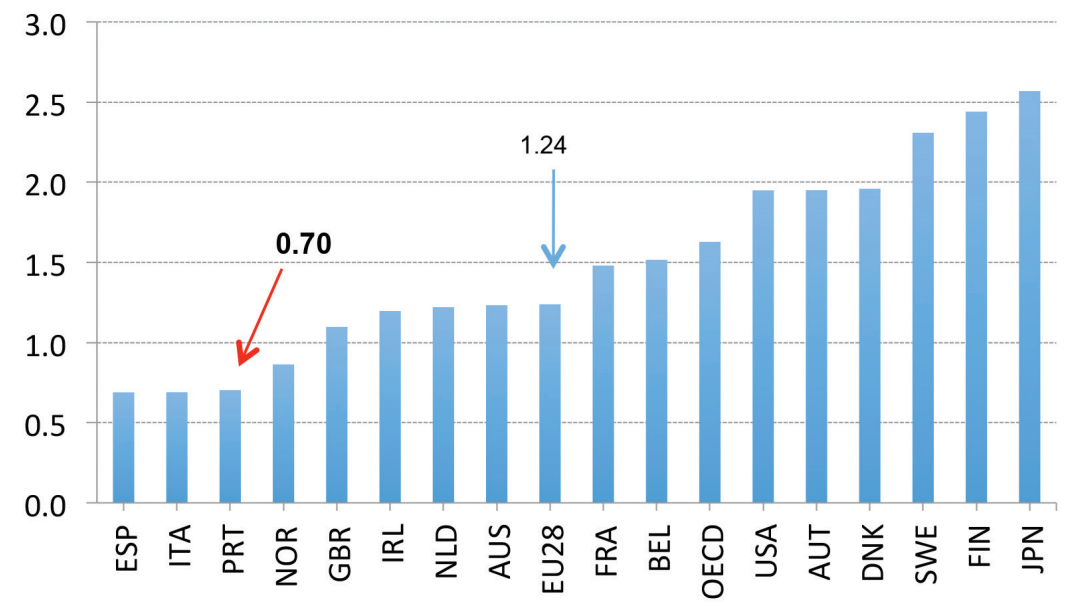

Source: Based on OECD Economy Surveys: Portugal, 2014, Figure 1.24.

Geo-political, social and cultural environments can influence flows of talented human resources. So, one can wonder: how are women doing in universities in Portugal? For example, to what extent are women represented in the teaching ranks in Portugal?

FIGURE 3: Women as a percent of teachers (tertiary level), selected countries, 2012

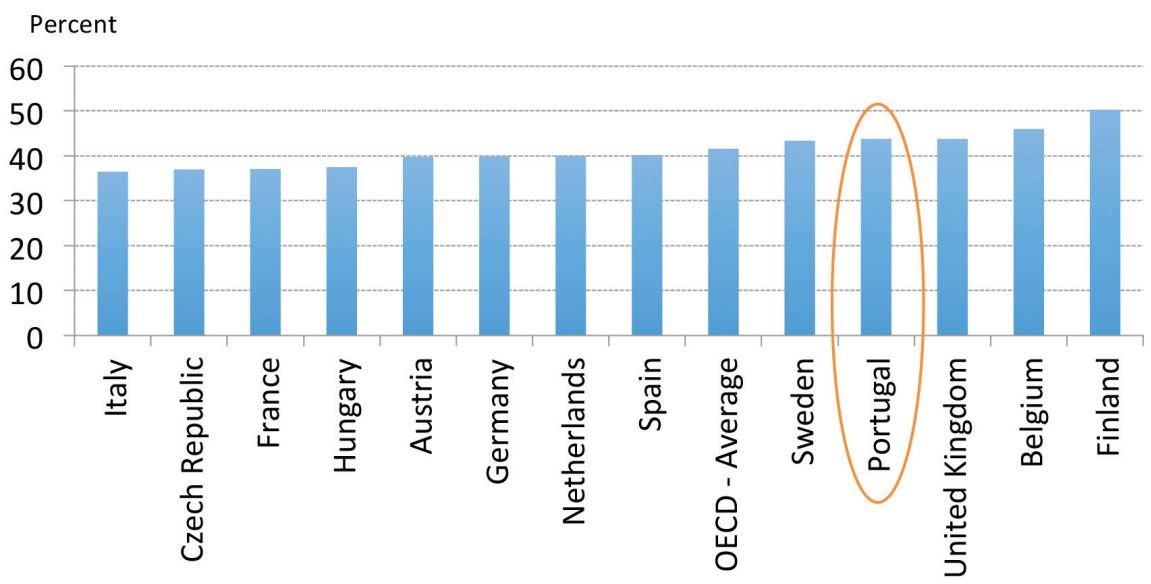

Source: Based on OECD data from https://data.oecd.org/eduresource/women-teachers.htm \#indicator-chart. 
Women have substantial representation in teaching at the postsecondary level. In Portugal in 2012, women accounted for $44 \%$ of teachers at the postsecondary (tertiary) level, a percentage higher than that of their southern neighbours like Spain (40\%) and Italy (36\%). In fact, the representation of women among teaching ranks in Portugal at the tertiary level is higher than the OECD average (42\%), and indeed higher than in countries like France (37\%), Germany (40\%) and the Netherlands (40\%) where one might expect to see strong representation of women in academic ranks.

Before going on to information and discussion of international mobility and related issues, it is time to take a look at the master purveyor of foreign talent - the United States.

The U.S. is a world leader when it comes to tapping foreign sources for teachers and filling occupation demand for skills in key sectors. One simply cannot discuss the issue of brain drain and brain gain without being aware of this 'elephant in the room'. One might be tempted to observe that the U.S. hunger for talent has little direct impact on countries like Portugal, Italy and Spain. But of course, pressure on the supply of highly skilled human resources in S\&T in one region of the EU can result in a ripple effect in other regions - someone has to make up for the loss of skilled persons if U.K. or German sources are tapped.

The H-1B visa is used for persons entering the U.S. to work in a 'specialty' occupation on a temporary basis. This is the visa used, for example, for a scientist or engineer or technician or university professor to take up temporary employment in the U.S. There is a set job, salary, length of stay and location of employment. 
FIGURE 4: Distribution of $\mathrm{H}-1 \mathrm{~B}$ petitions approved, selected occupations, U.S., 2009 and 2014

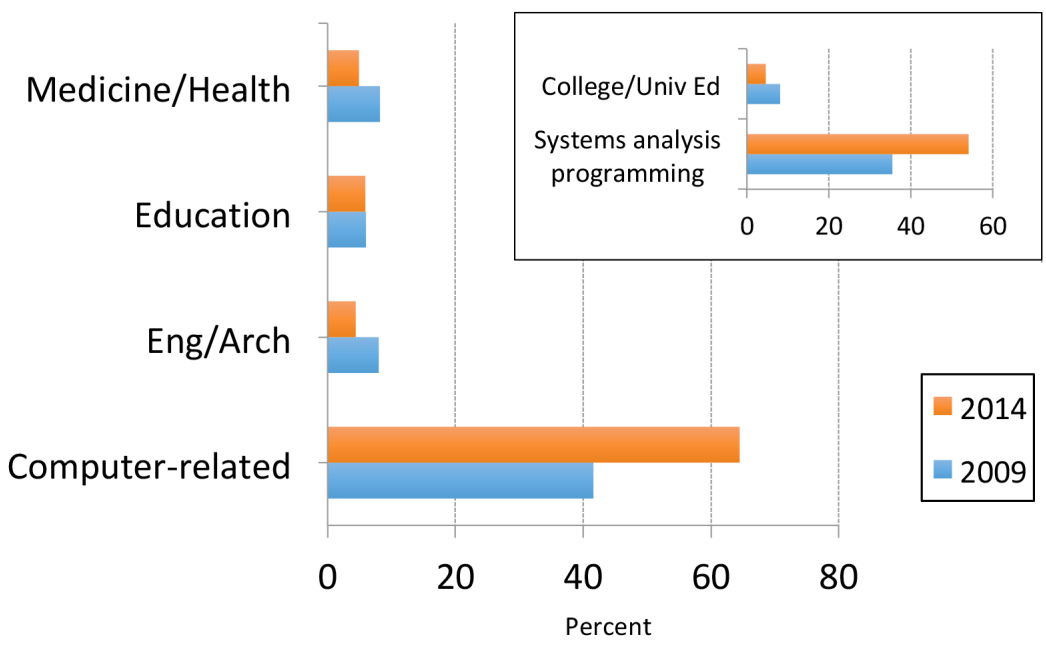

Source: Based on data from Characteristics of H-1B Specialty Occupation Workers, U.S. Citizenship and Immigration Services, February 2015, p. 13.

Note: Computer-related includes systems analysis, programming and other computer-related occupations; Eng/Arch includes engineering, architecture and surveying.

The U.S. continues to meet occupation demands with foreign-born. In $2009,42 \%$ of the $214,274 \mathrm{H}-1 \mathrm{~B}$ petitions approved in the U.S. were in computer-related occupations; five years later, in 2014, this occupation's share had expanded to account for $63 \%$ of the 315,857 petitions approved. If we dig deeper we see that in 2014 more than half of the H-1B petitions approved were in systems analysis programming compared with just over one third in 2009.

Today the U.S. economy is recovering and demand for highly talented scientists and engineers is likely to expand once again. In fact, the projection for occupations in computer systems analysts is a $25 \%$ increase from 2012 to 2022.

Before leaving the U.S. setting, it is worthwhile to look at a trend that set in at the beginning of this decade when it comes to level of degree of the foreign-born talent the U.S. is bringing in under the $\mathrm{H}-1 \mathrm{~B}$ visas. The share with a doctorate entering the U.S. to work on the $\mathrm{H}-1 \mathrm{~B}$ visa is shrinking as the Bachelor- and Master's qualified cohorts undergo expansion. This is perhaps 
not unexpected when one considers the expansion of computer and computer-related occupations and computer systems analyst occupations where the working degree level is more typically the Bachelor or Master's level.

FIGURE 5: Degree level of H-1B petitions approved, U.S., 2007 to 2014.

Percent

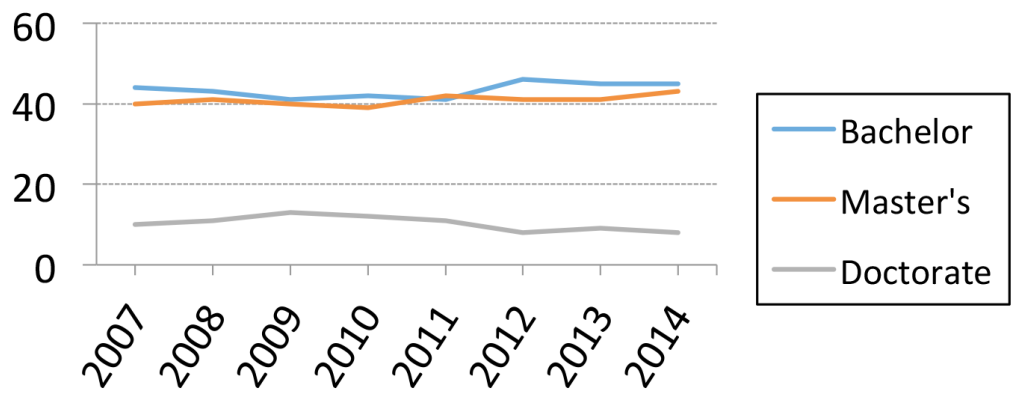

Source: Based on data from Characteristics of H-1B Specialty Occupation Workers, February 2015, U.S. Citizenship and Immigration Services.

So why is it that some scientists and researchers have their travel cases at the ready to go to the U.S. or other countries to work while others choose to stay in their native countries? Why is it that some absences are temporary while others become permanent? What factors influence international mobility - are scientists and researchers pushed into leaving - cessation of funding, political shifts and change in domestic priorities? Or are they pulled away with the lure of funding, access to top quality labs and facilities or big salaries and benefits?

In 2008/09, information was collected on choices of doctoral candidates across Europe - some 8,900 doctoral candidates answered the survey of the Eurodoc project. Respondents were enrolled in doctoral programmes and/or working on their degree as academic and research assistants. The intent was to develop a comparative database for institutional staff and policy and decision makers for a wide audience from institutional planners to funding agencies. Of particular significance is the gender variable that provides for a look at different behaviours and intent among Portuguese doctoral candidates. 
When asked about time abroad for study prior to their doctorate, about one third, men and women, in Portugal said they had spent time abroad for study purposes. These were some of the lowest figures reported among the countries examined.

FIGURE 6: Percent of doctorate candidates who spent time abroad during course of study prior to doctorate, selected countries

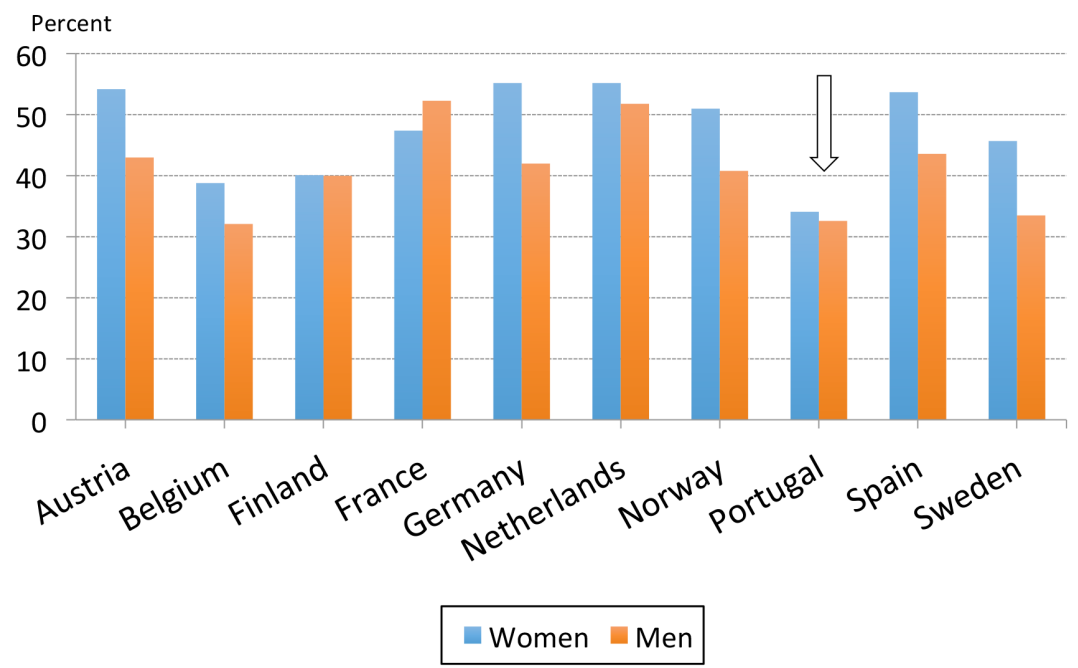

Source: Based on data from Table II-206, Eurodoc Survey I, 2011.

Questions were posed to probe reasons for going abroad. For example, to what extent were the doctoral candidates interested in going abroad for teaching activities? For Portugal, some one third or so of women and men alike reported they were not at all interested in going abroad to teach. However, it is at the other end of the scale, the to a very high extent variable, where Portuguese men and women are in the middle or higher range of a potential signal for brain drain. For example, $14 \%$ of the women and $13 \%$ of the men doctorates said they were interested in going abroad to teach to a very high extent...that's more than one in ten doctorate candidates, women and men, who are very interested in teaching abroad. 
FIGURE 7: Percent of doctorate candidates who are interested to a bigh extent in going abroad to teach, selected countries.

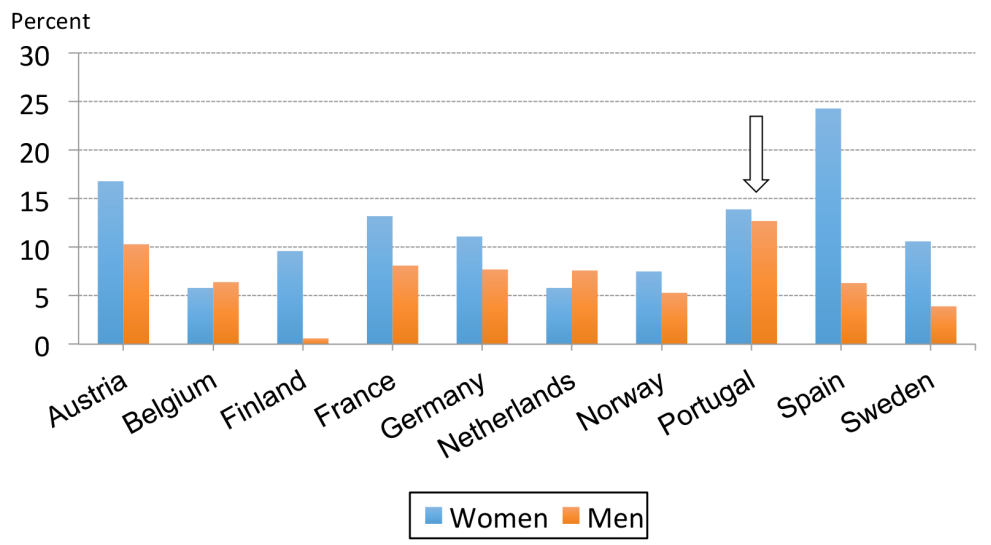

Source: Based on data from Table II-212, Eurodoc Survey I, 2011.

Doctorate graduates are mobile. When questioned about plans to move abroad, results for Portugal reveal that one quarter of the women and almost one third of the men plan to move abroad or stay abroad for work. Results like this may ring alarm bells. Almost half of the women and men in Spain reported plans to leave and work abroad.

FIGURE 8: Percent of doctorate candidates who intend to move abroad or stay abroad for work, selected countries.

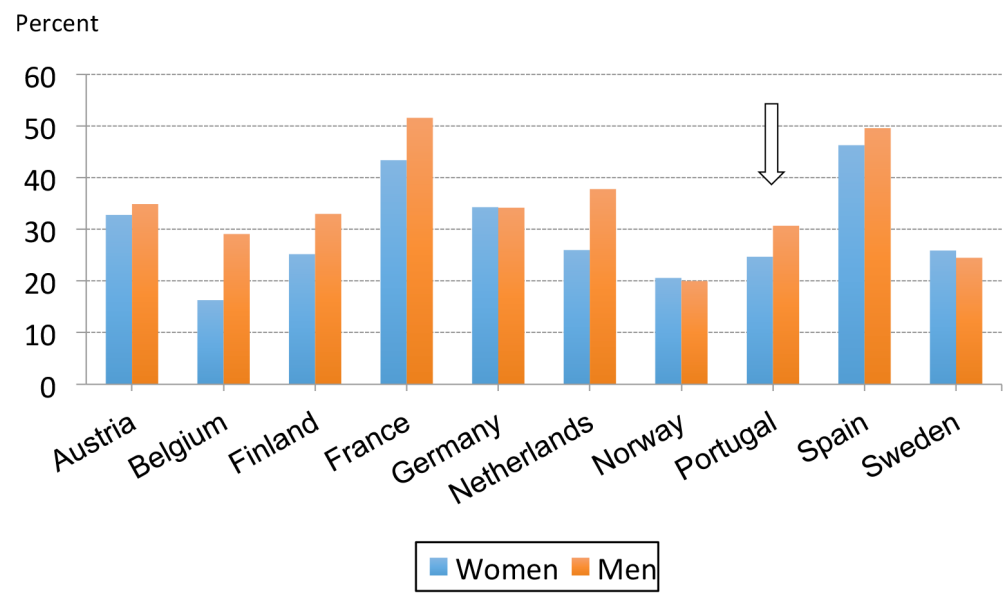

Source: Based on data from Table II-226, Eurodoc Survey I, 2011. 
In the spring/summer of 2011, the Italian government and the U.S. National Bureau of Economic Research funded GlobSci - a web-based survey of more than 17,000 authors in four fields (biology, chemistry, earth and environmental sciences, and materials science) in sixteen countries including countries of Europe, the Americas and Asia (Franzoni, Scellato e Stephan, 2012). Respecting limits of the survey, findings suggest that foreign-born scientists perform at a higher level than scientists who have never experienced mobility, and returnees perform at a higher level than home-grown nationals who have not been abroad).

In 2012, Nature published results of its survey that probed for incentives and barriers to international mobility. Some 2,300 readers were surveyed almost one third were women. Among those surveyed, one in four was a postdoc and one in five a research/staff scientist; at least one in ten of the respondents were either a full professor or an associate professor; and, using years since highest degree was obtained as a measure of 'experience', some two in five had had their highest degree for at least 11 years, and one in four for 11 years or more.

No one will disagree that salary is an important consideration when choosing a position but it does not rank as high a 'pull' factor compared to the ability to gain overseas experience, the reputation of the lab or institute or the quality of training offered in a foreign nation.

'Showing the money' doesn't guarantee full advantage when it comes to attracting top talent. The top reason was to take up a specific job or position (46\%). Thirty-five percent cited gaining overseas experience as the 'pull' factor. The reputation of the lab or institute was ranked third (28\%) when it came to incentives for the move, followed by the opportunity to experience a new culture (26\%), and prospects for better training (25\%). Salary, in fact, ranked $6^{\text {th }}(23 \%)$ along with better job market. 
FIGURE 9: Incentives for international mobility

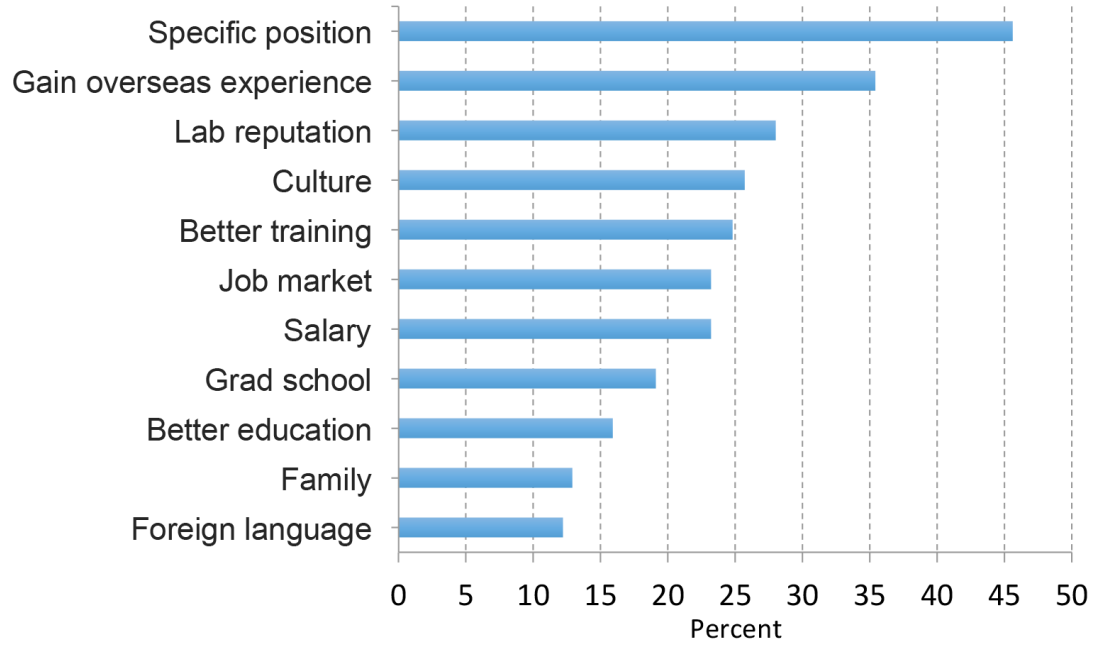

Source: Based on data from 'Science on the Move', "Nature, 490(7420)", 2012.

When asked about the importance of the drivers of relocation, the message is in harmony. For example, when it comes to increased availability of research funding, $45 \%$ reported it was very important, and another $39 \%$ that it was quite important.

FIGURE 10: Increased availability of research funding

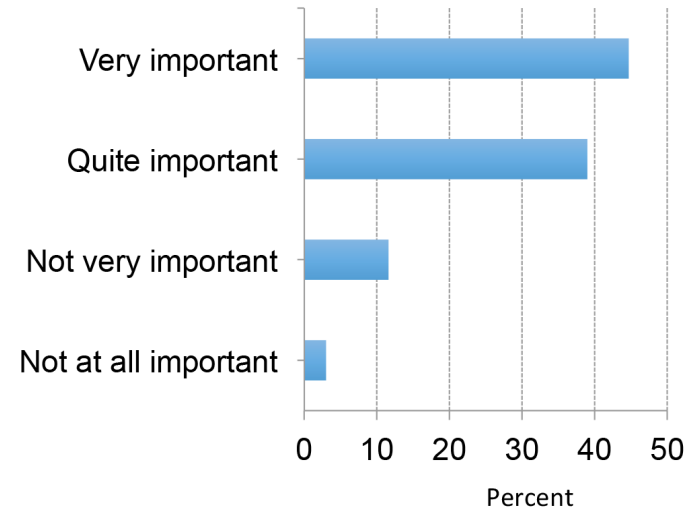

Source: Based on data from 'Science on the Move', "Nature, 490(7420)", 2012. 
When it comes to salary, only $31 \%$ said it was very important compared with $46 \%$ who said it was quite important.

FIGURE 11: Increased salary.

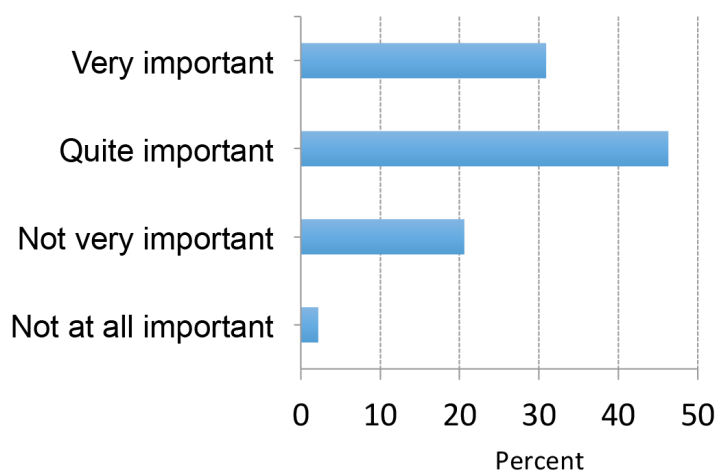

Source: Based on data from 'Science on the Move', Nature Vol 490, 18 October 2012.

What about the costs and benefits? What can we suppose about the countries that lose their talented people and the countries that take advantage of the foreign-trained talent?

Potential costs and benefits of international mobility of human resources in S\&T.
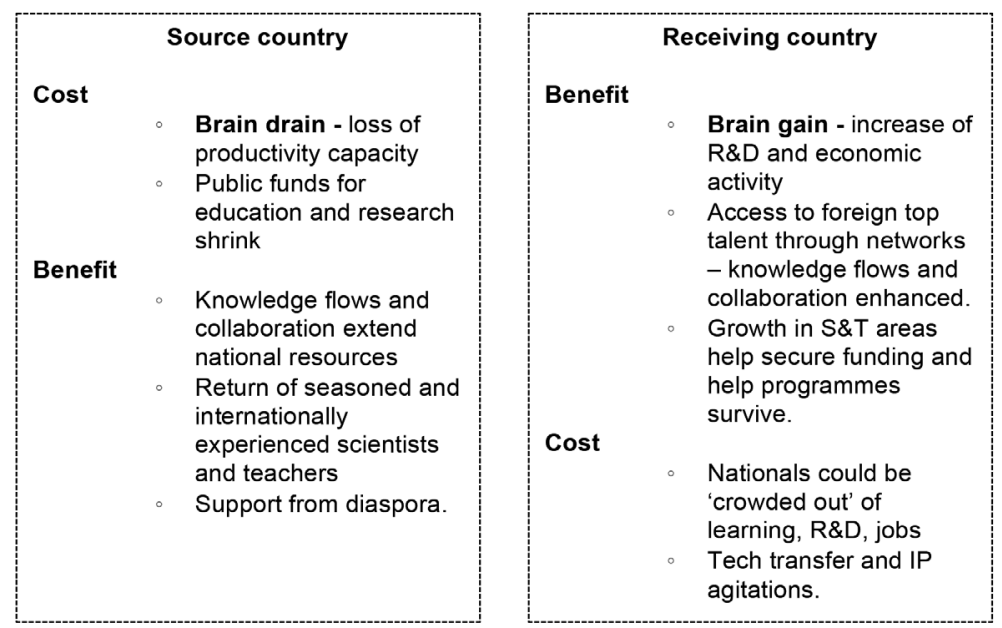

Source: Based on notes from "Research and Policy Issues in High-Skilled International Migration", M. C. Regets, 2001, IZA Discussion Papers No. 366., and other sources. 
What about the bigger picture - international mobility in a world of globalised scientific, economic, social and cultural activity? Cost/benefit analyses for sending and receiving countries include:

- International mobility of human resources encourages international flow of knowledge.

- Scientists have more options to 'match' their skills and interests with occupation and sector of interest.

- Greater funding options for researchers may become available.

- Employers are in a better position to recruit top talent for their needs - a global marketplace for skilled persons.

- International clusters emerge - research is shared and markets are opened.

- Reduction of waste of talented scientists and engineers - can lower rates of underemployment and unemployment.

\section{Enduring Challenges}

The measurement of human resources in science and technology remains a daunting endeavour for a number of reasons. Despite the rhetoric of the importance of S\&T knowledge workers, the critical role scientists and researchers play in today's economic, health and social well-being, the subject area remains a 'poor cousin' compared with other members of the innovation data and indicator family such as R\&D investment, trade and performance. In 2016, 25 years have passed since the discussions initiated in an OECD meeting in Rome to produce a manual dedicated to data collection and measurement of human resources in science and technology. The OECD revises its definition and measurement manuals for scientific and technological activities and innovation on a regular and timely basis, yet the one manual dedicated to measuring human resources remains in draft form for for some twenty years now. But organizations like the OECD cannot be held responsible - they respond to priorities set by policy and decision makers. Perhaps we as social scientists have to make more efforts to improve funding and support for data develop- 
ment on human resources in S\&T. And perhaps we as social scientists need to generate more evidence-based narratives to secure this funding and support ${ }^{2}$.

Lack of timely and consistent data time series - resources for data collection and indicator development are linked to national priorities and this introduces disparities in availability in terms of scope, coverage, timeliness and access. Surveys come and go based on political will and associated funding (Hansen, 2015).

Policies of remit organizations can limit access to aggregate data. Access limitations multiply when seeking discipline-based data or more specialized data. Limitations of confidentiality block access to micro-data. Add to this the complication of different rules and regulations across different countries and one can start to appreciate the magnitude of the task at hand.

Data development and acquisition costs - there is a lot of information on the Internet and sometimes the availability of data and reports can be overwhelming. However, when it comes to micro-data or more targeted data needs, cost can quickly become a barrier.

There is a lot of inaccessible data - if it could be made available to researchers, more insights might be secured (Auriol et al., 2012).

There needs to be a move away from narrow focus on doctorates and consideration of other degree levels - doctorate graduates account for a small proportion of the overall postsecondary population and S\&T workforce but their skills and knowledge are highly regarded because of their contribution, technology and innovation. The role and contribution of PhD-trained human resources is irrefutable, however, science and research is a team sport and more resources need to be directed at information on other members of the team - those persons with a Bachelor or Master's degree.

We have lots of little studies on particular groups of scientists, but no world bank of data - there is no organization of the volumes of information gathered and analysed through reports generated at great cost to the tax payer. I have mentioned only several of virtually hundreds and perhaps thou-

2 Reference(s) in this section, refer to W. Pearson, L. M. Frehill, C. L. McNeely, (Eds.) (2015). Advancing Women in Science - An International Perspective. (Chap. 4). New York: Springer. 
sands (I suspect) of different studies and approaches under the umbrella of human resources in science and technology.

Valuable work like that of this BRADAMO project relies upon conferences like this, the press and the communication strategy of the authors and the networking of social scientists to share the findings and keep discussions moving ahead on this critical subject. Science is global and science is about networking. If we consider the resources and efforts expended around the world, it behooves us as social scientists to think on how all of this information might be brought together at a global level.

\section{Moving Forward}

A monitoring system capable of monitoring flows across a range of geo-political, social, cultural and economic landscapes including:

- Flows within the EU - flows in and out of the EU.

- Types of flows.

- Factors of flows.

Build a knowledge base for timely cost/benefit analyses of international mobility of scientists and engineers that:

- Adheres to international definitions and standards for data collection and indicator development.

- Enhances comparability.

- Increases access to data and indicators.

Develop methodology for measurement and analysis of international mobility:

- Indicators for flow of human resources in S\&T.

- Indicators to explore cost/benefit impacts. 
Joint initiatives with international organizations like the OECD, Eurostat, UNESCO to:

- Enhance access, timeliness and comparability.

- Build on work already done.

- Avoid duplicative efforts and wasting of resources.

- Pool resources for common objectives.

\section{Bibliography}

EUROPEAN COUNCIL OF DOCTORAL CANDIDATES AND JUNIOR RESEARCHERS (2011). Eurodoc Survey I: The First Eurodoc Survey on Doctoral Candidates in Twelve European Countries - Descriptive Report. Brussels: Eurodoc.

FrANZONI, C., Scellato, G., \& Stephan, P. (2012). The Mover's Advantage: Scientific Performance of Mobile Academics. (NBER Working Paper No. 18577). Retrieved from: (https://www.nber.org/papers/w18577)

HANSEN, W. (2015). Building Knowledge to Narrow the Gender Divide: Data and Indicators for Women in STEM and International Benchmarking. In W. Pearson, L. M. Frehill, \& C. L. McNeely (Eds.), Advancing Women in Science - An International Perspective. (pp. 93-127). New York: Springer International Publishing.

U.S. CitizENShIP AND IMMIGRATION SERVICES. Workers. Fiscal Year 2014 Annual Report to Congress. Washington, DC: U.S. Department of Homeland Security. OECD (2014). OECD Economic Surveys: Portugal 2014. Paris: OECD Publishing.

OECD (2015). Women teachers (indicator). available at: https://data.oecd.org/eduresource/women-teachers.htm\#indicator-chart.

REGETS, M. C. (2001). Research and Policy Issues in High-Skilled International Migration: A Perspective with Data from the United States. (IZA Discussion Paper No 366). Arlington: National Science Foundation. Bonn: IZA.

VAN NOORDEN, R. (2012). Global mobility: Science on the move. Nature 490(7420). Nature Publishing Group. 
(Página deixada propositadamente em branco) 
VELHAS E NOVAS EMIGRAÇÕES 
(Página deixada propositadamente em branco) 


\section{A NOVA EMIGRAÇÃO E A RELAÇÃO \\ COMA SOCIEDADE PORTUGUESA: PERFIS \\ E ESTRATÉGIAS DOS EMIGRANTES \\ MAIS E MENOS QUALIFICADOS}

\section{Introdução}

O texto que agora se apresenta pretende analisar algumas caraterísticas, práticas e aspirações dos emigrantes mais qualificados portugueses, em comparação com os seus compatriotas menos qualificados. Tal como sucede em vários estudos sobre este tema, a fronteira entre os mais e menos qualificados é a posse de um diploma de nível superior. É certo que as "qualificações" transcendem, em larga medida, as competências da educação formal e, em particular, a conclusão de um curso de ensino superior. Desde há muito, porém, que, devido a necessidades de operacionalização ou a limitações de acesso aos dados, se opta por aquela perspetiva para distinguir os emigrantes mais e menos qualificados - ou, mais comummente, os "altamente qualificados" e os que não o são. Esta será também a perspetiva adotada neste estudo.

Os dados empíricos que serão apresentados foram recolhidos no âmbito do projeto "Regresso ao Futuro: A nova emigração e a sua relação com a sociedade portuguesa" (REMIGR), que reuniu investigadores da Universidade

\footnotetext{
${ }^{1}$ Autores: Pedro Candeias (SOCIUS/CSG e IGOT - Universidade de Lisboa); João Peixoto (SOCIUS/CSG, ISEG, Universidade de Lisboa); Joana Azevedo (CIES, ISCTE-IUL); Isabel Tiago de Oliveira (CIES, ISCTE-IUL); Bárbara Ferreira (CEG/IGOT e CIES, ISCTE-IUL); Alexandra Ferro (CIES, ISCTE-IUL); José Carlos Marques (CICS.NOVA e CES, Universidade de Coimbra); Pedro Góis (CES, Universidade de Coimbra); Jorge Macaísta Malheiros (CEG/IGOT, Universidade de Lisboa); Paulo Miguel Madeira (CEG/IGOT, Universidade de Lisboa); Aline Schiltz (CEG/IGOT, Universidade de Lisboa); Eugénio Santana (CEG/IGOT, Universidade de Lisboa).
} 
de Lisboa, Universidade de Coimbra e ISCTE-Instituto Universitário de Lisboa. O projeto, financiado pela Fundação para a Ciência e a Tecnologia (PTDC/ ATP-DEM/5152/2012), decorreu entre 2013 e 2015. Uma vez que este texto foi produzido no período de divulgação dos resultados definitivos do projeto, ele adota uma abordagem sobretudo descritiva. $\mathrm{O}$ aprofundamento da informação apresentada será efetuado noutros contextos.

\section{Enquadramento}

Na última década tem-se vindo a observar um crescente interesse pelos estudos da emigração portuguesa qualificada ou altamente qualificada. Alguns trabalhos mais abrangentes analisam o fenómeno à luz da teoria do brain drain (Delicado \& Alves, 2013; Emília \& Ferreira, 2013; Gomes et al., 2015). Outros analisaram o discurso mediático sobre o tema (Cogo \& Badet, 2013; Emília \& Ferreira, 2013). Também foi estudado o impacto que o fenómeno tem em Portugal (Faria, 2012). Uma obra recente dedicou-se a este tipo de emigração para um país em particular - França (Lopes, 2014) e com um escopo mais abrangente foi analisada esta emigração com destino à Europa (Azevedo, 2014). Contudo, mais frequentes têm sido os estudos dedicados a um grupo profissional específico, como os profissionais de saúde (Pereira, Pinto \& Pires, 2015; Ribeiro et al., 2013), professores e leitores de português (Pereira, 2007) e, especialmente, académicos e alunos de doutoramento (Araújo, 2007; Delicado, 2010, 2011; Delicado \& Alves, 2013; Fontes, 2007; Fontes \& Araújo, 2013).

O ponto em comum dos trabalhos supracitados é todos eles tomarem como unidade de análise o subgrupo dos emigrantes detentores de um grau académico de nível superior, habitualmente designados por emigrantes qualificados. Não tem sido examinado em detalhe, pelo menos de forma explícita, o universo dos emigrantes detentores de menores qualificações, incluindo aqueles cujo domínio de qualificações profissionais (não académicas), médias ou elevadas, é considerável. O facto de a emigração não ter sido objeto de estudo sistemático em Portugal nos últimos anos contribui para alguma invisibilização deste fenómeno (Candeias, Ferreira, \& Peixoto, 2014; Malheiros, 2010; Marques, 2010; Peixoto, 2012). Em paralelo, o aumento do mediatismo 
da emigração mais qualificada, em particular dos jovens licenciados no contexto da crise atual, explicará também parcialmente a maior 'saliência' deste objeto de estudo nos últimos anos.

Com este texto, pretende-se deslocar a análise com enfoque nos emigrantes mais qualificados para uma análise comparativa, em que a posição deste grupo é contrastada com a dos emigrantes menos qualificados - isto é, dos que não apresentam uma escolarização do nível terciário. Nos próximos pontos, depois de uma secção metodológica, serão tidos em conta indicadores do perfil sociodemográfico destes sujeitos, da sua trajetória migratória, da sua integração nos países de destino e das relações que mantêm ou tencionam manter com Portugal no futuro.

\section{Metodologia}

O material empírico de suporte a este texto provém do projeto "Regresso ao Futuro: A nova emigração e a sua relação com a sociedade portuguesa" (REMIGR). O objetivo principal deste projeto foi traçar o perfil da emigração portuguesa mais recente - indivíduos nascidos em Portugal ou com nacionalidade portuguesa que saíram do país a partir do ano 2000 (inclusive) - e as suas relações com o país de origem. Uma das particularidades do projeto foi o de procurar abranger tanto emigrantes mais qualificados como menos qualificados. Este procedimento permite estabelecer um grupo de referência, não analisando os subgrupos dos mais ou menos qualificados por si só.

Neste texto são apresentados os resultados de um inquérito aplicado segundo uma abordagem mista, ou de mixed-modes surveys (cf. Dillman, Smyth, \& Christian, 2014, cap. 11), que combinou inquéritos online com inquéritos em formato de papel-e-caneta. Os primeiros recolheram respostas oriundas de mais de 100 países. Os inquéritos por questionário na versão tradicional foram aplicados em seis países: França, Luxemburgo, Reino Unido, Brasil, Angola e Moçambique. O processo de inquirição decorreu entre 6 de maio de 2014 e 25 de maio de 2015. Foram validados, após depuração, 6.086 questionários. Destes, $73 \%$ foram recolhidos via internet, através do website criado para o efeito (www.remigr.pt). 
Para o presente texto, consideram-se como emigrantes "mais qualificados" aqueles com grau académico de nível superior e como emigrantes "menos qualificados" os que se encontram abaixo deste patamar. Deste modo, o exercício será comparar os inquiridos com bacharelato, licenciatura, mestrado ou doutoramento $(n=4.263)$, tendo como categoria de referência os inquiridos com escolaridade de nível secundário ou inferior $(n=1.805)$. Uma versão desagregada destas qualificações encontra-se na Tabela 1.

TABELA 1: Níveis de escolaridade

\begin{tabular}{|l|c|c|}
\cline { 2 - 3 } \multicolumn{1}{c|}{} & $\mathrm{n}$ & $\%$ \\
\hline Nenhum & 11 & 0,2 \\
$2 .^{\circ}$ Ciclo EB $1 .^{\circ}$ Ciclo EB & 99 & 1,6 \\
$3 .^{\circ}$ Ciclo EB & 168 & 2,8 \\
Secundário & 405 & 6,7 \\
Licenciatura/Bacharelato & 1.122 & 18,5 \\
Mestrado & 2.392 & 39,4 \\
Doutoramento & 1.553 & 25,6 \\
Total & 318 & 5,2 \\
\hline
\end{tabular}

Fonte: Inquérito aos Portugueses no Estrangeiro - Projeto REMIGR

O peso dos respondentes com escolarização mais elevada foi uma consequência esperada da aplicação do inquérito online e, também, da estratégia de divulgação desta forma de inquirição, que privilegiou as redes em que a presença dos mais qualificados é dominante. Também por isso se explica que entre os "menos qualificados" predominem indivíduos com o ensino secundário completo. Um dos objetivos da realização de inquéritos tradicionais em seis países foi, precisamente, tentar corrigir o enviesamento da amostra, permitindo chegar a um universo mais próximo da realidade migratória - que se sabe continuar a ser dominada por emigrantes com escolarização pouco elevada (cf. Pires, Pereira, Azevedo, \& Ribeiro, 2014; Pires et al., 2015) ${ }^{2}$.

2 Segundo o Observatório da Emigração, a taxa bruta de emigração dos mais qualificados era de $10,7 \%$ em 2001 e de $10,6 \%$ em 2011, o que mitiga a hipótese de um brain 
Refira-se ainda, de novo, que a opção teórica e metodológica de separar os emigrantes "mais e menos qualificados" pela escolarização de nível superior é assumidamente redutora e incompleta: redutora, uma vez que reduz o conceito de qualificação a níveis escolares ou académicos; incompleta, pois não contempla qualquer indicador de qualificação profissional.

Mesmo tendo em conta a não representatividade da amostra e o enquadramento dos níveis de qualificação profissional, acredita-se que os resultados são interessantes e significativos, dada a quase inexistência de estudos comparativos entre os perfis de emigrantes mais e menos qualificados em Portugal.

\section{Resultados}

\section{Perfil sociodemográfico}

No que respeita à distribuição por sexo e idade (Tabela 2), a amostra dos emigrantes mais qualificados apresenta-se muito equilibrada entre os sexos, com um peso superior das mulheres por apenas dois pontos percentuais. Já nos emigrantes com qualificações escolares mais reduzidas a preponderância é masculina, com uma relação de perto de 60/40 a favor dos homens. Estes dados parecem refletir, por um lado, a realidade da emigração tradicional menos qualificada, com maior peso dos homens. Por outro lado, refletem também a estrutura da população portuguesa, onde as mulheres são ligeiramente mais qualificadas que os homens ${ }^{3}$. Quanto à idade, tal como na estrutura da população portuguesa, os inquiridos menos qualificados são ligeiramente mais velhos do que os mais qualificados, com médias de 37 e 34 anos, respetivamente.

drain massivo neste período. Por sua vez, a OCDE e as Nações Unidas (OECD-UN-DESA, 2013) revelam uma taxa ligeiramente superior, na ordem de $12,9 \%$, com base nos Censos de 2010/11. Todavia, sublinha-se que estes dados se referem ao período censitário, pelo que podem não ter captado o eventual crescimento acelerado das saídas de qualificados ocorrido desde então.

3 ver http://www.pordata.pt/Portugal/População+residente++segundo+os+Censos++com+o +ensino+superior+completo+em+percentagem+da+população+residente+total+e+por+sexo-677 
TABELA 2: Distribuição por sexo

\begin{tabular}{|l|c|c|c|c|}
\cline { 2 - 5 } \multicolumn{1}{c|}{} & \multicolumn{2}{c|}{ Mais qualificados } & \multicolumn{2}{c|}{ Menos qualificados } \\
\hline & $\mathrm{n}$ & $\%$ & $\mathrm{n}$ & $\%$ \\
\hline Masculino & 2.089 & 49,0 & 1.072 & 59,5 \\
\hline Feminino & 2.173 & 51,0 & 731 & 40,5 \\
\hline Total & 4.262 & 100,0 & 1.803 & 100,0 \\
\hline
\end{tabular}

Fonte: Inquérito aos Portugueses no Estrangeiro - Projeto REMIGR

\section{Trajetória migratória}

Os indicadores escolhidos para ilustrar a trajetória migratória dos grupos em análise foram os países de destino, os fatores que os levaram a sair de Portugal, bem como a existência de uma experiência emigratória prévia.

\section{Principais países de destino}

Os países de destino dos inquiridos que compõem a amostra (Tabela 3) são dotados tanto de diferenças como de similaridades. Uma das similaridades posiciona o Reino Unido como o principal destino, independentemente do nível de qualificação em análise. Este é o destino de mais de 1/4 dos mais qualificados e de mais de $1 / 5$ dos menos qualificados. A segunda concordância entre ambas as amostras é a predominância de destinos europeus. Contudo, a amostra menos qualificada apresenta maior incidência no velho continente, onde $76 \%$ dos inquiridos se encontravam; na amostra mais qualificada a proporção é de $62 \%$.

TABela 3: Principais países de destino

\begin{tabular}{|l|c|c|l|c|c|}
\hline \multicolumn{3}{|c|}{ Mais qualificados } & \multicolumn{3}{c|}{ Menos qualificados } \\
\hline & $\mathrm{n}$ & $\%$ & & $\mathrm{n}$ & $\%$ \\
\hline Reino Unido & 1.035 & 24,3 & Reino Unido & 413 & 22,9 \\
\hline Brasil & 402 & 9,4 & França & 368 & 20,4 \\
\hline Angola & 396 & 9,3 & Luxemburgo & 252 & 14,0 \\
\hline
\end{tabular}




\begin{tabular}{|l|c|c|l|c|r|}
\hline \multicolumn{3}{|c|}{ Mais qualificados } & \multicolumn{3}{c|}{ Menos qualificados } \\
\hline Moçambique & 324 & 7,6 & Angola & 180 & 10,0 \\
\hline Alemanha & 290 & 6,8 & Brasil & 94 & 5,2 \\
\hline França & 226 & 5,3 & Moçambique & 90 & 5,0 \\
\hline Suíça & 151 & 3,5 & Alemanha & 79 & 4,4 \\
\hline Bélgica & 135 & 3,2 & Suíça & 71 & 3,9 \\
\hline Holanda & 124 & 2,9 & Holanda & 35 & 1,9 \\
\hline Luxemburgo & 114 & 2,7 & Bélgica & 26 & 1,4 \\
\hline Outros & 1.066 & 25,0 & Outros & 197 & 10,9 \\
\hline Total & 4.263 & 100,0 & Total & 1.805 & 100,0 \\
\hline
\end{tabular}

Fonte: Inquérito aos Portugueses no Estrangeiro - Projeto REMIGR

Deve notar-se que a distribuição por países é reflexo, em grande parte, dos seis países que foram escolhidos para estudos de caso e que tiveram, para além da possibilidade de resposta online, um inquérito a decorrer no terreno. Por este motivo, importa destacar os países que não faziam parte dos estudos de caso selecionados e que se encontram, ainda assim, no top dos principais destinos: Alemanha, Suíça, Holanda e Bélgica.

Independentemente das questões metodológicas envolvidas, o forte peso dos destinos europeus em toda a mobilidade internacional portuguesa recente é um dado adquirido. O regime de livre circulação no interior da União Europeia, a proximidade geográfica, as redes sociais e as redes ativas de recrutamento são os principais fatores explicativos.

\section{Fatores de repulsão}

Um conjunto de variáveis que importa comparar diz respeito aos motivos pelos quais os inquiridos saíram de Portugal (Figura 1). A maior diferença entre os mais e menos qualificados reside no item "realizar novas experiências", que recolheu $41 \%$ das respostas no grupo dos mais qualificados vis-à-vis $23 \%$ no grupo dos menos qualificados. A predominância dos valores neste item pode remeter para motivações que podem ser classificadas como pós-materialistas, na terminologia de Inglehart (1977, 1990). As motivações 
pós-materialistas já tinham sido constatadas nas gerações mais jovens de emigrantes croatas (Colic-Peisker, 2008), ou no estudo de médicos espanhóis no Reino Unido (Blitz, 2014, cap. 4) ${ }^{4}$.

FIGURA 1: Fatores de repulsão

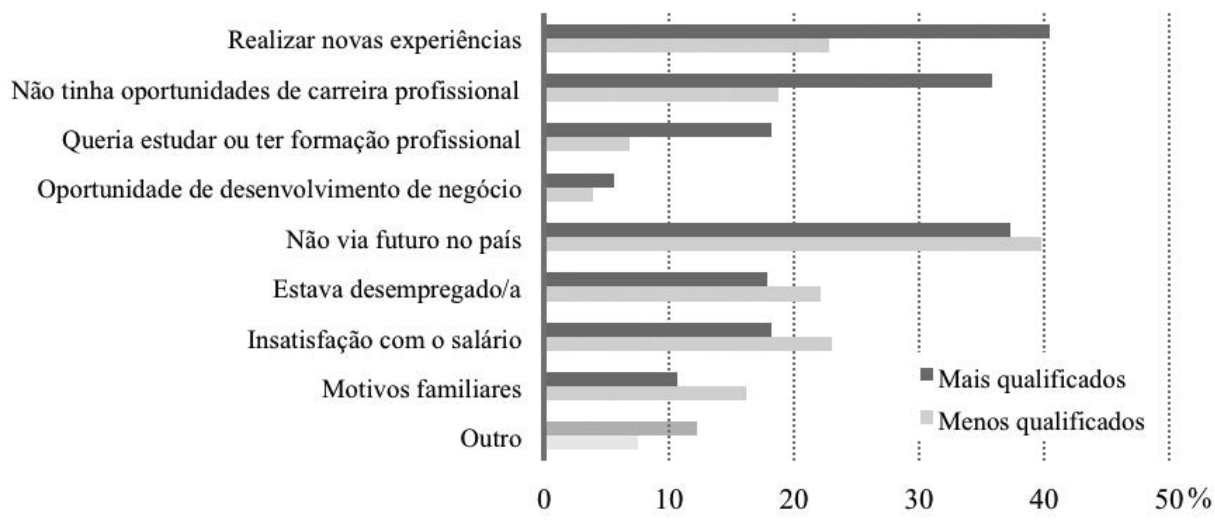

Fonte: Inquérito aos Portugueses no Estrangeiro - Projeto REMIGR

Nota: Ordenado pela grandeza da diferença entre os mais qualificados e os menos qualificados

Outros fatores que se mostraram mais relevantes para o grupo dos emigrantes mais qualificados são as expetativas em relação ao futuro ("não via futuro no país") e as motivações que remetem para a dimensão da realização profissional, seja a inexistência de oportunidades de carreira ou a vontade de adquirir formação escolar ou profissional.

Em contrapartida, os motivos em que mais se destacam os emigrantes menos qualificados são igualmente as baixas expetativas em relação ao futuro (cerca de $40 \%$ dos inquiridos assinalaram este item) ${ }^{5}$ e a realização de novas

${ }^{4}$ Segundo a proposta de Inglehart, os valores pós-materialistas tendem a regredir em situações de crise e incerteza (que conduzem ao reforço dos valores materialistas) e a reforçar-se em situações de segurança económica. Os resultados, interpretados segundo esta, revelam um paradoxo: os emigrantes qualificados (e não só) parecem optar por sair do país, não porque se encontram numa situação marcada por fortes incertezas, mas porque se sentem economicamente seguros e, por isso, privilegiam valores pós-materialistas.

5 As respostas dos dois grupos em relação a este tema são da mesma ordem de grandeza, com apenas mais alguns pontos percentuais para os menos qualificados. Talvez este aspeto seja o principal "fator comum" aos dois grupos. 
experiências, mas também a insatisfação com o salário e as situações de desemprego.

Analisando as motivações pelas quais o grupo dos mais qualificados se destaca pelas baixas proporções relativas, enunciam-se as motivações familiares, a insatisfação salarial e as situações de desemprego. Os valores mais reduzidos nas motivações familiares parecem indicar que a emigração mais qualificada se enquadra num projeto individual. O segmento mais qualificado tende a sair do país sozinho (56\% versus 46\%). Também associada se encontra uma proporção mais elevada de solteiros (48\% versus 33\%). Tanto o estado civil como a estratégia de emigrar sozinho podem ser resultado do perfil etário mais jovem, como já foi referido.

\section{Experiência emigratória}

Quando se compara a experiência emigratória anterior entre ambos os grupos (Tabela 4), a primeira conclusão é a de que, independentemente do grupo, a tendência é de se estar perante a primeira experiência emigratória dos sujeitos. Contudo, é no grupo dos mais qualificados que a proporção de emigrantes com anteriores experiências migratórias é mais elevada: 38\%, em comparação com $24 \%$ dos menos qualificados. No grupo dos mais qualificados, algumas destas experiências podem remeter para experiências académicas realizadas, por exemplo, no âmbito do programa Erasmus e outros similares.

TABELA 4: Experiência emigratória anterior

\begin{tabular}{|l|c|c|c|c|}
\cline { 2 - 5 } \multicolumn{1}{c|}{} & \multicolumn{2}{c|}{ Mais qualificados } & \multicolumn{2}{c|}{ Menos qualificados } \\
\hline & $\mathrm{N}$ & $\%$ & $\mathrm{n}$ & $\%$ \\
\hline Sim & 1.594 & 38,1 & 431 & 24,1 \\
\hline Não & 2.590 & 61,9 & 1.355 & 75,9 \\
\hline Total & 4.184 & 100,0 & 1.786 & 100,0 \\
\hline
\end{tabular}

Fonte: Inquérito aos Portugueses no Estrangeiro - Projeto REMIGR 


\section{Integração}

Para analisar a integração diferenciada dos sujeitos em análise nos países de destino, foram comparados os setores de atividade laboral em dois momentos no tempo, bem como as respostas a uma bateria de indicadores referentes às dificuldades de integração vivenciadas.

\section{Setores de atividade}

A comparação longitudinal dos setores de atividade laboral (Tabela 5) permite conhecer as alterações que podem ter ocorrido na trajetória profissional dos sujeitos que se analisam.

TABELA 5: Comparação longitudinal dos setores de atividade (\%)

\begin{tabular}{|l|c|c|c|c|}
\cline { 2 - 5 } \multicolumn{1}{c|}{} & \multicolumn{2}{c|}{ Mais qualificados } & \multicolumn{2}{c|}{ Menos qualificados } \\
\cline { 2 - 5 } \multicolumn{1}{c|}{} & Portugal & Atualmente & Portugal & Atualmente \\
\hline Indústria & 9,3 & 11,5 & 14,2 & 12,9 \\
\hline Construção & 11,6 & 11,7 & 18,8 & 19,5 \\
\hline $\begin{array}{l}\text { Comércio, alojamento e restauração, } \\
\text { transportes }\end{array}$ & 10,1 & 9,0 & 30,2 & 26,2 \\
\hline $\begin{array}{l}\text { Atividades financeiras, serviços às } \\
\text { empresas }\end{array}$ & 16,9 & 17,6 & 8,3 & 9,3 \\
\hline Educação & 16 & 12,9 & 4,0 & 3,3 \\
\hline Saúde & 9,4 & 11,6 & 2,8 & 2,4 \\
\hline $\begin{array}{l}\text { Atividades pessoais, familiares } \\
\text { e domésticas }\end{array}$ & 1,2 & 1,8 & 3,7 & 8,8 \\
\hline Outra situação & 25,6 & 23,8 & 18,0 & 17,7 \\
\hline Total & 100,0 & 100,0 & 100,0 & 100,0 \\
\hline
\end{tabular}

Fonte: Inquérito aos Portugueses no Estrangeiro - Projeto REMIGR

No caso dos mais qualificados, existia e existe uma maior dispersão pelos diversos setores. Verifica-se apenas um peso mais reduzido nas atividades 
pessoais e domésticas. Em Portugal, este grupo laborava, em grande parte, no setor da educação e nas atividades financeiras e serviços às empresas. Um terço da amostra mais qualificada encontrava-se ocupada nestes dois setores quando residia em Portugal. Embora ambos continuassem a ser os mais frequentes, observa-se atualmente uma maior concentração no último, com cerca de $18 \%$ dos emigrantes qualificados. O grande peso das "outras situações" (quer em Portugal, quer no país de destino, representam cerca de 25\%), que incluem situações difíceis de classificar, coloca, porém, alguns obstáculos à análise.

Já no segmento menos qualificado da amostra predominavam, em Portugal, os trabalhos associados aos serviços de comércio, de alojamento, de restauração e transportes, com 30\%, bem como o setor da construção civil e obras públicas, com 19\%. No país de destino estes dois setores continuavam a ocupar o topo da ordenação.

Com uma análise ao nível individual, que classifica a trajetória dos sujeitos entre estacionária (quando o setor de atividade se mantém nos dois momentos) ou de mudança (quando as áreas de atividade não coincidem entre os dois momentos), observa-se uma maior mudança nos setores de atividade no grupo dos menos qualificados. A taxa de estacionariedade que foi calculada assume valores na ordem dos $65 \%$ no segmento mais qualificado, enquanto no grupo menos qualificado o valor é de $53 \%$.

\section{Dificuldades de integração}

Grande parte dos problemas de integração com que os emigrantes inquiridos se deparam diferem de acordo com o seu nível de qualificação (Tabela 6). As diferenças com relevância estatística mais elevada dizem respeito ao acesso aos serviços de saúde e à dificuldade em lidar com o aparato administrativo, com valores mais elevados no segmento de qualificações superiores. Note-se, porém, que existe uma proporção relativamente maior de emigrantes mais qualificados em países como Angola e Moçambique, em que o acesso a serviços de saúde pode ser mais difícil. E, por se tratar de países fora do espaço Schengen, a necessidade de visto e da sua renovação pode pesar no item "burocracias". 
TABELA 6: Dificuldades de integração, médias

\begin{tabular}{|l|c|c|c|}
\cline { 2 - 4 } \multicolumn{1}{c|}{} & $\begin{array}{c}\text { Mais } \\
\text { qualificados }\end{array}$ & $\begin{array}{c}\text { Menos } \\
\text { qualificados }\end{array}$ & Diferença \\
\hline Dificuldades de acesso aos cuidados de saúde & 2,2 & 1,9 & 0,3 \\
\hline Burocracias & 2,9 & 2,7 & 0,2 \\
\hline Integração dos filhos na escola & 1,9 & 1,8 & 0,1 \\
\hline Obtenção de apoios sociais & 2,4 & 2,3 & 0,1 \\
\hline Dificuldades para alugar uma casa ou apartamento & 2,9 & 2,8 & 0,1 \\
\hline Poucos amigos ou solidão & 2,5 & 2,4 & 0,1 \\
\hline Custo de vida & 3,3 & 3,4 & $-0,1$ \\
\hline Dificuldades em encontrar emprego & 2,0 & 2,2 & $-0,2$ \\
\hline Clima & 2,6 & 2,7 & $-0,1$ \\
\hline Discriminação/racismo & 2,0 & 2,2 & $-0,2$ \\
\hline Língua/problemas com o idioma & 2,2 & 2,5 & $-0,3$ \\
\hline
\end{tabular}

Fonte: Inquérito aos Portugueses no Estrangeiro - Projeto REMIGR

Escala: 1: nada difícil, 5: muito difícil;

Os emigrantes menos qualificados destacam-se dos mais qualificados pelos valores mais elevados nos itens referentes à discriminação social e aos problemas com a língua do país de destino. No primeiro caso, interessa procurar fatores relacionados com estes valores, uma vez que, de acordo com as teorias da perceção de discriminação (Taylor, Wright, Moghaddam, \& Lalonde, 1990), seriam os grupos mais desfavorecidos aqueles com menor perceção de discriminação - situação que os dados não confirmam. Os problemas sentidos pelos emigrantes portugueses mais desqualificados em alguns países europeus poderão explicar estas respostas. Já as dificuldades com a língua do país de destino podem ter duas ordens de explicações associadas: por um lado, a maior concentração de emigrantes não qualificados em países cuja língua oficial não é o português; por outro, uma questão de literacia, pois as qualificações escolares mais reduzidas estarão associadas a um menor domínio de línguas estrangeiras.

No sentido contrário, observa-se que os emigrantes mais qualificados dão maior importância às dificuldades nas questões burocráticas e na área do acesso à saúde. No primeiro caso, os problemas deverão resultar do facto de 
os países de destino serem muitas vezes não europeus, o que torna difíceis os processos de legalização e de reconhecimento de diplomas. No segundo, os problemas deverão ser causados pelo facto de os sistemas universais de saúde não estarem tão desenvolvidos naqueles países.

\section{Transnacionalismo}

No que diz respeito às relações que os emigrantes mantêm com Portugal - ou transnacionalismo - são apresentados os resultados das questões respeitantes ao envio de remessas, visitas a casa, utilização dos media para comunicar e obter informações sobre Portugal, participação na esfera política e planos para o futuro.

\section{Remessas}

O envio de remessas assume proporções muito semelhantes entre os dois grupos, dividindo quase em duas partes idênticas ambas as amostras (50\% dos mais qualificados e $51 \%$ dos menos qualificados enviam remessas). Contudo, o envio de remessas assume ritmos e volumes distintos de acordo com as qualificações dos inquiridos (Tabela 7).

No caso dos menos qualificados, o envio de remessas é efetuado com uma periodicidade, no mínimo, mensal por $50 \%$ dos inquiridos. Este tipo de periodicidade muito curta é mais baixa nos mais qualificados, para os quais a proporção se cinge a 36\%. Para estes emigrantes, a situação mais frequente é o envio de remessas apenas algumas vezes por ano.

Mas a diferenciação está patente também no volume que as remessas assumem $^{6}$. Se para o grupo dos mais qualificados as remessas assumem uma média mensal de $985 €$, os menos qualificados enviam valores na ordem dos $803 €$. Mais de um terço dos emigrantes mais qualificados que enviam remessas indi-

\footnotetext{
${ }^{6}$ No questionário pedia-se aos inquiridos para assinalarem a média mensal das remessas, independentemente da periodicidade. As médias foram então calculadas através do ponto intermédio de cada escalão.
} 
cam valores superiores a $1000 €$ mensais. Por seu lado, o escalão com menores qualificações encontra-se dividido essencialmente entre os 251 a $500 €$ mensais e os mais de $1.000 €$ mensais ( $25 \%$ e $24 \%$, respetivamente). Ou seja, enquanto os menos qualificados enviam mais frequentemente menores valores, os mais qualificados enviam, não com tanta frequência, valores mais avultados.

TABELA 7: Periodicidade e montante mensal das remessas

\begin{tabular}{|l|c|c|c|c|}
\cline { 2 - 5 } \multicolumn{1}{c|}{} & \multicolumn{2}{c|}{ Mais qualificados } & \multicolumn{2}{c|}{ Menos qualificados } \\
\cline { 2 - 5 } \multicolumn{1}{c|}{} & $\mathrm{n}$ & $\%$ & $\mathrm{n}$ & $\%$ \\
\hline Uma ou mais vezes por mês & 692 & 35,7 & 408 & 50,2 \\
\hline Algumas vezes por ano & 800 & 41,3 & 212 & 26,1 \\
\hline Quando tem possibilidade & 445 & 23,0 & 193 & 23,7 \\
\hline Total & 1.937 & 100,0 & 813 & 100,0 \\
\hline Até $€ 100$ & 155 & 8,2 & 89 & 11,2 \\
\hline$€ 101-€ 250$ & 276 & 14,7 & 153 & 19,3 \\
\hline$€ 251-€ 500$ & 369 & 19,6 & 198 & 24,9 \\
\hline$€ 501-€ 1000$ & 389 & 20,7 & 160 & 20,2 \\
\hline Mais de $€ 1000$ & 690 & 36,7 & 194 & 24,4 \\
\hline Total & 1.879 & 100,0 & 794 & 100,0 \\
\hline
\end{tabular}

Fonte: Inquérito aos Portugueses no Estrangeiro - Projeto REMIGR

Nota: Valores calculados tendo como base os inquiridos que declararam ter enviado remessas no último ano.

\section{Visitas a casa}

As visitas a Portugal (Tabela 8) são mais frequentes no grupo com qualificações mais elevadas. Cerca de $30 \%$ dos mais qualificados visitam Portugal pelo menos uma vez a cada três meses. Se o período temporal for estendido até aos seis meses, o acumulado atinge os 64\%. Já no grupo menos qualificado, apenas $14 \%$ visita o país com uma frequência inferior a três meses e $37 \%$ com uma frequência inferior a seis meses. Para estes emigrantes, a situação mais frequente é a visita anual, protagonizada por $41 \%$. Os rendimentos mais elevados e a possibilidade de as empresas pagarem as viagens dos mais qualificados explicarão estas diferenças. 
TABELA 8: Frequência das visitas a Portugal

\begin{tabular}{|l|c|c|c|c|}
\cline { 2 - 5 } \multicolumn{1}{c|}{} & \multicolumn{2}{c|}{ Mais qualificados } & \multicolumn{2}{c|}{ Menos qualificados } \\
\cline { 2 - 5 } \multicolumn{1}{c|}{} & $\mathrm{n}$ & $\%$ & $\mathrm{n}$ & $\%$ \\
\hline Pelo menos uma vez por mês & 137 & 3,5 & 46 & 2,8 \\
\hline Pelo menos uma vez a cada três meses & 1.040 & 26,6 & 185 & 11,4 \\
\hline Pelo menos uma vez a cada seis meses & 1.330 & 34,0 & 362 & 22,3 \\
\hline Pelo menos uma vez por ano & 1.038 & 26,5 & 666 & 41,1 \\
\hline Menos frequentemente & 303 & 7,7 & 274 & 16,9 \\
\hline Nunca & 68 & 1,7 & 89 & 5,5 \\
\hline Total & 3.916 & 100,0 & 1.622 & 100,0 \\
\hline
\end{tabular}

Fonte: Inquérito aos Portugueses no Estrangeiro - Projeto REMIGR

FIGURA 2: Frequência de práticas transnacionais
5 média
Muito qualificados
Menos qualificados

4

3

2

Assistir a canais de Ouvir programas de Ler jornais portugueses Comunicar com a televisão portugueses rádio portugueses (em papel ou online) família ou amigos em online Portugal

Fonte: Inquérito aos Portugueses no Estrangeiro - Projeto REMIGR

Escala:1-nunca, 5-diariamente

\section{Utilização dos media}

A utilização dos media com o objetivo de manter os laços com Portugal também assume diferentes intensidades de acordo com os graus de qualificação dos inquiridos (Figura 2). No entanto, a hierarquia apontada por cada grupo não é muito distante. O mais frequente, para ambos, é a comunicação com familiares ou amigos que se encontram em Portugal. O menos frequente, 
em ambos os grupos, é o acompanhamento de programas de rádio online. A diferença entre os dois grupos está associada às práticas que ocupam uma posição intermédia: enquanto os mais qualificados tendem a consumir com mais frequência jornais portugueses (em papel ou online), os inquiridos com qualificações inferiores preferem assistir a canais de televisão portugueses.

\section{Práticas políticas}

Se forem analisados indicadores de práticas transnacionais relacionados com a participação política (Figura 3), a comparação atribui aos emigrantes mais qualificados maior atividade na esfera pública. Embora a hierarquia não seja muito distinta, os valores médios são sempre superiores no caso dos inquiridos com qualificação académica superior. Em todos os casos, a participação passiva (ouvir e ler notícias) predomina sobre a ativa (votar em eleições no país de origem ou de destino). A maior diferença entre os dois grupos é observada na participação eleitoral no país de origem ${ }^{7}$.

FIGURA 3: Frequência de práticas transnacionais políticas

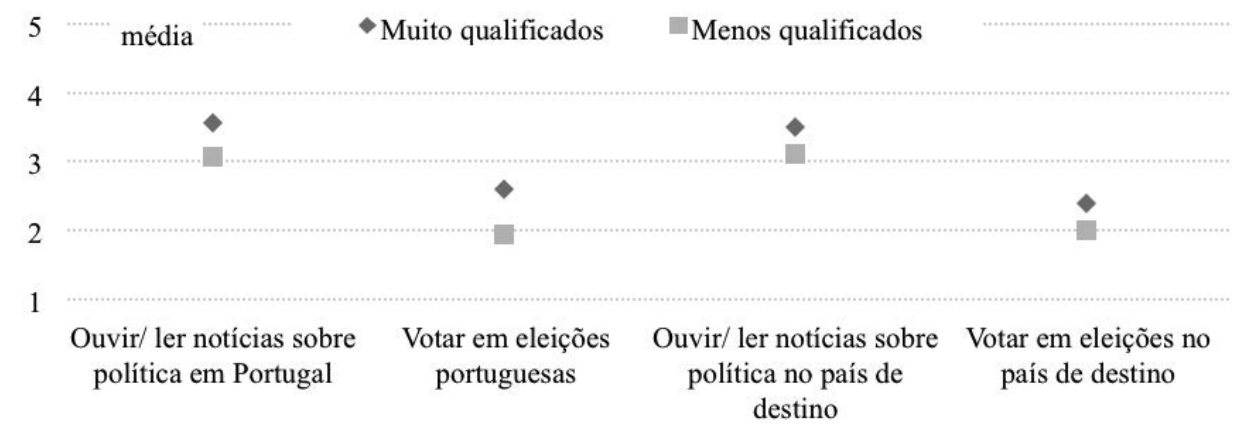

Fonte: Inquérito aos Portugueses no Estrangeiro - Projeto REMIGR

Escala:1-nunca, 2-raramente, 3-ocasionalmente, 4-frequentemente, 5-sempre que possível

7 Pode ter acontecido, porém, que uma parte dos inquiridos que emigraram mais recentemente não tenha tido oportunidade de participar em atos eleitorais no país de origem, porque desde o momento em que saíram não ocorreu nenhuma eleição em Portugal. 


\section{Planos para o futuro}

Por fim, é comparado o escopo dos inquiridos no que respeita ao seu futuro, que se apresenta bastante diversificado (Tabela 9). Cerca de 1/3 dos emigrantes qualificados não têm planos definidos para o futuro, sendo esta indecisão a situação mais frequente neste grupo. Já nos menos qualificados as opiniões distribuem-se entre a intenção de permanência definitiva no destino (35\%) e o regresso a Portugal (32\%). Os dois grupos distinguem-se também nos planos de onward migration (emigrar para outro país), expressos por $14 \%$ dos emigrantes mais qualificados, proporção que mais do que duplica face à encontrada no grupo menos qualificado (6\%).

TABELA 9: Planos para o futuro

\begin{tabular}{|l|c|c|c|c|}
\cline { 2 - 5 } \multicolumn{1}{c|}{} & \multicolumn{2}{c|}{ Mais qualificados } & \multicolumn{2}{c|}{ Menos qualificados } \\
\cline { 2 - 5 } \multicolumn{1}{c|}{} & $\mathrm{n}$ & $\%$ & $\mathrm{n}$ & $\%$ \\
\hline Ficar neste país & 955 & 24,6 & 563 & 34,8 \\
\hline $\begin{array}{l}\text { Ficar neste país um tempo e depois regressar } \\
\text { a Portugal }\end{array}$ & 1.091 & 28,1 & 509 & 31,5 \\
\hline Emigrar para um outro país & 531 & 13,7 & 91 & 5,6 \\
\hline Ainda não tenho planos definidos & 1.299 & 33,5 & 454 & 28,1 \\
\hline Total & 3.876 & 100,0 & 1.617 & 100,0 \\
\hline
\end{tabular}

Fonte: Inquérito aos Portugueses no Estrangeiro - Projeto REMIGR

\section{Conclusão}

Com este texto, pretendeu-se comparar a situação dos emigrantes portugueses recentes, isto é, os indivíduos naturais ou nacionais de Portugal que deixaram o país a partir do ano 2000 , tendo como critério diferenciador o seu nível de qualificação académica. Foram classificados como emigrantes "mais qualificados" os detentores de um grau académico superior e como "menos qualificados" os que estão abaixo desse patamar.

Os resultados apresentados devem ser interpretados com algumas ressalvas. Em primeiro lugar, não se trata de um retrato fiel da emigração portuguesa, 
uma vez que não foram cumpridos critérios de aleatoriedade e representatividade da amostra. Em segundo lugar, a comparação sistemática entre os dois grupos peca por não testar o efeito espúrio destas relações, isto é, a existência de outros fatores subjacentes ao cruzamento por qualificação. Trata-se de uma primeira análise exploratória dos dados obtidos, que será desenvolvida no futuro próximo. Não obstante as limitações, a análise efetuada leva a traçar um duplo perfil da emigração portuguesa.

Por um lado, os emigrantes mais qualificados são ligeiramente mais novos e mais equilibrados em termos de sex ratio do que os menos qualificados. Emigram em grande parte para o Reino Unido, mas em termos comparativos apresentam um peso superior nos países da CPLP - nomeadamente Angola, Moçambique e Brasil. A maioria encontra-se na sua primeira deslocação emigratória e iniciou-a, na maior parte dos casos, por se tratar de uma nova experiência, mas também por considerar que não tinha futuro em Portugal e pelas fracas oportunidades de progressão na carreira profissional. No país de destino, a sua inserção profissional dá-se especialmente no setor das atividades financeiras e nos serviços às empresas, seguido pelo setor da educação. As suas principais dificuldades de integração são, tal como no grupo dos menos qualificados, o custo de vida, o acesso à habitação e o clima. No que respeita às suas relações com Portugal, cerca de metade envia remessas e embora tendencialmente não o façam com uma base mensal, enviam valores mais elevados que os menos qualificados. A maioria visita Portugal uma vez a cada três ou seis meses. No país de destino, utilizam os media para comunicar com os familiares e leem frequentemente jornais online portugueses. Por fim, no que concerne aos planos para o futuro, os emigrantes mais qualificados apresentam-se maioritariamente indecisos.

Por outro lado, existe uma emigração menos qualificada, ligeiramente mais velha e mais assimétrica em termos de distribuição por sexo. Esta emigração tem como principal destino a Europa, em geral, e o Reino Unido, em particular. Os que emigraram para estes países fizeram-no maioritariamente porque consideravam que não havia futuro em Portugal, mas também por insatisfação com o salário e por um desejo de realizar novas experiências. Esta foi, em grande parte dos casos, a sua primeira experiência de emigração. No que respeita à sua integração laboral, encontram-se inseridos sobretudo 
nas áreas da construção civil e obras públicas, no comércio, nos serviços de alojamento, restauração e transportes. Enunciam como principais dificuldades o custo de vida no destino, o acesso à habitação e o clima. Nas relações com Portugal, cerca de metade dos portugueses menos qualificados enviam remessas, tendencialmente com uma periodicidade mensal, e o mais comum é visitarem Portugal uma vez por ano. Utilizam os media para comunicar com a família e assistem a canais de televisão portugueses. Grande parte destes emigrantes planeia permanecer no país de destino, enquanto uma proporção ligeiramente inferior tenciona regressar a Portugal.

\section{Referências bibliográficas}

ARAúJO, E. R. (2007). Why Portuguese Students Go Abroad to Do Their PhDs. Higher Education in Europe, 32(4), 387-397.

AZEVEDO, J. (2014). Emigração portuguesa qualificada no contexto europeu - Resultados preliminares. Comunicação à Conferência Emigração Portuguesa Contemporânea, ISCTE-IUL, Lisboa, 12 março 2014.

BLITZ, B. K. (2014). Migration and Freedom. Mobility, Citizenship and Exclusion. Cheltenham: Edward Elgar Pub.

CAndeIAS, P., Ferreira, B., \& Peixoto, J. (2014). Emigração Portuguesa: o que temos vindo a estudar e o que nos falta saber - uma análise bibliométrica entre 1980 e 2013. População e Sociedade, 22, 10-31.

Cogo, D., \& Badet, M. (2013). De braços abertos... A construção midiática da imigração qualificada e do Brasil como país de imigração. In E. Araújo, M. Fontes \& S. Bento (Eds.), Para um debate sobre Mobilidade e Fuga de Cérebros (eBook) (pp. 32-57) Braga: CECS - Centro de Estudos de Comunicação e Sociedade.

COLIC-PEISKER, V. (2008). Migration, Class, and Transnational Identities. Croatians in Australia and America. Urbana/Chicago: University of Illinois Press.

DeliCAdo, A. (2010). Going Abroad to do Science: Mobility Trends and Motivations of Portuguese Researchers. Science Studies, 23(2), 36-59.

DELICADO, A. (2011). The consequences of mobility: careers and work practices of Portuguese researchers with a foreign PhD degree. In F. Dervin (Ed.), Analysing the 
consequences of international academic mobility (pp. 163-180). Newcastle: Cambridge Scholars Publishing.

DEliCADO, A., \& Alves, N. d. A. (2013). "Fugas de Cérebros", "Tetos de Vidro" e "Fugas na Canalização": mulheres, ciência e mobilidade. In E. Araújo, M. Fontes \& S. Bento (Eds.), Para um debate sobre Mobilidade e Fuga de Cérebros (eBook) (pp. 8-31). Braga: CECS - Centro de Estudos de Comunicação e Sociedade.

Dillman, D. A., Smyth, J. D., \& Christian, L. M. (2014). Internet, Phone, Mail, and Mixed-Mode Surveys. The Tailored Design Method. (4th ed.) New Jersey: Wiley. EMíliA, A., \& Ferreira, F. (2013). A "Fuga de Cérebros": um discurso multidimensional. In E. Araújo, M. Fontes \& S. Bento (Eds.), Para um debate sobre Mobilidade e Fuga de Cérebros (eBook) (pp. 58-82): CECS - Centro de Estudos de Comunicação e Sociedade.

FARIA, A. M. A. (2012). A emigração portuguesa qualificada: circulação e redes de emigrantes como contributo para o país de origem. (Dissertação de Mestrado, Universidade do Minho). Disponível em: http://repositorium.sdum.uminho.pt/ handle/1822/23323

FONTES, M. (2007). Scientific mobility policies: how Portuguese scientists envisage the return home. Science and Public Policy, 34(4), 284-298.

FONTES, M., \& Araújo, E. (2013). (I) Mobilidades e redes científicas internacionais: Contextos e relações em mudança. In E. Araújo, M. Fontes \& S. Bento (Eds.), Para um debate sobre Mobilidade e Fuga de Cérebros (eBook) (pp. 58-82): CECS - Centro de Estudos de Comunicação e Sociedade.

GOMES, R. (coord.) et al. (2015). Fuga de cérebros: retratos da emigração portuguesa qualificada. Lisboa: Bertrand.

INGLEHART, R. (1977). The Silent Revolution - Changing Values and Political Styles Among Western Publics. New Jersey: Princeton University Press.

INGLEHART, R. (1990). Culture Shift in Advanced Industrial Society. New Jersey: Princeton University Press.

LOPES, J. T. (2014). Geração Europa? Um estudo sobre a jovem emigracão qualificada para França. Lisboa: Mundos Sociais.

MALHEIROS, J. (2010). Portugal 2010: o regresso do país de emigração? Notas e reflexões. Janus - anuário de relações exteriores, 2(1), 133-142.

MARQUES, J. C. (2010). A emigração portuguesa em tempos de imigração. POLÍGONOS. Revista de Geografía (20), 115-129. 
OECD-UN-DESA (2013). World Migration in Figures. OECD-United Nations Department of Economics and Social Affairs. Disponível em: (www.oecd.org/els/mig/ World-Migrationin-Figures.pdf)

PEIXOTO, J. (2012). A emigração portuguesa hoje: o que sabemos e o que não sabemos. (SOCIUS Working Paper n. ${ }^{\circ}$ 5). Lisboa: ISEG.

PEREIRA, A. P. F. (2007). Leitores de Língua e Cultura Portuguesas no Estrangeiro. Experiências de Leitorado e Percursos Profissionais no Estrangeiro. (Dissertação de Mestrado, Faculdade de Ciências Sociais e Humanas, Universidade Nova de Lisboa (FSCH-UNL)). Disponível em: http://cesnova.fcsh.unl.pt/cms/files/publicacoes/PUB4e08c66c5f5e2.pdf

Pereira, C., Pinto, N., \& Pires, R. P. (2015). Enfermeiros portugueses no Reino Unido 2014. OEm Fact Sheets, n. ${ }^{\circ}$ 3: Observatório da Emigração, CIES-IUL, ISCTE-IUL doi: 10.15847/CIESOEMFS032015-pt-en.

PIRES, R. P., Pereira, C., Azevedo, J., \& Ribeiro, A. C. (2014). Emigração Portuguesa. Relatório Estatístico 2014. Lisboa: Observatório da Emigração e Rede Migra, Instituto Universitário de Lisboa (ISCTE-IUL), CIES-IUL, e DGACCP.

PIRES, R. P., Pereira, C., Azevedo, J., Santo, I. E., Vidigal, I., \& Ribeiro, A. C. (2015). Emigração Portuguesa. Relatório Estatístico 2015. Lisboa: Observatório da Emigração e Rede Migra, CIES-IUL, ISCTE-IUL, e DGACCP.

RiBeIRO, J. S., Conceição, C., Pereira, J., Leone, C., Mendonça, P., Temido, M., Vieira, C. P., \& Dussault, G. (2013). Health professionals moving to... and from Portugal. Health Policy, 114(2-3), 97-108.

TAYlOR, D. M., Wright, S. C., Moghaddam, F. M., \& Lalonde, R. N. (1990). The Personal/Group Discrimination Discrepancy. Perceiving My Group, but not Myself, to be a Target for Discrimination. Personality and Social Psychology Bulletin, 16(2), 254-262. 
(Página deixada propositadamente em branco) 
JOSÉ CARLOS MARQUES ${ }^{1}$

https://orcid.org/0000-0002-4690-5943

\section{A EMIGRAÇÃO PORTUGUESA : DA AUS ÊNCIA À REDESCOBERTA DOS MOVIMENTOS EMI G RATÓR I OS NACIONAIS ${ }^{2}$}

\section{Introdução}

A emigração constitui uma caraterística secular da sociedade portuguesa que, ao longo dos tempos, foi conhecendo diferentes ritmos e variados contextos económicos e sociopolíticos de origem e de destino. O interesse científico (e também literário) por esta temática foi, em termos genéricos, acompanhando os diferentes momentos de emigração dos portugueses. Um olhar sobre a produção científica entre 1960 e 2013 (Figura 1) mostra que dois períodos se apresentam como particularmente frutíferos em termos de produção científica sobre a emigração portuguesa: o que se segue à emigração intraeuropeia do segundo pós-guerra e o que se inicia com o novo milénio. Enquanto no primeiro é possível notar que uma parte significativa das referências bibliográficas se debruça sobre a emigração que se seguiu ao final do segundo período bélico, no segundo o estabelecimento de uma relação com

${ }^{1}$ Professor Adjunto da Escola Superior de Educação e Ciências Sociais do Instituto Politécnico de Leiria, investigador do Centro Interdisciplinar em Ciências Sociais - Polo do Instituto Politécnico de Leiria (CICS.NOVA.IPLeiria). Doutorado em Sociologia pela Universidade de Coimbra, os seus interesses de investigação têm incidido sobre a migração internacional, as políticas migratórias, os fluxos migratórios portugueses, a migração qualificada e a integração dos migrantes. E-mail: jclaranjo@sapo.pt.

$2 \mathrm{O}$ presente texto recorre extensivamente a trabalhos já publicados pelo autor, sintetizando e desenvolvendo algumas ideias avançadas nesses trabalhos (cf. Marques, 2008, 2010). O texto beneficia dos debates ocorridos no âmbito do projeto "Regresso ao Futuro: a nova emigração e a relação com a sociedade portuguesa" (Projeto PTDC/ATP-DEM/5152/2012, coordenado por João Peixoto). 
movimentos migratórios próximos é menos evidente. Assim, por exemplo, num levantamento das referências bibliográficas realizado em 2014, o número de referências à emigração portuguesa pós-1980 não ultrapassa as duas dezenas de textos publicados a partir dessa data (Candeias et al., 2014).

FIGURA 1: Produção bibliográfica sobre a emigração portuguesa, 1960-2013

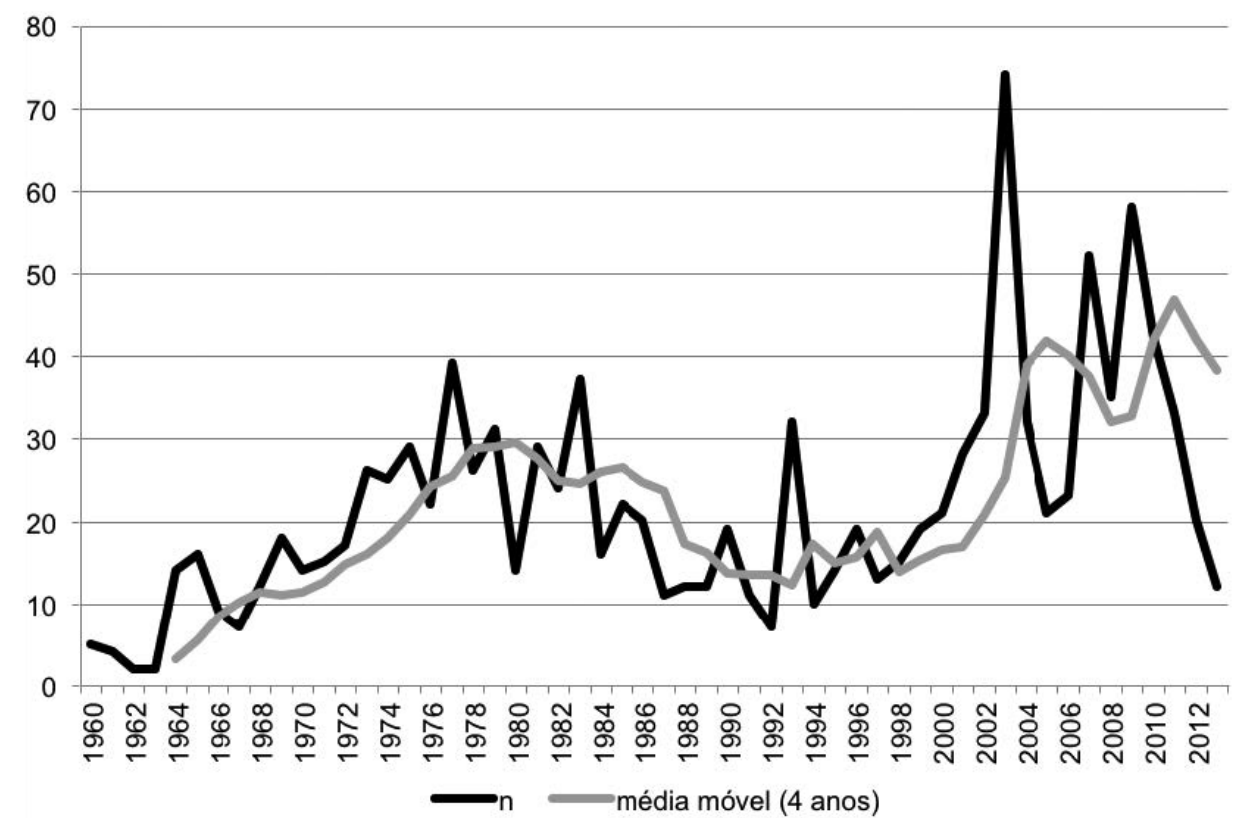

Fonte: Para as referências até 1984, Rocha-Trindade \& Arroteia (1984); para as referências posteriores, Candeias, Góis, Marques e Peixoto (2014).

Tão relevante como apontar para a intensificação da produção bibliográfica sobre a emigração portuguesa em dois períodos particulares é analisar as razões para a sua menor visibilidade científica durante os anos 60, 80 e 90 do século passado. Se a desatenção dos anos 60 pode ser atribuída à dificuldade do regime político da altura em lidar com a questão emigratória e com o conhecimento científico sobre a mesma, a quase ausência do estudo das migrações durante os anos 80 e 90 tem razões mais complexas e não necessariamente relacionadas com as caraterísticas dos movimentos emigratórios desta época. 


\section{A ausência do estudo dos movimentos emigratórios portugueses}

Como referido, até ao início do século XXI a emigração portuguesa pós1973/74 foi frequentemente negligenciada, quer a nível político, quer a nível científico. Associada a um 'regresso ao passado', só esporadicamente era objeto de estudo e de análises mais aprofundadas, mesmo quando a evolução da paisagem migratória nacional insistia em mostrar que esses tempos idos não se encontravam assim tão distantes e que o presente e o futuro pareciam divergir pouco em termos emigratórios do tempo que se acreditava pertencer ao passado.

Evidência da pouca atenção dedicada ao estudo da emigração pode ser encontrada na análise dos dados relativos aos projetos de investigação financiados pela Fundação para a Ciência e Tecnologia. Estes dados mostram que entre 1996 e 2012 foram financiados 55 projetos de investigação sobre a temática genérica das migrações, dos quais apenas oito abordavam a temática da emigração portuguesa e destes somente dois tinham por tema central os fluxos emigratórios nacionais (ambos aprovados em 2012) ${ }^{3}$.

Tal como noutros países, também em Portugal o desenvolvimento das agendas de investigação sobre as migrações foi mais estimulado pela evolução da imigração do que pelos desenvolvimentos registados na emigração, confirmando, assim, que a sociologia das migrações na Europa foi durante largos anos uma sociologia da imigração (e não tanto uma sociologia das migrações) (Sciortino, 2014) ${ }^{4}$. É de admitir que esta situação esteja relacionada com o facto de o desenvolvimento da disciplina ser orientado pelos acontecimentos ('event-driven' segundo Portes (1995, p. 1)) e de as conjunturas da sua evolução terem sido, quase sempre, influenciadas pelos acontecimentos políticos

3 Ao longo deste período, os projetos genericamente enquadráveis na área do estudo das migrações foram financiados em 3.251.903€. Deste valor, $17,8 \%$ foi alocado a projetos que abordavam de alguma forma a questão da emigração. Se apenas forem contabilizados os projetos exclusivamente sobre a emigração, esta percentagem reduz-se para $11,4 \%$, correspondendo a quatro projetos (aprovados um em 2003, outro em 2006 e dois em 2012).

${ }^{4}$ Como reconhece este autor, esta afirmação não pretende negar a crescente importância dedicada ao estudo de atividades transnacionais e ao estudo da interligação entre migrações e desenvolvimento que tem atendido aos efeitos das migrações nos países de origem. 
relevantes em cada momento - neste caso, relacionados com a imigração, ou, como acontece no momento atual, pela emigração.

Não será este o local para proceder à aferição aprofundada das razões para esta ausência do estudo da emigração portuguesa durante grande parte dos anos 80 e 90 do século XX. Como referido noutro local uma parte destas razões relaciona-se com o incómodo que representava, sobretudo, a nível político, a manutenção de fluxos de saída num país que se queria afirmar como desenvolvido. Outra parte da explicação poderá ser encontrada na dificuldade em obter dados fidedignos sobre o número de saídas a partir de meados dos anos 80, em resultado da eliminação do 'passaporte de emigrante'5 no qual se tinham, até então, baseado as estatísticas portuguesas relativas à emigração. A estes dois fatores explicativos é possível adicionar as condições sociais e institucionais de produção do conhecimento sobre os fluxos emigratórios portugueses. A nível social, a emigração, apesar de continuar a registar-se, não assumia os valores que a caraterizaram nos anos 60 e inícios dos anos 70 do século passado. A sua presença na sociedade portuguesa encontrava-se limitada a situações particulares (trabalhadores da construção civil, por exemplo) e só esporadicamente era objeto de atenção por parte dos meios de comunicação social portugueses. A nível institucional, o estudo da emigração portuguesa contemporânea não integrava, de forma geral e sistemática, os planos de estudo dos cursos universitários (quer os de formação inicial, quer os de formação pós-graduada), nem era objeto de especial atenção nos centros de investigação nacionais ${ }^{6}$ (o que, naturalmente, não significa que a emigração não tenha merecido a atenção dos investigadores sediados nestes centros de investigação).

Em síntese, enquanto o campo de estudo da imigração em Portugal oferecia múltiplas oportunidades de investigação e permitia aos investigadores o desenvolvimento de análises internacionalmente comparáveis, o estudo da emigração parecia estar associado a um 'regresso ao passado', mesmo quando a evolução da paisagem migratória portuguesa insistia em demonstrar que

\footnotetext{
5 Decreto-Lei . $^{\circ}$ 438/88 de 29 de novembro.

${ }^{6}$ A exceção é formada pelo Centro de Estudos das Migrações e das Relações Interculturais da Universidade Aberta que tem, desde a sua criação em 1989, uma linha de investigação que privilegia os estudos da emigração e da imigração.
} 
este regresso ao passado mais não era do que uma revisitação do presente e do futuro ${ }^{7}$. Por ser uma realidade estrutural, uma 'constante estrutural' como diria Vitorino Magalhães Godinho (1978), da sociedade portuguesa que colhe, atualmente, a atenção de um número crescente de investigadores nacionais, considerou-se oportuno olhar com alguma atenção para os fluxos emigratórios que ocorreram nos anos finais do século XX. Em muitos casos, estes fluxos serviram de base à intensificação dos fluxos emigratórios que se verifica no momento atual e que tem conduzido à redescoberta dos fluxos de saída por uma comunidade crescente de investigadores. Como é expetável que a emigração portuguesa continue durante os próximos anos, embora provavelmente a níveis inferiores aos registados nos últimos anos, é de admitir que o seu estudo continue a mobilizar um número cada vez maior de investigadores.

\section{A emigração portuguesa no final do século $\mathrm{XX}$}

A ausência do estudo da emigração portuguesa durante grande parte dos anos 80 e 90 do século XX poderá, em parte, ser explicada pela dificuldade em obter dados fidedignos sobre as saídas de portugueses. De modo a minorar esta dificuldade, importa olhar para as estatísticas dos países de destino (como recomendaram, nos anos 90, Baganha e Peixoto (1997)). Trata-se de um exercício necessariamente complexo e incompleto, dado o diverso grau de desenvolvimento dos sistemas de recolha de dados estatísticos dos países de acolhimento e a adoção de diferentes definições de migrante por parte desses mesmos sistemas estatísticos. Assim, face à impossibilidade de aceder a dados de todos os países em que é possível testemunhar a presença de portugueses e atendendo a que o objetivo deste artigo é somente apontar para a desatenção com que no passado recente se olhou para a emigração portuguesa, limitamos a análise a alguns países europeus. O principal critério de seleção adotado foi a existência de séries de dados suficientemente longas

7 É curioso assinalar neste local que um projeto de investigação destinado a estudar a nova emigração portuguesa, iniciado em 2013, tem precisamente por título "Regresso ao Futuro: a nova emigração e a relação com a sociedade portuguesa" (Projeto PTDC/ATP-DEM/5152/2012, coordenado por João Peixoto). 
sobre a entrada de portugueses nos seus territórios. Dado que este exercício foi já realizado por Baganha e Peixoto para a década de 80 e os primeiros anos da década de 90, limitamos a observação à década final do século XX, a qual, como tivemos ocasião de mostrar noutro local, integra um novo ciclo de expansão da emigração portuguesa (Marques \& Góis, 2013). Trata-se de um período particularmente interessante em termos de análise dos movimentos de saída de portugueses porque correspondeu quer à enunciação política do 'fim da emigração portuguesa', quer ao desenvolvimento das condições de mobilidade em virtude da adesão de Portugal, em 1992, ao espaço europeu de livre circulação.

Os dados apresentados na figura seguinte sintetizam a evolução da emigração portuguesa para destinos selecionados da Europa a partir de 1989. É possível notar que nos primeiros anos da década de 90 a evolução foi genericamente positiva (à exceção dos anos 1991 e 1992). A partir de 1996 inicia-se um período de retração da emigração portuguesa para os países integrados no grupo A que se prolonga, ainda que com diferentes intensidades e com diferentes velocidades de recuperação, até 2001 (nos casos da Suíça e Bélgica) e até 2006 no caso da Alemanha. Os países incluídos no grupo B apresentam uma evolução de sentido inverso, com um aumento contínuo a partir de 1999, o qual se interrompe apenas em 2008 em resultado da crise económica que assolou um dos principais destinos da emigração portuguesa nesse período (a Espanha). Durante este período regista-se uma ligeira retoma da emigração portuguesa para os países do grupo A, ainda que, a partir de 2003, a níveis inferiores do que os registados para os países do grupo B.

Os anos que enquadram a mudança de século parecem, assim, apontar para um efeito de amortecimento da contração da emigração para determinados destinos em resultado do desenvolvimento de novos destinos de acolhimento dos portugueses. À semelhança do verificado nos anos 80, testemunha-se deste modo no início do século XXI uma nova fase de reconfiguração dos destinos emigratórios portugueses (uma fase que se estenderá, a partir de meados da primeira década deste século, a destinos não europeus). Este efeito de diversificação dos destinos da emigração nacional no espaço europeu permite ampliar as possibilidades de acionamento de diferentes respostas migratórias em função do conjunto de oportunidades que se desenvolvem nos diferentes 
países e/ou de eventuais dificuldades de integração no mercado de trabalho que emergem em determinado destino migratório.

FIGURA 2: Entrada de Portugueses em países europeus selecionados, 1989-2013

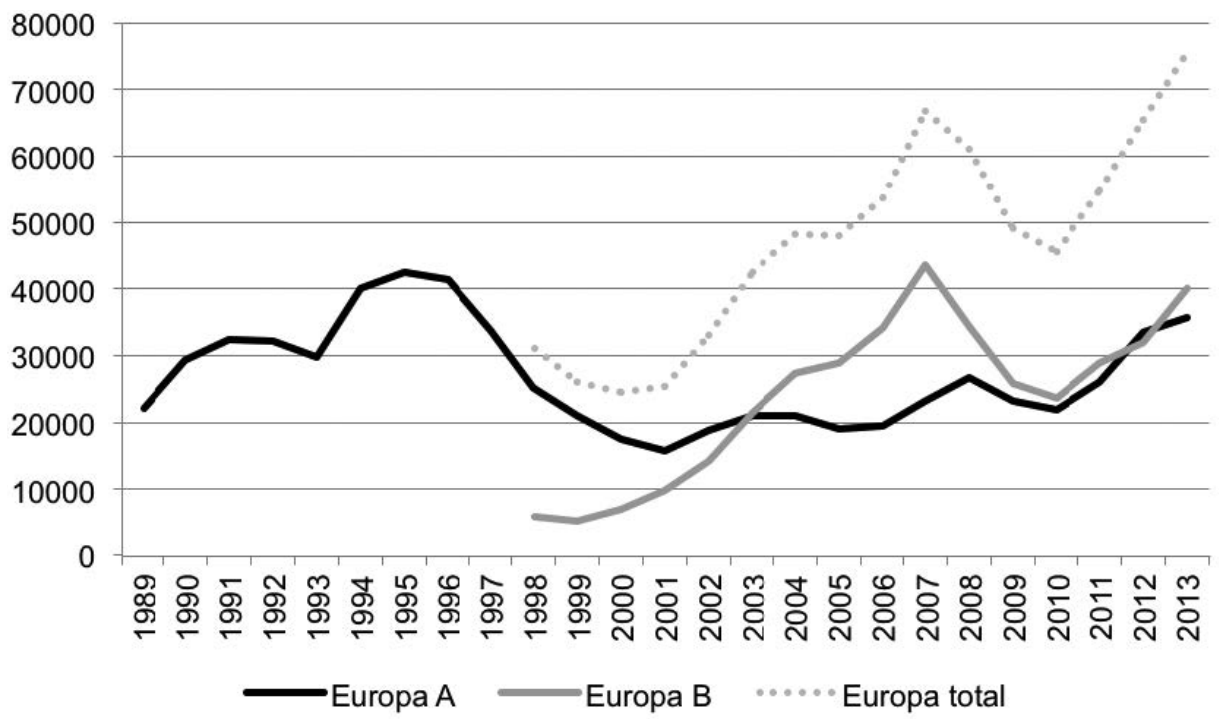

Nota: a) Europa A: Alemanha, Suíça e Bélgica; Europa B: Espanha, Luxemburgo e Reino Unido; Europa total = Europa A + Europa B;

b) A partir de 2002 os dados relativos ao Reino Unido (incluído no grupo Europa B) referem-se às inscrições anuais na Segurança Social inglesa.

Fontes: Alemanha: Statistische Bundesamt Deutschland, Statistische Jahrbuch, (diversos anos); Bélgica e Reino Unido: OCDE, International Migration Database (http://stats.oecd.org/Index. aspx?DatasetCode=MIG); Espanha: Instituto Nacional de Estadística. Series anuales Padrón Municipal de habitantes; Luxemburgo: Service central de la statistique et des études économiques (STATEC); Suíça: Bundesamt für Auslaenderfragen (diversos anos)

Esta possibilidade de reconfiguração e de ativação de oportunidades económicas em diferentes destinos emigratórios configura-se como uma caraterística importante da emigração portuguesa contemporânea (Marques, 2008, 2010), demonstrando, simultaneamente, a intensificação da integração do país no sistema migratório europeu (neste caso enquanto país de origem) e a ação das estruturas sociais de suporte à emigração (as designadas redes migratórias, às quais se voltará mais adiante). 
Aos movimentos emigratórios de cariz mais permanente deve adicionar-se um importante fluxo de saídas temporárias. Estas aproveitam os condicionalismos políticos dos países de acolhimento, os quais privilegiam, numa primeira fase, as entradas sazonais e as diferentes liberdades decorrentes da adesão do país à Comunidade Europeia (em especial a liberdade de prestação de serviços e a liberdade de circulação) para encetar formas migratórias que combinam períodos de duração variável no exterior com períodos de permanência em Portugal. Os dados sobre estes fluxos são bastante parcelares e não apresentam uma regularidade temporal que permita uma correta apreensão da sua real dimensão (cf. Figura 3). Só para a Suíça é possível apresentar uma série de dados que abrange toda a década de 90. Neste país o valor das entradas temporárias de portugueses rondou, anualmente, as 33.700 durante a década de 90, reduzindo-se durante a primeira década do século XXI, em resultado de alterações na política de imigração helvética, para 15.130 entradas anuais. Para França, o valor das entradas temporárias de portugueses foi de 14.719 em 1989, 16.592 em 1990, e 16.568 em 1991 (dados da OMI citados em Ruivo 2001, pp. 160-161) ${ }^{8}$. A partir de 1992 a emigração temporária para França deixou de ser contabilizada pelo OMI. É, contudo, de admitir que ela não tenha desaparecido por completo, ainda mais se atendermos ao facto de a livre circulação tornar este tipo de mobilidade mais simples.

Um caso particular da mobilidade temporária dos portugueses é formado pelos trabalhadores destacados que assumem maior relevância no decurso da década de 90, após a adesão do país à então denominada Comunidade Europeia. Esta forma de mobilidade dos trabalhadores portugueses decorre através da colocação no exterior de efetivos de empresas portuguesas que funcionam, geralmente, como subcontratadas das empresas dos países de destino (por exemplo, de empresas de construção alemãs ou francesas). O número exato de trabalhadores portugueses envolvidos nos processos de destacamento é difícil de determinar. Na Alemanha, país em que esta forma de mobilidade assume particular relevância, o número de portugueses destacados foi, em

\footnotetext{
${ }^{8}$ Alguns destes temporários foram posteriormente incluídos nos 15.368 trabalhadores permanentes portugueses registados, em 1992, pelos serviços do Office des Migrations Internationales e do Institut National d'Études Démographiques (Ruivo, 2001, p. 161).
} 
FIGURA 3: Migrações temporárias de Portugueses em países europeus selecionados, 1989-2013

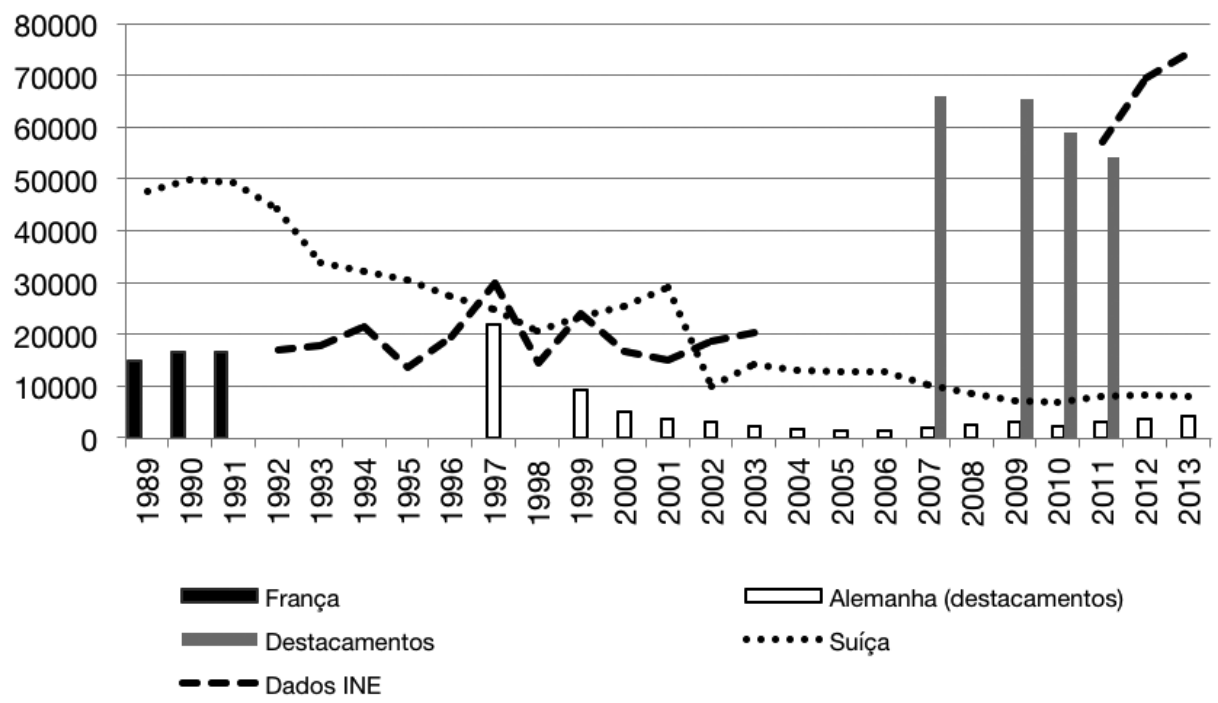

Fontes: França - Ruivo (2001, p. 160); Alemanha: 1997: Worthmann (2003) e 1999-2013: Soka-Bau (por solicitação particular, a partir de 1999 referem-se apenas ao setor da construção); Suíça: Bundesamt für Ausläenderfragen (diversos anos); Dados INE: www.ine.pt (dados estatísticos); Destacamentos: European Commission (2011 e 2012).

1997, de 21.919 , o que representava $12,1 \%$ do total de trabalhadores destacados e 40,1\% dos destacados com origem num dos estados comunitários (Worthmann, 2003). Os portugueses seriam, assim, o maior grupo de trabalhadores destacados com origem num país membro da União Europeia. Trata-se de um número que, de acordo com algumas fontes, peca por defeito, dado referir-se apenas aos que se encontram em situação regular, não incluindo, por isso, os estimados 35.000 portugueses que nesse período estariam a trabalhar como destacados de forma irregular (Gago \& Vicente, 2002, p. 212). Dados mais recentes mostram que no final da primeira década do século XXI esta forma de mobilidade continua a ser relevante, abrangendo, em 2007 e $2009^{9}$, respetivamente, 66.000 e 65.000 trabalhadores portugueses. A partir

9 Não se apresentam os dados relativos a 2008, dado que apenas seis dos 18 Centros Distritais da Segurança Social responsáveis pela emissão do formulário E-101 (que, no 
deste ano os valores reduzem-se para 58.948 em 2010, e 54.183 em 2011 (European Commission, 2012, 2011). Neste último ano, à semelhança dos anos anteriores, os principais países de destino foram a França (34,1\% dos trabalhadores destacados), a Espanha (23,6\%), a Holanda (13,0\%) e a Alemanha $(8,8 \%)$ (European Commission, 2012, 2011).

\section{Determinantes da manutenção da emigração portuguesa}

Até ao final do século XX, os fluxos emigratórios portugueses dirigiram-se preferencialmente para os destinos integrados no sistema migratório europeu, retomando, assim, a orientação que tinha sido dominante nas décadas de 60 e inícios dos anos 70 desse século. A recuperação das saídas para o espaço europeu não significa porém que sejam semelhantes as condições de natureza sociopolítica em que se produzem estas saídas. Atendendo a que, segundo a afirmação clássica de Kingsley Davis, os movimentos migratórios "espelham o mundo tal como ele é no momento em que se processam“ (1974, p. 105), não surpreende que os movimentos migratórios portugueses das décadas de 80 e 90 apresentem caraterísticas e motivos que decorrem do contexto histórico, institucional e social em que se desenvolveram.

Para explicar a manutenção e a recente intensificação dos movimentos migratórios nacionais podem conjugar-se fatores de natureza económica e fatores de natureza institucional e sociopolítica. Quanto aos fatores de ordem económica, o fluxo emigratório contemporâneo tem, à semelhança de fluxos migratórios anteriores, origem em cálculos económicos e na procura da realização de oportunidades económicas e/ou profissionais que escasseiam em Portugal. O modelo de desenvolvimento seguido durante décadas pelo país não foi suficiente para ultrapassar os desequilíbrios de rendimento entre os países de destino da emigração e Portugal e para responder às aspirações de prestígio (sobretudo, social) e de poder (económico) de uma fração signifi-

estrangeiro, atesta a inscrição do cidadão nacional na segurança social do país de origem) é que forneceram nesse ano os dados relativos aos números de formulários emitidos (European Commission, 2011). 
cativa da população portuguesa que, através da mobilidade exterior, procura aproveitar as vantagens comparativas existentes noutros contextos nacionais (Marques, 2008). Para esta parte da população nacional “os 'gloriosos anos' da modernização à portuguesa" (Lopes, 2014, p. 1) não terão contribuído para a redução do seu sentimento de privação relativa, levando-a a considerar mais eficiente procurar melhorar o seu nível de vida através da mobilidade exterior do que aguardar o impacto do desenvolvimento económico sobre as suas condições de vida. A emigração mantém-se, assim, como uma opção importante para milhares de portugueses que a consideram uma possibilidade real de ultrapassar os constrangimentos que enfrentam no mercado de trabalho nacional (Marques, 2008).

Ao nível das condições institucionais e políticas já foi referido atrás que os movimentos migratórios do final do século $\mathrm{XX}$ ocorrem num contexto marcado pela emergência e desenvolvimento de um espaço transnacional, delimitado pelas fronteiras exteriores dos países aderentes ao espaço europeu de livre circulação no qual os cidadãos nacionais adquirem novos direitos de mobilidade. Estas novas condições de mobilidade ajudam a explicar o crescimento de diferentes formas de movimentos de saída temporários atrás descritos, explicando igualmente que a frequente indefinição entre "movimentos 'permanentes' e 'temporários'” (Peixoto, 1993, p. 68) surja como um dos aspetos mais marcantes da transformação verificada nos movimentos migratórios externos portugueses. Trata-se, em muitos casos, de movimentos com contornos fluidos em que a estada permanente é, por vezes, conseguida através da reiteração de movimentos temporários e de estadas superiores ao permitido pelo título de permanência do migrante (nos contextos nacionais em que é exigido um título de permanência) (Marques, 2010, 2008).

Um outro fator explicativo da manutenção dos movimentos emigratórios refere-se à existência de comunidades portuguesas espalhadas por diversas regiões do mundo que se constituem como verdadeiras estruturas sociais de apoio à emigração. A participação dos indivíduos nestas redes migratórias permite-lhes o acesso às informações difundidas na rede e ao suporte material à realização dos projetos migratórios. De uma forma geral, no atual contexto emigratório português, as redes migratórias não se limitam a manter o fluxo migratório entre dois locais específicos: Antes se reconfiguram continuamente 
de modo a possibilitar a ligação entre a origem e vários possíveis destinos, os quais são ativados de acordo com o sancionamento económico e político vigente no mercado internacional de trabalho. É, assim, de admitir a existência de redes migratórias multipolares com diferentes graus de produtividade e com uma forte capacidade de inclusão de novos destinos emigratórios. Isto é, redes que, em relação a um destino particular, se podem encontrar momentaneamente hibernadas, mas que, relativamente a outro destino, se podem encontrar em plena atividade.

O facto de estas redes se encontrarem ativas em países integrados num sistema supranacional propício à mobilidade internacional e beneficiarem dos desenvolvimentos tecnológicos registados nas últimas décadas (ao nível dos transportes e ao nível das tecnologias de comunicação, por exemplo) tem contribuído para potenciar o efeito cumulativo de um conjunto de fatores promotores da mobilidade contemporânea. Para além dos já mencionados atrás, é importante acrescentar ao conjunto de fatores propiciadores dos movimentos migratórios o desenvolvimento de uma 'cultura migratória' (Kandel \& Massey, 2002), vocacionada para o exterior em determinadas regiões do país. A presença desta cultura migratória em algumas regiões ou comunidades de Portugal, alicerçada num sistema de valores de suporte a modos de vida com uma forte propensão migratória (Baganha \& Góis 1998/1999, p. 231) tenderá a enquadrar positivamente as decisões migratórias dos seus membros. Num contexto caraterizado pela eliminação de uma parte substancial dos obstáculos à mobilidade (em particular dos trabalhadores comunitários) e pelo funcionamento de uma densa rede migratória, este sistema de valores interiorizado pela prática continuada dos movimentos de saída sustenta as condições necessárias à realização da emigração logo que se desenvolvam as condições suficientes (isto é, as circunstâncias externas) à sua efetivação (Marques, 2008).

\section{Notas finais}

Através da análise da evolução da emigração portuguesa após meados dos anos 80, procurou-se mostrar que a atual hiperatenção sobre os fluxos 
de saída dos portugueses contrasta com a desatenção com que no passado se olhou para esta realidade estrutural da sociedade portuguesa. O volume da emigração registada nas décadas finais do século XX mostra que esta nunca deixou realmente de existir e que a emigração que se produziu a partir da crise económica de 2007 pode ser analisada como um período que combina a intensificação de anteriores fluxos migratórios com o desenvolvimento de novos fluxos de saída.

À semelhança de fluxos anteriores, também os atuais fluxos podem ser explicados pela conjugação de condições que, do lado dos países de destino, se apresentam como favoráveis à receção dos emigrantes portugueses e de circunstâncias que, do lado português, influenciam a efetivação do estrutural potencial migratório nacional. De entre as condições que concorrem para a efetivação deste potencial migratório assumem particular relevância as determinantes económicas, em especial, os diferenciais de rendimento e de oportunidades profissionais entre Portugal e os diversos países de destino. A esta explicação 'tradicional' para a emigração nacional é necessário acrescentar os fatores institucionais que, sobretudo a partir de meados dos anos 80 , criaram um contexto mais propício à mobilidade internacional dos portugueses, o desenvolvimento dos transportes de baixo custo e das tecnologias de informação e comunicação e a ação (com diferentes graus de intensidade) das estruturas sociais de suporte aos potenciais e efetivos emigrantes. Relativamente a estas redes sociais de apoio à emigração, é importante reconhecer a sua crescente complexidade, resultante dos seus diferentes graus de produtividade em função do perfil do emigrante e da complementaridade (e/ou substituição) entre redes fisicamente identificáveis e limitadas e redes que no espaço virtual assumem, frequentemente, funções outrora limitadas à existência de alguma proximidade física. Este conjunto de condições, elencadas neste local de forma bastante breve, permite apontar para a importância de atender ao contexto económico, político, tecnológico e social em que se desenvolvem os fluxos emigratórios. A análise deste contexto multidimensional e de configuração variável (no tempo e no espaço) contribui para informar o olhar atual sobre os novos movimentos de emigração portuguesa e sobre as suas caraterísticas distintivas. Não será surpreendente que, ao aprofundar-se a observação desta realidade, se confirme que algumas das suas caraterísticas (ditas) 
originais têm precedentes na emigração portuguesa das décadas de 1980 e 1990 e que novo é, sobretudo, o modo como a comunidade científica, política, os media e a sociedade em geral olham para a emigração contemporânea.

\section{Referências bibliográficas}

BAGANHA, M. I., \& Góis, P. (1998/1999). Migrações internacionais em Portugal: o que sabemos e para onde vamos. Revista Crítica de Ciências Sociais, n. ${ }^{\text {s }} 52-53,229-280$.

Baganha, M. I., \& Peixoto, J. (1997). Trends in the 90's: the portuguese migratory experience. In M. I. Baganha (Ed.), Immigration in Southern Europe, (pp.15-40). Oeiras: Celta.

Candeias, P., Góis, P., Marques, J. C., \& Peixoto, J. (2014). Emigração portuguesa: bibliografia comentada (1980-2013). (SOCIUS Working Paper n. ${ }^{\circ}$ 1). Lisboa: ISEG.

DAVIS, K. (1974). The migrations of human populations. Scientific American, 231(3), 96-106.

EUROPEAN COMMISSION (2011). Posting of workers in the European Union and EFTA countries: Report on E101 certificates issued in 2008 and 2009. DG Employment, Social Affairs \& Inclusion.

EUROPEAN COMMISSION (2012). Posting of workers in the European Union and EFTA countries: Report on A1 portable documents issued in 2010 and 2011. DG Employment, Social Affairs \& Inclusion.

GAGO, C., \& Vicente, T. (2002). Alemanha. In M. I. Baganha, J. Ferrão, \& J. Malheiros (Eds.), Os Movimentos Migratórios Externos e a Sua Incidência no Mercado de Trabalho em Portugal, (pp. 177-224). Lisboa: Observatório do Emprego e Formação Profissional.

GODINHO, V. M. (1978). L'émigration portugaise: XV-XXe siècles: une constante structurale et les réponses aux changements du monde. Revista de História Económica e Social I, 5-32.

KANDEL, W., \& Massey, D. S. (2002). The culture of Mexican migration: a theoretical and empirical analysis. Social Forces, 80(3), 981-1004.

LOPES, J. T. (2014). Geração Europa? Um Estudo sobre a Jovem Emigração Qualificada para França. Lisboa: Mundos Sociais. 
MARQUES, J. C. (2008). Os Portugueses na Suiça: Migrantes Europeus. Lisboa: Imprensa de Ciências Sociais.

MARQUES, J. C. (2010). A emigração portuguesa em tempos de imigração. POLÍGONOS. Revista de Geografía (20), 115-129.

MARQUES, J. C., \& Góis, P. (2013). Dinâmicas do sistema migratório lusófono: um olhar a partir das migrações portuguesas. In L. Fonseca, P. Góis, J. C. Marques, \& J. Peixoto (Eds.), Migrações na Europa e em Portugal. Ensaios de homenagem a Maria Ioannis Baganha, (pp. 185-203). Coimbra: Almedina.

PORTES, A. (1995). Economic Sociology and the Sociology of Immigration: A Conceptual Overview. In A. Portes (Ed.), The Economic Sociology of Immigration. Essays on Networks, Ethnicity, and Entrepreneurship, (pp. 1-41). New York: Russel Sage Foundation.

ROCHA-TRINDADE, M. B., \& and Arroteia, J. C. (1984). Bibliografia da emigração portuguesa. Lisboa: Instituto Português de Ensino à Distância.

RUIVO, J. R. (2001). Portugais et population d'origine portugaise en France. Paris: L'Harmattan.

SCIORTINO, G. (2014). A European Sociology of Migration? Not Yet, Not Quite. In S. Koniordos, \& A. Kyrtsis (Eds.), Handbook of European Sociology. London: Routledge.

Worthmann, G. (2003). Nationale Autonomie trotz Europäisierung: Probleme der Arbeitsmarktregulierung und Veränderungen der industriellen Beziehungen in der deutschen Bauwirtschaft. München: Rainer Hampp Verlag. 
(Página deixada propositadamente em branco) 
JOANA SOUSA RIBEIRO

https://orcid.org/0000-0002-5779-7503

\section{AS QUALIFICAÇÕ ES COMO PASSAPORTE? \\ PROCESSOS DE (RE)PRODUÇÃO \\ DE MOBILIDADES NA SAÚDE ${ }^{1}$}

\section{Introdução}

Em 19 de outubro de 2012, numa carta pública dirigida ao Presidente da República, o enfermeiro Pedro Miguel anunciava que “(...) Em menos de 48 horas estarei a embarcar para o Reino Unido numa viagem só de ida. É curioso, creio eu, porque a minha família (inclusive o meu pai) foi emigrante em França (onde ainda conservo parte da minha família) e agora também eu o sou. Os motivos são outros, claro, mas o objetivo é o mesmo: trabalhar, ter dinbeiro, ter um futuro.

Lamento não poder dar ao meu país o que ele me deu. Junto comigo levo mais 24 pessoas de vários pontos do país, de várias Escolas de Enfermagem. Somos dos melhores do mundo, sabia? E não somos reconhecidos, não somos contratados, não somos respeitados".

A situação retratada por este enfermeiro traduz uma realidade que poderá ser comum a mais de 550 enfermeiros portugueses registados em 2012 na homóloga Ordem dos Enfermeiros no Reino Unido - a Nursing and Midwifery Council (NMC).

\footnotetext{
${ }^{1}$ Este capítulo resulta de uma comunicação apresentada na Conferência Internacional "Fuga de Cérebros: a mobilidade académica e a emigração portuguesa qualificada", pelo que os dados estatísticos, referências bibliográficas e entrevistas semiestruturadas apresentados reportam à data da participação na referida conferência (18 de setembro de 2015) e enquadram-se no âmbito de um projeto de doutoramento em curso.
} 
A migração de profissionais de saúde na Europa, num tempo de contração económico-financeira, representa um duplo desafio, na medida em que se relaciona diretamente com a consolidação ou, pelo contrário, com o esvaziamento, do Mercado Único Europeu e, indiretamente, com o desenvolvimento da sociedade do conhecimento, essencial para a superação das múltiplas crises com que se defronta o continente europeu - demográfica, social, humanitária, política, económica e financeira.

As migrações qualificadas têm tido um suporte institucional, independentemente do enquadramento sociopolítico do contexto de receção. O investimento na sociedade do conhecimento, baseado numa retórica de competitividade, empreendedorismo e mobilidade, traduz-se, na prática, no reconhecimento das potencialidades dos benefícios económicos, sociais e formativos de uma mão-de-obra em circulação.

Perante necessidades laborais, sobretudo num setor de mão-de-obra intensiva, regulada e de fracas possibilidades de relocalização como o da saúde ${ }^{2}$, o recrutamento internacional de profissionais neste setor compreende uma possibilidade que perfilha o interesse comum, da sociedade recetora e dos sujeitos individuais. No entanto, se tivermos em consideração uma análise multidimensional da questão, não serão de negligenciar os contextos de partida e os condicionalismos estruturais que lhes estão subjacentes, nomeadamente, o desenvolvimento das políticas de educação, das políticas de saúde e das políticas de recrutamento e de retenção do mercado de trabalho, e dos seus reflexos nos condicionalismos individuais como seja, concretamente, a decisão de migrar.

Este capítulo procura debater a mobilidade internacional de dois grupos profissionais de saúde - médicos/as e enfermeiros/as -, tendo como referência o caso particular de um país de receção e de origem - Portugal.

Para o efeito, exploram-se as seguintes questões:

\footnotetext{
2 De acordo com as estimativas da Comissão Europeia, a União Europeia terá uma falta de 970.000 profissionais de saúde em 2020, o que se traduz na possibilidade de $14 \%$ dos cuidados não serem, efetivamente, prestados (Glinos, 2014).
} 

a) O que é que o contexto revela?
b) Serão os movimentos de entrada e de saída simples jogos de espelhos?
c) Para que servem as tipologias?

\section{O que é que o contexto revela?}

Em Portugal, a organização de cuidados de saúde sob prestação pública, de forma consentânea com os princípios equitativos de justiça social, tem expressão concreta na previsão constitucional de um direito à saúde (art. 64. ${ }^{\circ} \mathrm{da}$ CPR). Segundo o n. ${ }^{\circ} 1$ deste preceito, "todos têm direito à proteção da saúde e o dever de a defender e promover".

$\mathrm{O}$ direito social à saúde tem como primeira concretização institucional a criação de um Serviço Nacional de Saúde (n. ${ }^{\circ}$, alínea a), n. ${ }^{\circ}$ 3, alínea d), e n. ${ }^{\circ}$ 4, universal (abarcando a generalidade dos cidadãos), geral (compreendendo todos os domínios e cuidados médicos) e tendencialmente gratuito, tendo em conta as condições económicas e sociais dos cidadãos ${ }^{3}$.

No entanto, e de acordo com dados divulgados pela OCDE (2015), Portugal continua a ser um dos países cujo financiamento público menos cobre as despesas de saúde. Desde 2012 que a despesa pública em saúde em percentagem do PIB (5,9\%) se afasta da média observada na OCDE $(9,3 \%$, em 2014). Nos últimos anos, Portugal é mesmo o país em que a contribuição dos utentes mais aumentou, representando, em 2015, 37,4\% da despesa total (35\% em 2008). Este aumento da despesa direta das famílias ocorre num contexto em que a despesa total com a saúde no Orçamento Geral do Estado é das que mais desce, se tivermos em conta o cômputo geral dos países da OCDE. Refira-se ainda que, em 2015, o Orçamento do SNS se apresentou ao nível das dotações de 2005/2006 (7,8 mil milhões de euros).

O Memorando de Entendimento sobre as Condicionalidades de Política Económica em Portugal (MdE), assinado em maio de 2011 pelo Governo por-

\footnotetext{
3 Para uma análise integrada da questão, cf. João Arriscado Nunes (2009, p. 144), onde salienta que "O que está em jogo quando se fala de direito à saúde é tanto a luta pela definição do que conta como saúde, como daquilo que conta como direito à saúde".
} 
tuguês, o Fundo Monetário Internacional (FMI), o Banco Central Europeu (BCE) e a Comissão Europeia (CE) (a designada Troika), sob a égide de garantir a sustentabilidade económica e financeira do sistema de saúde, contemplava, entre outras, a realização das seguintes medidas, associadas à prestação de cuidados de saúde no Serviço Nacional de Saúde (SNS), e de interesse para a análise em apreço:

- rever e aumentar as taxas moderadoras do SNS (em vigor desde 1 de janeiro de 2012), cuja aplicação pelo XIX Governo Constitucional introduziu alterações significativas nas condições elegíveis para isenção do pagamento;

- reorganizar a rede de serviços de saúde, nomeadamente através da racionalização da rede hospitalar e do aumento do número de Unidades de Saúde Familiares (USF) contratualizadas com as Autoridades Regionais de Saúde (ARS). Esta última medida, que procura uma redução da utilização dos serviços de âmbito hospitalar, tem ficado aquém da meta estabelecida ${ }^{4}$;

- alocar recursos humanos no âmbito do SNS, particularmente tendo como intuito reduzir a despesa com horas extraordinárias, monitorizar necessidades de contratação e contribuir para a mobilidade geográfica dos profissionais de saúde. Procura-se a operacionalização destes objetivos através, entre outros, do alargamento do número de utentes por médico de família (máximo de 1900 utentes); do controlo, através do sistema biométrico, da assiduidade e pontualidade dos profissionais; e de um regime excecional de contratação de médicos aposentados.

No âmbito do SNS, o impacto da aplicação de políticas de austeridade na oferta, procura e acesso aos cuidados de saúde revela-se, entre outras, nas seguintes dimensões:

${ }^{4}$ Com efeito, em 2015, estava prevista a constituição de 33 novas USF (do modelo A), tendo apenas sido criadas 9, até 10 de setembro de 2015 (ACSS, 2015a). 
- desmotivação dos profissionais, em resultado do congelamento da progressão nas carreiras, da desvalorização salarial no setor público (o que favorece a mobilidade interna para o setor privado), da flexibilização das relações de trabalho, do atraso de pagamentos dos incentivos e da pressão para o racionamento;

- insatisfação dos utentes em situação de maior vulnerabilidade socioeconómica, cuja permanente necessidade de comprovar a condição de recursos produz o efeito de uma efetiva estigmatização social. Acresce ainda as desigualdades de acesso, também de ordem geográfica, uma vez que os residentes nas zonas do interior do país têm maiores dificuldades em receber tratamentos mais diferenciados;

- representatividade dos atendimentos nos serviços de urgência per capita. Em 2011, num conjunto de 21 países da OCDE, Portugal posiciona-se em primeiro lugar no número de admissões na urgência por 100 habitantes (70,5 admissões), um indicador muito distanciado de Espanha, o país com o lugar imediatamente inferior (com 57,3 admissões) (Berchet, 2015);

- falta de anestesistas e de enfermeiros especializados na área da cirurgia condiciona fortemente a capacidade de resposta das unidades hospitalares. A nível nacional, verifica-se uma taxa média de ocupação das salas de operações na ordem dos $64 \%$, quando os níveis ótimos devem rondar os $80 \%$ ACSS (2015a).

O desinvestimento numa política integrada de recursos humanos na área da saúde é visível numa análise depurada dos contingentes de profissionais afetos a esta área.

Se tivermos em conta o conjunto de profissionais a trabalhar nas instituições tuteladas pelo Ministério da Saúde em 2014 (124.260), verificou-se um decréscimo de pessoal na ordem dos $2,5 \%$, comparativamente ao ano transato. Esta tendência acompanha a evolução decrescente verificada no cômputo geral da Administração Pública (- 2,7\%).

A este nível, o cenário futuro não se revela muito promissor. As recentes previsões do Centro Europeu para o Desenvolvimento da Formação Profissional (CEDEFOP, 2015), que abrangem o atual período até 2025, revelam 
que, ao contrário do que acontece noutros países europeus, a maior parte das oportunidades de emprego em Portugal (cerca de 40\%) exigirão um nível baixo de qualificações.

De facto, no seu conjunto, a maior parte das oportunidades de trabalho criadas na União Europeia (cerca de 24\%) centrar-se-ão no recrutamento de profissionais na área da ciência, engenharias da saúde, gestão e ensino; ao invés do que se prevê que aconteça em Portugal, onde as estimativas apontam para que apenas $14 \%$ dos empregos criados se dirijam a profissionais qualificados. Não obstante, continuará a tendência para a qualificação da força de trabalho em Portugal, prevendo-se que, em 2025, cerca de $47 \%$ da população entre os 30-34 anos detenha uma escolaridade de nível superior. Antecipa-se, assim, um possível desencontro ao nível das qualificações, entre a oferta e a procura no mercado de trabalho em Portugal, tanto mais acentuado se não houver um investimento em setores que exijam mão-de-obra muito especializada.

Dentro deste âmbito, um estudo da Comissão Europeia (CE, 2015) salienta que a percentagem de emprego de jovens licenciados em Portugal (entre os 20 e os 34 anos) era de $73,6 \%$ em 2014, quando a média europeia se situa nos $80,5 \%$.

Uma das conclusões do estudo Education and Training Monitor 2015 (CE, 2015) é de que a taxa de desemprego entre os licenciados em Portugal está a contribuir para um afastamento relativo do ensino superior. Na última década, a população inscrita no ensino superior tem estado sujeita a flutuações, como sejam uma descida de inscritos nos anos letivos de 2002/2003 e 2005/2006, apresentando, contudo, uma tendência de crescimento já nos anos de crise económico-financeira, concretamente um crescimento ténue em 2008/2009, mas mais expressivo em 2010/2011. Simultaneamente, e a espelhar os efeitos de uma diminuição do rendimento dos agregados familiares, Portugal foi o país europeu onde se registou uma maior quebra na taxa de conclusão do ensino superior, de 86\% (em 2008) para 67\% (em 2011).

Porém, se tivermos em conta uma análise de longo alcance das mudanças estruturais na sociedade portuguesa, sobressai, sem dúvida, a crescente importância atribuída às qualificações, que se materializa na expansão da rede de estabelecimentos de Ensino Superior, público e privado. No caso concreto 
da área da medicina, existem oito estabelecimentos de ensino públicos, sendo que um deles ministra o curso de medicina apenas a quem seja titular de um grau de licenciado em ciências da natureza, ciências da saúde ou ciências exatas. Tendo em conta que o numerus clausus em medicina tem vindo a aumentar nos últimos anos (de 150 vagas, em 2000, para 1.441 em 2015), e não estando assegurada a formação pós-graduada de todos os médicos internos, atores institucionais da área (de âmbito regulatório, como seja o caso da Ordem dos Médicos; ou de caráter associativo, como é o caso da Associação Nacional de Estudantes de Medicina) procuram pressionar as entidades governativas no sentido de se rever o número de ingressos anuais. Com efeito, o risco de uma mão-de-obra de reserva de médicos indiferenciados, isto é, médicos sem a atribuição de uma especialidade, poderá propiciar situações de proletarização da profissão (Braverman, 1974) ${ }^{5}$.

Paralelamente, na área de enfermagem, assiste-se a uma proliferação de Escolas Superiores (47, das quais 20 privadas), sobretudo depois daquilo que podemos designar como sendo uma crescente 'profissionalização' da enfermagem em Portugal (Ribeiro, 2015). Saliente-se que este processo de institucionalização do reconhecimento do papel da enfermagem na prestação de cuidados de saúde em Portugal se revela pioneiro na União Europeia. Inicia-se por altura de 1990, data da criação da Ordem dos Enfermeiros e de graus universitários em enfermagem.

Apesar do número de enfermeiros por 100 mil habitantes ter aumentado na última década, o rácio de enfermeiros por médico tem permanecido estável, ainda que sendo um dos indicadores mais baixos da Europa - 1,5 (ou 1,38 se considerarmos também os médicos em internato de especialidade) (OPSS, 2015). De acordo com a OCDE (2014), constata-se que Portugal tem um rácio de 5,8 enfermeiros por mil habitantes (contemplando enfermeiros em funções de gestão, educação e investigação), um indicador inferior à média da União Europeia constituída por 28 Estados-Membros, que se situa em oito enfermeiros por mil habitantes.

5 Note-se que existem mais de um milhão de portugueses (1.192.273) sem médico de família atribuído (ACSS, 2015b)). 
Como noutros países, a área de enfermagem é a que concentra o grupo mais numeroso de profissionais de saúde em Portugal. Na última década, houve um aumento de enfermeiros registados na Ordem dos Enfermeiros, de 37.623 em 2000 para 64.535 em 2011, sendo que a maioria (74\%) trabalha em meio hospitalar (Barros et al., 2011). A profissão de enfermagem é desempenhada por uma população jovem (em 2012, 52\% dos enfermeiros registados têm menos de 40 anos) e predominantemente por mulheres (em 2012, correspondem a $81 \%$ do total) (OE, 2013).

Neste grupo profissional, verifica-se uma diminuição de 1.153 enfermeiros em 2014, relativamente a 2011 (o que equivale a uma diminuição de 1,4\%). Note-se que, em 2013, ocorreu um aumento do período normal de trabalho para as 40 horas semanais, o que se repercutiu num aumento de $1,3 \%$ do número de horas de trabalho prestadas na área de enfermagem.

No caso da medicina, desde 2011 que se tem observado um acréscimo do número de profissionais no SNS (de 26.767 em 2011 para 29.642 em 2014), em parte devido ao número de médicos em internato (13\%). O número de médicos no SNS por mil habitantes era de 1,87 em 2013, sendo que, para uma avaliação mais precisa, será necessário atender à distribuição geográfica, pois convém relembrar que Portugal é um dos países onde se observa uma maior disparidade na distribuição de médicos, a favor das áreas urbanas (OPSS, 2015). Ressalve-se, no entanto, que as zonas de maior concentração populacional (Lisboa e Porto) têm um rácio inferior ao da média nacional.

Saliente-se ainda o crescente processo de feminização da profissão, sobretudo se tivermos em conta os estratos mais jovens da população médica.

\section{Movimentos de entrada e de saída: simples jogos de espelhos?}

Segundo Maria Ioannis Baganha (2001), o interesse heurístico de Portugal enquanto espaço nacional privilegiado para a análise dos impactos dos processos de globalização no desenvolvimento dos fluxos migratórios internacionais reside, precisamente, no facto de só nos anos 80, em pleno período de expansão dos processos de globalização, Portugal se assumir como um país de entrada atrativo, reflexo de uma sociedade recentemente concebida 
como pós-colonial e com importantes lacunas ao nível do topo da estrutura socioprofissional.

Nessa década, mais precisamente a partir de 1986, Portugal participa como Estado-Membro no processo de consolidação do espaço da União Europeia, o que proporcionará, já com a adesão ao Tratado de Maastricht e ao acordo de Shengen, um novo estatuto de cidadania - a cidadania pós-nacional conferida aos portugueses emigrados (Estrada, 2011). Portugal, na sua condição semiperiférica, legitimada por um discurso do Estado que, segundo Boaventura de Sousa Santos, se perceciona como um coletivo "imaginado do centro" (Santos, 1993), configura-se, também na área das migrações, como uma plataforma giratória de fluxos das 'periferias' para os 'centros' (Baganha \& Peixoto, 1997). De referir que, no início dos anos 90, o discurso científico 6 (Esteves, 1991) e político ${ }^{7}$ se norteava pela mudança do regime migratório, isto é, defendia-se a transição de 'país de emigração' para 'país de imigração'.

Entre o final dos anos 90 e o início do século XXI, a par do que acontece com outros países do sul da Europa ${ }^{8}$, Portugal recebe, num período de tempo relativamente curto e de uma forma intensiva ${ }^{9}$ (Baganha, Marques \& Góis, 2004), população imigrante proveniente de um contexto - a designada 'Europa de Leste' - com o qual Portugal não possui relações privilegiadas, sejam de ordem social, económica, histórica ou cultural. Será, assim, já durante as últimas décadas do século XX/início do século XXI, sobretudo após um período

\footnotetext{
${ }^{6}$ Para se comprovar este desinvestimento científico na área da emigração, cf. a inventariação bibliográfica e documental (de 1980 a 2013) efetuada sobre o tema (Candeias et al., 2014), onde se constata que a maioria da produção científica não incide sobre emigração contemporânea e, quando o faz, não recorre a dados primários.

7 Cf. entrevista de João de Deus Pinheiro - Ministro dos Negócios Estrangeiros da altura - ao jornal suíço Le Nouveau Quotidien e parcialmente reproduzida no Jornal Público, de 1 de outubro de 1991 (Baganha \& Góis, 1999).

${ }^{8}$ Convém, no entanto, atender ao facto de que "(...) a recente história migratória do sul da Europa é uma soma de casos nacionais específicos, que reflete os passados históricos respetivos e os interesses geoestratégicos e políticos de cada um dos países que constituem esta área geográfica" (Baganha \& Góis, 1999, p. 255).

${ }^{9}$ Em resultado da implementação do dipositivo legal que estabelece condições de regularização a quem comprove a titularidade da relação laboral (Decreto-Lei n. ${ }^{\circ} 4 / 2001$, de 10 de janeiro), o número de imigrantes a residir legalmente em Portugal passou de 208.198, no ano 2000, para 350.503, no ano seguinte, um aumento de cerca de $68 \%$ da população estrangeira a residir legalmente em Portugal, espelhando as entradas de população proveniente de alguns países da "Europa de Leste" (como sejam Moldávia, Federação Russa, Ucrânia e Roménia), ocorridas no final da década de 1990.
} 
de contração económica e financeira, que Portugal se assume com um duplo estatuto - como um país de emigração e um país de imigração (Baganha et al., 2002; Pires et al., 2010).

Ambas as dimensões demográficas - emigração e imigração - compõem, ainda que com incidência temporal diferenciada, a estrutura social e económica portuguesa, o que leva alguns autores (Peixoto, 2004) a denominar de "regime misto" as dinâmicas de mobilidade internacional no caso português.

Neste momento, apesar de ter havido uma diminuição do número de emi-

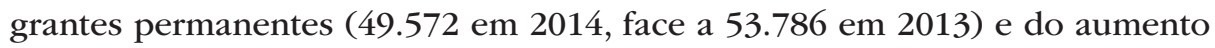
do número de imigrantes permanentes (19.516 em 2014, face a $17.554 \mathrm{em}$ 2013), o 'regime emigratório' prevalece, como aliás o discurso institucional recentemente o reconheceu. O último relatório elaborado pelo Observatório da Emigração (Pires et al., 2015), um organismo tutelado pela Secretaria de Estado das Comunidades, refere-se concretamente ao facto de Portugal passar a ser um país de emigração, com 110 mil saídas entre 2013 e 2014 (incluindo emigrantes permanentes e temporários), um número similar ao ocorrido em 1973, num contexto influenciado pela crise petrolífera (Pires et al., 2015) ${ }^{10}$.

Em termos do perfil do nível das habilitações académicas, e recorrendo aos dados do último Recenseamento Populacional (Censos de 2011) e à Labour Force Survey (LFS) da Eurostat (Naumann, 2013), é possível verificar que:

- em 2011, os emigrantes que saíram de Portugal há menos de três anos e com qualificações mais baixas correspondem ao dobro dos emigrantes na mesma condição provenientes de outros países da Europa do Sul (Espanha, Grécia e Itália) e da União Europeia no seu total;

- os emigrantes de Portugal com qualificações superiores e que emigraram há menos de três anos representam quase metade dos emigrantes dos restantes países da Europa do Sul.

\footnotetext{
${ }^{10}$ Refira-se que um dos projetos de investigação sobre a emigração em Portugal (REMIGR - "Regresso ao Futuro: a nova emigração e a relação com a sociedade portuguesa") tem salientado a possibilidade de ter existido um recente aumento da "circulação", o que se pode comprovar pelo crescimento do perfil "emigração temporária" na corrente migratória desde 2011 (segundo o Instituto Nacional de Estatística (INE), 56.980 em 2011 e 85.052 em 2014). Estaremos, desta forma, perante o que poderíamos designar como sendo a emergência de um "regime de circulação".
} 
Os dados confirmam, no entanto, a hipótese de uma mudança estrutural na composição educacional da emigração em Portugal; isto é, em plena crise económico-financeira (entre 2008-2011) a proporção de emigrantes com menos de três anos de migração e com qualificações elevadas quase que duplicou (de 14\% em 2008 para 27\% em 2011) ${ }^{11}$. Uma tendência que não se observou nos outros países da Europa do Sul, uma vez que a percentagem de emigrantes nessa condição se manteve idêntica de 2008 para 2011 (correspondendo a metade do total da população recentemente emigrada).

Segundo uma outra fonte (Arslan et al., 2014), Portugal não consta na lista dos trinta países emissores de um maior número de migrantes altamente qualificados. Os Censos de 2011 revelam uma percentagem de emigração de $14 \%$ (no caso dos emigrantes altamente qualificados esse indicador varia entre $14 \%-9.8 \%$ ), um valor um pouco superior ao verificado em 2001 (no total, $12,8 \%$ e entre $8 \%-7 \%$, no caso dos altamente qualificados). Comprova-se, assim, o que se poderia designar como sendo uma tendência para a progressiva 'qualificação' do perfil da população emigrada. No entanto, apesar de em alguns países a percentagem de emigrantes portugueses com Ensino Superior ser substancial (em 2011, um indicador superior a 30\% no Reino Unido, Irlanda, Dinamarca e Noruega), predominam ainda os indivíduos com baixas e muito baixas qualificações entre a população portuguesa emigrada (Pires et al., 2015).

Por outro lado, uma outra tendência - a da sobrequalificação dos imigrantes - traduz a dificuldade de inserção no mercado de trabalho a um nível compatível com as qualificações. Segundo um estudo do Centro Europeu para o Desenvolvimento das Competências (CEDEFOP, 2011), os migrantes provenientes de países que não pertencem à UE têm uma maior probabilidade de sobrequalificação. No caso português, esse indicador é de $23 \%$ (de $14 \%$ se considerarmos os migrantes que obtêm níveis de qualificação em Portugal). Em alguns grupos de migrantes, essa percentagem é muito superior, como sejam os migrantes provenientes de alguns países da Europa de Leste, onde

11 Note-se que esta mudança estrutural reflete uma tendência da sociedade portuguesa no seu todo - um aumento da escolarização da população (em 1991, 4\% da população completou o ensino universitário ou politécnico; enquanto, em 2011, 14,8\% concluiu esse nível de ensino, uma percentagem superior no caso das mulheres - 16,9\%). 
90\% dos imigrantes altamente qualificados trabalham em áreas para as quais estão sobrequalificados. Acresce que em Portugal, comparativamente com os outros países europeus, há uma maior probabilidade de os falantes de português como língua estrangeira serem sobrequalificados (38\%).

A confluência destas duas tendências - o desperdício de qualificações da população emigrada e da população imigrada - poderá representar um constrangimento futuro ao potencial transformador da sociedade portuguesa.

No caso concreto das mobilidades internacionais no setor da saúde, podemos distinguir três fases: a primeira, que ocorre até 2004, de crescimento; uma segunda fase, de diminuição, começando em 2005 até ao ano em que se manifesta a crise económico-financeira (2008) e, daí em diante, uma fase caraterizada por flutuações constantes.

Desde o início de 1990, Portugal recebeu profissionais de saúde, sendo que, no espaço de seis anos, o número mais do que triplica (de $1.231 \mathrm{em}$ 1998, para 4.490 em 2004), altura em que atinge o valor mais elevado, correspondendo a um rácio de 36,7 profissionais estrangeiros por mil profissionais. A partir de 2005, principalmente devido à saída de enfermeiros com nacionalidade espanhola (Ribeiro et al., 2015), os valores nunca ultrapassam os quatro mil, sendo que, no último ano disponível (2014), atingem os 3.074 (ACSS, 2015c)).

Compreende-se, assim, como os fluxos imigratórios na área da saúde estão dependentes não só de políticas de recrutamento dos países de destino (neste caso, Portugal), como também da maior ou menor capacidade de retenção, e subsequente política de recrutamento, dos países de origem. De facto, foi precisamente no ano de 2005 que se verificou uma política de recrutamento mais intensiva por parte das instituições públicas espanholas, sobretudo no caso da área de enfermagem. Um ano mais tarde (2006), o Ministério de Saúde português inicia um processo de recrutamento de médicos de clínica geral em alguns países da América Latina (Cuba, Costa Rica, Colômbia, Uruguai), por forma a preencher algumas vagas carenciadas no interior sul do país.

A maioria dos profissionais de saúde pertence ao grupo profissional de medicina e de enfermagem, sendo que, em 2014, o peso percentual de médicos estrangeiros nas instituições tuteladas pelo Ministério da Saúde (MS) é de pouco mais do que $7 \%(7,01 \%)$ e o de enfermeiros estrangeiros não chega aos 
2\% (1,12\%). Note-se que o Observatório Europeu dos Sistemas e Políticas de Saúde categorizou Portugal como estando altamente dependente de médicos estrangeiros (11,1\%-18, 4\%), ao invés do que acontece no caso dos enfermeiros, cuja dependência não é significativa (Wismar et. al., 2011).

À semelhança dos profissionais de nacionalidade portuguesa, a maioria concentra-se em Lisboa (46,9\%) e no Norte (23\%), registando-se uma preponderância de profissionais de saúde estrangeiros do sexo feminino (61,8\%).

Quanto às dinâmicas emigratórias neste setor, e apesar de não dispormos de dados sobre a monitorização dos fluxos de profissionais de saúde ${ }^{12}$, podemos retratar o fenómeno de uma forma indireta, recorrendo a indicadores, tais como pedidos de reconhecimento de qualificações, suspensão ou cancelamento de registo, indicação de um endereço estrangeiro, saída do SNS ou percentagens de expatriação (Ribeiro et al., 2014).

A Ordem dos Enfermeiros (OE) portuguesa registou 929 suspensões ou cancelamentos da licença de enfermagem no ano de 2008. Decorridos cinco anos, a OE recebeu 2.516 pedidos de emissão de um documento - a Declaração das Diretivas Comunitárias - para apresentar nas congéneres europeias. A grande maioria dos enfermeiros que responderam a um inquérito da $\mathrm{OE}$ (1.837 enfermeiros) solicitou esse documento com a intenção de migrar para o Reino Unido (1.101), não tendo, na sua grande maioria, mais de cinco anos de experiência profissional. De qualquer forma, se atendermos ao facto de terem dado entrada 1.211 pedidos de atribuição de título profissional na $N u r$ sing and Midwifery Council (NMC), solicitados por enfermeiros portugueses, poderemos ter uma compreensão mais real do fenómeno (OE, 2014) ${ }^{13}$.

Segundo a Ordem dos Médicos (OM), em 2014, emigraram 387 médicos e cerca de 1.100 solicitaram a Declaração das Diretivas Comunitárias. Dados recolhidos junto das congéneres europeias revelam os principais destinos Inglaterra, Alemanha e França.

12 Com exceção de Pires et al. (2015), para o caso dos enfermeiros no Reino Unido em 2014.

13 Note-se que este tipo de pedidos apenas revela a intenção de migrar e não a ação de migrar de per se. Refira-se ainda que os que emigram não têm necessariamente de suspender a sua licença. 
Um estudo recente, que procura avaliar a satisfação dos médicos internos com a formação específica realizada em Portugal, salienta que a maioria (mais concretamente 65\%) tem planos de emigrar após o terminus da especialidade (Martins et al., 2015).

\section{Para que servem as tipologias?}

Os movimentos de saída, e o segmento mais qualificado não será exceção, tendem a ser analisados, na sua generalidade, segundo fatores de atração e de repulsão, mais ou menos determinísticos.

Os modelos de 'atração-repulsão', de inspiração económica neoclássica, concebem as migrações como um movimento que pressupõe uma análise ponderada de custos/benefícios (Lee, 1966; Todaro, 1969; Borjas, 2000). Compreende-se, assim, o ato de migrar na sua vertente racional, como uma decisão individual face a constrangimentos, no sentido de desajustamentos, do mercado de trabalho. Apesar de esta perspetiva negligenciar, de certo modo, o caráter estrutural das migrações (por exemplo, subjacente na proposta de Piore (1979) sobre o dualismo do mercado de trabalho), ressalta o papel dos processos de decisão individual na ativação dos movimentos de partida. De facto, uma abordagem micro, sobretudo quando não exclusivamente economicista, poderá ser útil na análise da (re)construção de projetos migratórios individuais, particularmente na forma como os migrantes expressam as suas motivações, expetativas e aspirações; o modo como é contextualizada, e explicada, a sua experiência migratória (Ferro, 2006).

Porém, aquilo que pode ser apreendido como um comportamento biográfico, mais ou menos isolado, mais ou menos circunstancial, face a respostas, ou à sua ausência, de um suporte institucional, político ou social reveste-se de uma componente sistémica que convém não descurar. Daí que, em termos metodológicos, a proposta de 'Retratos Sociológicos', cunhada por Bernard Lahire (2002), tenha potencial heurístico nos estudos migratórios, como se verificou com um dos projetos de investigação (Gomes, 2015) sobre a recente emigração portuguesa. 
A este título, a teoria do Sistema-Mundo, que concebe a divisão do mundo em centro, periferia, semiperiferia (Wallerstein, 1974), e que se consubstancia na ideia da interdependência económica e articulação assimétrica de poderes entre regiões/países (Cheng \& Yang, 1998), configura-se relevante na interpretação da (re)distribuição de recursos ao nível da estrutura centro-periferia, segundo o que alguns autores designam como a 'hierarquia do trabalho à escala mundial' (Takenouchi, 2001).

Precisamente, será a partir da década de 70 que se começará a enquadrar o fenómeno migratório numa perspetiva sistémica, ao compreender-se, num primeiro momento, a espacialidade das mobilidades internas (Mabogunje, 1970).

A conceção do sistema migratório ${ }^{14}$, particularmente na sua dinâmica internacional, torna-se interessante, uma vez que permite compreender os movimentos da população mais qualificada numa vertente relacional, entre países emissores e países recetores e, por essa via, sublinhar os desajustamentos estruturais e as divergências regionais que traduzem posicionamentos históricos e geoestratégicos de desigualdades estruturais.

Daí que o recurso a tipologias, como as que se apresentam para o caso das mobilidades internacionais de profissionais de saúde (Glinos, 2014; Humphries et. al., 2015), terá de ser equacionado com cautela, nomeadamente, tendo em conta as descontinuidades e a diversidade dos percursos biográficos dos sujeitos, contextualmente situados. Refira-se, no entanto, o seu caráter heurístico para uma leitura dos fluxos migratórios que transcende análises mais nomotéticas.

A este título, o desafio será, pois, a construção e sistematização de informação que tenha em consideração a heterogeneidade e a relação interescalar dos movimentos. Aliás, segundo alguns autores (Glinos \& Buchan, 2014), no caso específico dos profissionais de saúde, a identificação e a compreensão

\footnotetext{
14 Para uma operacionalização do conceito "sistema migratório internacional" vide Hania Zlotnick (1992). Na esteira de alguns autores (Peixoto, 2002; Malheiros, 2005; Peixoto, 2007; Baganha, 2009; Góis \& Marques, 2009), é possível equacionar a inserção de Portugal em vários sistemas migratórios, estruturalmente não excludentes. Pensa-se, nomeadamente, no sistema migratório do sul e norte-americano, sistema migratório lusófono e sistema migratório intraeuropeu.
} 
dos vários tipos de mobilidade, como os que se apresentam de seguida, constituem um elemento essencial no desenho de instrumentos de monitorização dos fluxos (Kuhlmann et. al., 2013).

\section{Migrantes económicos: o caso da Tânia}

Tânia, que nasceu na Grande Lisboa em 1988, está desde 2011 a trabalhar num hospital distrital a sul de Londres, onde há cerca de 100-150 enfermeiros portugueses, entre eles, o seu namorado. Apesar de, quando terminou o curso, ter tido experiência na área dos cuidados básicos de enfermagem, num posto de socorro de bombeiros (fazer pensos, dar injeções, medir a tensão arterial), só em Inglaterra conseguiu um emprego não precário, com um contrato indeterminado e um horário fixo, de segunda a sexta. Em Portugal, entregou Curriculum Vitae em todos os hospitais, sem nunca ser chamada. Como desabafa, "uma pessoa começa a ficar frustrada".

Durante seis meses, Tânia passou por um período de integração e no início teve de ir comprovando os atos de enfermagem que poderia exercer, os chamados Student Day. Pelo menos uma vez por ano tem de frequentar uma formação, o que já se traduziu num curso de "mentora de estudantes". Como realça, "Em Portugal, quem ia às formações era a enfermeira chefe, muitas vezes nem partilham informação". O facto de ser possível progredir na carreira e conciliar o trabalho e a formação são dois aspetos que destaca. Quando pondera a questão do regresso, tem consciência de que o ordenado em Portugal seria bastante inferior, que teria de abdicar das férias, das viagens, mas ressalva que quem tenha interesse em vir, não o deve fazer "só por causa do dinbeiro".

\section{Migração por motivos de carreira: o caso da Francisca}

Francisca nasceu no Porto em 1984, teve uma experiência de trabalho em Lisboa como enfermeira dos cuidados intensivos durante dois anos e, neste momento, trabalha há pouco mais de um ano em Abu Dhabi, como enfermeira instrumentista no bloco operatório, uma posição que dificilmente alcançaria em Portugal numa idade tão jovem. Normalmente, as enfermei- 
ras europeias fazem o turno da manhã, mas ela faz questão de fazer turnos rotativos, de modo a não ser privilegiada e de se colocar à prova em vários contextos, como refere "(...) aqui tenho experiência em todas as áreas, como não têm pessoal, tenho de aprender a instrumentar tudo”.

Considera que está num país culturalmente fechado, mas "desde que se respeite a cultura e não se intrometer..." A sua chefe é indiana e como há uma estratificação social baseada na nacionalidade, sendo europeia, apesar de mais nova e com menos experiência, Francisca obtém uma remuneração superior.

Neste momento, está a tirar um curso de árabe por conta própria, uma vez que considera ser uma mais-valia saber a língua do país. Para além da língua e das diferenças culturais, existe a necessidade de avaliação in situ das competências técnicas. Francisca está inscrita em três entidades reguladoras da profissão, a Ordem dos Enfermeiros portuguesa, a NMC e a autoridade de saúde de Abu Dhabi. A inscrição na NMC permitiu-lhe o ingresso direto nesta última entidade reguladora, ultrapassando a fase dos exames escritos ${ }^{15}$.

Antes de vir, Francisca recebeu uma proposta num hospital privado do norte de Portugal, onde iria ganhar perto de oitocentos Euros. Em Abu Dhabi, ganha cinco vezes mais, trabalha menos, tem melhor qualidade de vida. Em Portugal, quando não trabalhava aos fins de semana, só dormia. Por isso, conta ficar pelo menos cinco anos, "para compensar em todos os aspetos". Coloca mesmo a possibilidade de reemigrar para a Austrália. Francisca aconselha todos os enfermeiros portugueses a emigrar, como observa, "se calhar só assim é que vão dar valor à enfermagem! Alguns aceitam dois euros à bora”.

\section{Migração como modo de vida: o caso do Pedro}

Pedro, nascido em 1983, fez o curso de medicina no Porto, o que representou a sua primeira experiência de mudança de residência, uma vez que

15 O registo na Nursing and Midwifery Council favorece, assim, oportunidades de remigração, particularmente para países do Médio Oriente e para países que pertencem à Commonwealth. 
morava em Castelo de Paiva. Por altura do sexto ano, teve a sua primeira experiência de mobilidade internacional, neste caso no Rio de Janeiro, cidade de onde provém a sua mulher (médica de medicina interna) e onde teve a oportunidade de contactar com uma cultura diferente da europeia. Para esta primeira mobilidade, contou com um empréstimo bancário. Depois seguiu-se o internato em Neurologia, uma especialidade que sempre lhe agradou, na Suíça. Esta escolha surge depois de exploradas outras alternativas em vários países europeus, como França, Suécia e Inglaterra. Acabou por ir para a Suíça em outubro de 2009, onde já tinha efetuado um estágio remunerado de dois meses, que lhe possibilitou o aperfeiçoamento da língua francesa. Dessa experiência destaca o facto de ter gostado do sistema (cada interno envia o curriculum e tem de procurar os serviços de formação), de ter percebido melhor como "as coisas funcionavam aqui, o que tinha que fazer para vir para cá”, da dimensão multicultural do país e da abertura dos médicos. Como explica, “(...) sempre me imaginava a fazer algo fora do país. Lembro-me uma vez estar na aula de Machado Vaz-também ele fez a especialidade fora - ... Eu revi-me na experiência que partilhou connosco!". O Internato fora de Portugal permitiu-lhe "ver outra realidade, mas para além das possibilidades económicas, conbecer outras coisas, viajar, contacto com outra medicina. Existem sempre estímulos para ir mais além, se quiser fazer outros estágios (...) Se calhar em Portugal não tinha o mesmo acesso que tenbo aqui".

Neste momento, e já com a especialidade terminada, Pedro irá com a mulher para Paris, com uma bolsa de pelo menos um ano, que lhes permitirá fazer investigação clínica, especializarem-se num tema dentro da especialidade, como enfatiza, "vou ver outra realidade, ir um pouco mais além da medicina".

\section{Em trânsito: o caso do Luís}

Luís exerce, desde 2012, cirurgia num dos maiores hospitais de Londres. Esta não é a sua primeira experiência de mobilidade internacional, uma vez que já tinha efetuado um estágio de três meses nos EUA, dois meses em França e um mês em Barcelona. 
Anteriormente, trabalhou num hospital do Porto, mas "(..) quando começaram a dizer que iam fazer cortes, comecei a ver outras opções (...) eram oito candidatos para um lugar... nunca pensei... Passado um mês estava a trabalhar! (...) Pensava que ia por três meses, não me ia adaptar... Não sabia para o que vinha... Entrei logo para 'consulting' (...) o 'consulting' é lei!"

Em Portugal, "começava a ter de fazer controlo do dedo, a entrar às $8 e$ sair às 17. Aqui em Inglaterra não há livro de ponto, não há nada. Funciona muito melhor!" Em Inglaterra, apesar de não pertencer ao quadro, e ainda que estando sujeito a avaliações anuais, Luís tem uma equipa de cinco internos, pela qual é responsável. Em cada doze semanas, faz urgências no fim de semana, mas "não custa nada. Não há aquela coisa de operar os doentes ao meio da noite. É muito mais sossegado!"

Separado, com três filhos, Luís vai quase todos os fins de semana ao Porto, "garantidamente vai duas vezes por mês (...) tenho a minha casa em Portugal!'. Pensa, objetivamente, na possibilidade de os filhos fazerem o Ensino Superior em Londres, onde é mais fácil arranjar trabalho.

O regresso a Portugal está definitivamente posto de parte, "vou para Portugal, para trabalhar como médico nas urgências?! Nem pensar! Já dei para esse peditório!" Luís realça, "vejo que Portugal perdeu... (...) andaram a investir na minha formação e quando chegou a bora, Inglaterra teve um cirurgião sem ter de pagar nada por isso! Aos ingleses saiu-lhes muito barato."

Este cirurgião, nascido em 1967, continua atento às ofertas internacionais de trabalho, enviando currículos de forma espontânea. Porque está coletado na Royal College of Physicians, está automaticamente reconhecido nos países dos Emirados Árabes Unidos. Neste momento, tem uma proposta de trabalho para um hospital privado em Abu Dhabi, como salienta "empregos para cirurgião é que não faltam!"

\section{Não documentados: o caso da Valentina}

Valentina, enfermeira, nascida em 1956 na Ucrânia, veio para Portugal com um visto turístico. Começou a trabalhar num lar de idosos, no Algarve, como auxiliar, só conseguindo a regularização na altura em que esteve empregada como ama interna numa casa particular. Tendo sido alertada por uma médica 
ucraniana acerca do programa de reconhecimento de qualificações na área de enfermagem, dinamizado por uma Organização Não Governamental, com o apoio de uma Fundação, resolveu apresentar os seus documentos para acionar o processo de equivalências. Neste momento, trabalha num lar em Lisboa, como enfermeira, num local onde já lhe tinha sido recusado emprego porque não tinha a sua situação regularizada.

Antes de vir para Portugal, esta enfermeira ucraniana trabalhava num colégio, na prestação de cuidados pediátricos, ao mesmo tempo que acabava o curso universitário em pedagogia infantil. Decidiu vir para Portugal pois não possuía condições monetárias suficientes para o financiamento dos estudos superiores do seu filho, atualmente cirurgião na Ucrânia. Como explica, “(...) porque a economia baixou muito e nós estamos pobres! Antigamente era um país bonito, um país com trabalbo, ninguém pensava trabalhar noutro país, por exemplo, fazer limpezas, essas coisas... Não! Nós estudámos, trabalhámos, muitos engenheiros, muitos médicos!"

Valentina pensa no seu país apenas como destino de férias. Como revela, "a minha vida caminhou sozinha, fugiu para este sítio". Demonstra-se desencantada com os políticos ucranianos, "porque eles não fizeram nada para nós voltarmos".

\section{Migração de regresso/remigração: o caso da Isabel}

Isabel, após fazer o Internato Geral no Porto, entrou no Internato de Genética, que interrompeu. Aquilo a que chama "espírito de aventura" levou-a a fazer o doutoramento na Suécia, seguindo-se um pós-doutoramento em Londres. Tendo percebido que queria voltar ao Internato, regressou a Portugal em 2009, mais concretamente a Coimbra, onde estava o seu marido dinamarquês a fazer um pós-doutoramento. Entretanto, houve uma mudança no período de atribuição da bolsa do marido, encurtaram-na e, como as "coisas pareciam negras", a Genética Molecular "não era uma boa aposta (...) já não era muito novo”, decidiram sair. Num mês arranjou emprego em Bruxelas.

Em Bruxelas, Isabel teve uma má experiência de trabalho. Como salienta esta médica nascida em 1976, “(...) infelizmente, a especialidade de Genética não existe. Trabalhava como médica sem especialidade e apercebi-me de cada 
vez mais abusos, cada vez mais responsabilidades (...) quem faz várias funções, acaba por não fazer nada bem (...) acabei por vir para aqui [Londres], já me tinha registado como especialista, e conbecia pessoas."

Neste momento, está como Consultant em Genética Infantil. Considera que em Inglaterra "as coisas estão mais organizadas (...) ninguém espera que trabalhes mais do que isso.” Os designados 'long day' são compensados financeiramente, não é como em Portugal "trabalhamos sempre mais e não recebemos nenbum extra", mas depois, "à medida que sobes na carreira o acréscimo salarial não é assim tão grande".

Mantém ligações a Portugal porque, como diz, "nunca se sabe". A quota para a Ordem dos Médicos é a "única coisa que os meus pais me pagam (...) O valor anual não é assim tão caro. Se eu deixar de pagar e quiser voltar, vão obrigar a pagar quotas". O regresso é frequentemente equacionado, como explicita “(...) Eu via-me a trabalhar em Portugal. Aqui [Londres] há clínica e investigação, mas não é a nossa casa. Custou-me imenso sair!" Em Portugal, "(...) as oportunidades não existem. Há uma certa resistência... Se as chefias fossem mais rotativas... Não há dinâmica!"

Neste momento, Isabel espera ficar pelo menos um ano, que “(...) eu tenbo intenções de cumprir, porque não é muito agradável estar sempre a mudar (...) estou um bocado escaldada (...) Quem me dera não ter de mudar! E se mudar, mudar para Portugal!".

Por agora, como tem a irmã na Suécia, Inglaterra revela-se uma boa solução, uma vez que está a duas horas do Porto. Não quer ficar longe dos pais, como refere “(...) Estão a ficar velhotes e não têm lá [Portugal] ninguém!"

\section{Considerações finais: rumo a uma (di)visão do conhecimento e/ou do trabalho?}

Mais do que explicar as causas associadas às migrações qualificadas a migração internacional de médicos e de enfermeiros -, procurou-se compreender a inter-relação de contextos que, apesar de exteriores ao campo migratório strictus sensus (como sejam, a saúde, a educação, o mercado de trabalho), confluem na dinamização do fenómeno. Por outro lado, ao consi- 
derar-se os percursos subjetivos de mobilidade internacional e a sua inserção em tipologias, realçou-se não só a diversidade, mas também a complementaridade, cruzamento e justaposição dos perfis analisados. Ao compreendermos a e-/imigração como um movimento alicerçado num enquadramento geo-histórico-político (no caso em apreço, um país europeu semiperiférico com um passado colonial e sujeito a significativas restrições de índole económico-financeira); tornamos visível o papel de transformações sociais - neste caso de caráter regressivo - na mobilização de movimentos de partida.

Convém realçar que estamos perante um segmento particular das migrações qualificadas, classificado mesmo por alguns autores como sendo excecional, dadas as questões éticas que comporta (Alkire \& Chen, 2004). Com efeito, a expressão 'fuga de cérebros' 16 apresenta-se como um fenómeno heterogéneo na área da saúde, apresentando diferentes facetas que transcendem a vertente internacional: a mobilidade interna dos cuidados primários para os cuidados diferenciados, da prestação de cuidados à inserção em posições de investigação ou de gestão, do setor público para o setor privado (Marchal \& Kegels, 2003).

No caso concreto, a migração internacional de profissionais de saúde induz, e contribui mesmo para reforçar, desigualdades globais de nível estrutural. Esta migração qualificada não pode ser compensada pelo envio de remessas aos países de formação, uma vez que esta prática transnacional não se traduz, diretamente, num melhor desempenho dos serviços de saúde e/ou numa retribuição relativa dos custos educacionais (Paker, Runnels \& Labonté, 2009). Deste modo, e se pensarmos estes movimentos na sua escala global, um eixo de análise será, certamente, o desequilíbrio manifesto entre escolhas individuais (o direito de emigrar) e oportunidades estruturais (o direito de acesso a cuidados de saúde).

A esse título, pensar nas migrações no setor da saúde, e sobretudo nas suas assimetrias, é uma forma de nos interrogarmos sobre justiça/injustiça global.

16 A 'fuga de cérebros' é um fenómeno que, não raras vezes, é compreendido de uma forma negativa, representando um estigma social nacional. A este título, associa-se a perda de qualificados a um reduzido crescimento económico. Aproximando-se de uma interpretação neocolonial deste movimento de saída, instituições supranacionais como as Nações Unidas compreendem a unilateralidade deste fluxo, de sul para norte (Gaillard, 1991). 
A aplicação de políticas de austeridade, nomeadamente no que se refere a restrições orçamentais na despesa pública, com impactos diretos em setores sociais como o da saúde, crescentemente feminizados, reflete, no fundo, o papel cada vez mais preponderante de instituições financeiras internacionais (como sejam o FMI ou o BCE) nas políticas públicas nacionais. Ainda que não plenamente estudados os seus efeitos na área da saúde (Ribeiro, 2015), convém lembrar o papel desses atores transnacionais nos desequilíbrios regionais. Aliás, refira-se a permeabilidade do setor da saúde à mercantilização dos serviços, contemplada, nomeadamente, em acordos de políticas globais do comércio, quer negociados no âmbito do Acordo Geral sobre o Comércio de Serviços (GATS), quer em fase de negociação no quadro do TTIP (Transatlantic Trade and Investment Partnership).

Paralelamente, floresce toda uma 'indústria' de recrutamento internacional, envolvendo uma amplitude de atividades, como sejam empresas de recrutamento, escolas de línguas, serviços de tradução e de autenticação de documentos que, nos termos sugeridos por Stephen Castles e Mark J. Miller (2003), se aproximam de uma 'indústria migratória' específica para o segmento mais qualificado da população migrante.

O papel destes novos agentes na dinamização, discricionariedade e segmentação dos fluxos ${ }^{17}$ permite equacionar as "qualificações" como um recurso de mobilidade, assim que estiverem reunidas as oportunidades estruturais (da esfera estatal mas também de mercado) para as ativar. Deste modo, as mobilidades internacionais contemporâneas tendem a não se rever no binómio "migrações forçadas/migrações voluntárias", sobretudo se pensarmos na relação intrínseca entre condicionalismos individuais e condicionalismos estruturais, visível, por exemplo, mas não só, no processo de decisão de migrar.

O caso particular da "fuga de cérebros", independentemente das considerações que se possam tecer quanto à representatividade da expressão (e, não

17 Sobretudo se considerarmos a especificidade do perfil dos migrantes em função dos países de destino, ou seja, se atendermos ao facto de determinados países, em função de necessidades laborais e da posição histórico-geo-estratégica que ocupam, terem a capacidade de atrair certos grupos profissionais. No caso português, observa-se uma direcionalidade dos fluxos para os países do sistema lusófono e sul-americano, essencialmente, de engenheiros e arquitetos; enquanto os profissionais de saúde se direcionam, na sua maioria, para o sistema intraeuropeu. 
menos importante, dos seus efeitos na produção de processos de diferenciação social), permite-nos questionar a circularidade da argumentação determinística nas migrações, quer na procura de causas para uma mobilidade qualificada, quer na descrição das suas consequências.

A nosso ver, de maior interesse se revela a discussão de como, num contexto em que a crise económico-financeira parece constituir "o" modelo económico das sociedades atuais, desígnios basilares de um Estado de direito social (como o direito a um trabalho digno) podem ser secundarizados pelas instâncias de poder. Tal circunstância impele à realização desse interesse vital muitas vezes em sociedades (e, por isso mesmo, em mercados de trabalho) inspiradas por princípios com limitada orientação democrática. Simultaneamente esvaziam-se países democráticos de origem de uma massa crítica jovem, precisamente numa altura em que o Estado de direito social está a ser fortemente questionado, como é o que acontece no caso dos países da Europa do Sul.

Percursos de precariedade, insegurança económica e de descontinuidades de vínculos laborais, por um lado; procura de uma mão-de-obra qualificada, sem custos diretos de formação, por outro; definem uma conjugação de interesses que contribui para o acentuar de diferenças regionais e, por essa via, de desigualdades estruturais entre "centro"/"periferia”, Norte Global/Sul Global, países emigrantes/países imigrantes.

As qualificações de um determinado país, região ou instituição académica assumem-se como um dos mecanismos facilitadores (e diferenciadores) de acesso a mobilidades geográficas, sociais, económicas e culturais. Constituem, por isso, um recurso coadjuvante ao passaporte, afinal, o instrumento por excelência de regulação das mobilidades internacionais.

\section{Referências bibliográficas}

ACSS (Administração Central dos Sistemas de Saúde). (2015a). Relatório de candidaturas de USF e UCC. Lisboa: Ministério da Saúde.

ACSS (Administração Central dos Sistemas de Saúde). (2015b). Publicação periódica sobre o número de inscritos nos centros de saúde primários - Julbo 2015. Lisboa: Administração Central dos Sistemas de Saúde. 
ACSS (Administração Central dos Sistemas de Saúde). (2015c). Boletim Informativo: Recursos Humanos Estrangeiros no Ministério da Saúde - Atualização 2011/2014. Lisboa: Administração Central dos Sistemas de Saúde.

ALKIRE, S., \& Chen, L. (2004). Medical exceptionalism in international migration: should doctors and nurses be treated differently? (JLI Working Paper) 7-3, 1-10.

Arslan, C., Dumont, J-C., Kone, Z., Moullan, Y., Ozden, C., Parsons, C., \& Xenogiani, T. (2014). A New Profile of Migrants in the Aftermath of the Recent Economic Crisis. (Paper No. 160). Paris: Publicações da OCDE.

BAGANHA, M. I. (2001). A cada Sul o seu Norte: dinâmicas migratórias em Portugal. In B. S. Santos (Org.), Globalização - Fatalidade ou Utopia?, (pp. 135-159). Porto: Edições Afrontamento.

BAGANHA, M. I. (2009). The Lusophone migratory system: patterns and trends. International Migration, 47(3), 196-210.

Baganha, M. I., Ferrão J., \& Malheiros J. (Eds). (2002). Os Movimentos Migratórios Externos e a sua incidência no mercado de trabalho em Portugal. Lisboa: Observatório do Emprego e Formação Profissional.

BAGANHA, M. I., \& Góis, P. (1999). Migrações internacionais de e para Portugal: o que sabemos e para onde vamos? Revista Crítica de Ciências Sociais, n. ${ }^{\circ}$ 52/53, 229-280.

BAGANHA, M. I., Marques, J. C., \& Góis, P. (2004). Novas migrações, novos desafios: a imigração do leste europeu. Revista Crítica de Ciências Sociais, n. ${ }^{\circ}$ 69, 95-115.

Baganha, M. I., \& Peixoto J. (1997). Trends in the 90's: the Portuguese Migratory Experience. In M. I. Baganha (Ed.), Immigration in Southern Europe, (pp. 15-40). Oeiras: Celta.

BARRos, P., Machado, S., \& Simões, J. (2011). Portugal: Health System Review. Health System in Transition, 13(4), 1-156.

BERCHET, C. (2015). Emergency Care Services - trends, drivers and interventions to manage the demand. (Paper No. 83). doi: https://doi.org/10.1787/18152015).

BORJAS, G. (2000). Economics of migration. International Encyclopedia of the Social and Behavioral Sciences, Section n. ${ }^{\circ}$ 3.4., Article n. ${ }^{\circ}$ 38. Fev., 1-22.

BRAVERMAN, H. (1974). Labor and Monopoly Capital: The Degradation of Work in the Twentieth Century. Nova Iorque: Monthly Review Press.

CANDeias, P., Góis, P., Marques, J. C., \& Peixoto, J. (2014). Emigração portuguesa: bibliografia comentada (1980-2013). (Paper n. ${ }^{\circ}$ 1). Lisboa: ISEG). 
CASTLES, S., \& Miller, M. J. (2003). The Age of Mass Migration. Nova Iorque: Guilford Press.

CE (Comissão Europeia). (2015). Education and Training Monitor 2015. Luxemburgo: Publicações da União Europeia.

CEDEFOP (Centro Europeu para o Desenvolvimento da Formação Profissional). (2011). Migrants, minorities, mismatch? Skill mismatch among migrants and ethnic minorities in Europe. Luxemburgo: Publicações da União Europeia.

CEDEFOP (Centro Europeu para o Desenvolvimento da Formação Profissional). (2015). O regresso desigual da Europa ao crescimento do emprego. Nota informativa. Julho 2015.

CHENG, L., \& Yang, P. Q. (1998). Global interaction, global inequality and migration of the highly trained to the United States. International Migration, 32(3), 626-653.

ESTEVes, M. C. (Ed.). (1991). Portugal, País de Imigração. Lisboa: Instituto de Estudos para o Desenvolvimento.

ESTRADA, I. C. (2011). Questionando a cidadania pós-nacional em tempos de crise. Atas da $1^{a}$ Conferência Internacional do OBSERVARE (Observatório de Relações Exteriores da Universidade Autónoma de Lisboa).

FERRO, A. (2006). Desired Mobility or Satisfied Immobility? Migratory aspirations among knowledge workers. Journal of Education and Work, 19(2), 171-200.

GAILLARD, J. (1991). Scientists in the third world. Lexington: Kentucky University Press.

GLINOS, I. (2014). Going beyond numbers: a typology of health professional mobility inside and outside the European Union. Policy and Society, 33(1), 25-37.

GLINOS, I., \& Buchan, J. (2014). Health professionals crossing the European Union's internal and external borders: a typology and health professional mobility and migration. In J. Buchan, M. Wismar, I. Glinos, G. Dussault, \& J. Figueras (Eds.), Health professional mobility in a changing Europe: new dynamics, mobile individuals and policy responses, (vol. 2, pp. 129-52). Londres: Observatório Europeu dos Sistemas e Políticas de Saúde e OMS.

GÓIS, P., \& Marques, J. C. (2009). Portugal as a Semi-peripheral country in global migration system. International Migration, 47(3), 21-50.

GOMEs, R. M. (coord.) (2015). Fuga de Cérebros: retratos da emigração portuguesa qualificada. Lisboa: Bertrand Editora. 
HumPhries, N., McAleese, S., Tyrrell, E., Thomas, S., Normande, C., \& Brugha, R. (2015). Applying a typology of health worker migration to non-EU migrant doctors in Ireland. Human Resources for Health, 13(52), 1-12.

Kuhlmann, E., Batenburg, R., Groenewegen, P. P., \& Larsen, C. (2013). Bringing a European perspective to the health human resources debate: a scoping study. Health Policy, 110(1), 6-13.

LAHIRE, B. (2002). Portraits Sociologiques. Dispositions et Variations Individuelles. Paris: Nathan.

LEE, E. S. (1966). A Theory of Migration. Demography, 3(1), 47-57.

Mabogunje, A. L. (1970). Systems Approach to a Theory of Rural-Urban Migration. Geographical Analysis, 2(1), 1-17.

MAlHeIROS, J. (2005). Jogos de Relações Internacionais: repensar a posição de Portugal no arquipélago migratório global. In A. Barreto (Ed.), Globalização e Migrações, (pp. 251-272). Lisboa: Imprensa de Ciências Sociais.

MARCHAL, B., \& Kegels, G. (2003). Health workforce imbalances in times of globalization: brain drain or professional mobility? International Journal of Health Planning Management, Oct.-Dec., 18(Suppl. 1), S89-101.

MARTINS, M. J. et al. (2015). Satisfação com a especialidade entre os internos da formação específica em Portugal. Acta Médica Portuguesa, mar.-apr., 28(2), 209-221.

NAUMANN, R. (2013). Geographical labour mobility in the context of the crisis - Portugal. Lisboa: Observatório do Emprego Europeu e DINÂMIA.

NUNES, J. A. (2009). Saúde, direito à saúde e justiça sanitária. Revista Crítica de Ciências Sociais, 87, 143-169.

OCDE (2014). Health Statistics 2014. Retrieved from: http://dx.doi.org/10.1787/ health-data-en.

OCDE (2015). OECD Reviews of Health Care Quality: Portugal 2015. Raising Standards. Paris: OCDE.

OE (Ordem dos Enfermeiros). (2013). Dados Estatísticos da Ordem dos Enfermeiros. Lisboa: OE (não publicado).

OE (Ordem dos Enfermeiros). (2014). Dados Preliminares do Estudo 'A Emigração dos Enfermeiros Portugueses'. GRI-OE (Gabinete de Relações Internacionais): Lisboa.

OPSS (Observatório Português dos Sistemas de Saúde). (2015). Acesso aos cuidados de saúde. Um direito em risco?. In OPSS, Relatório de Primavera 2015. Lisboa: Observatório Português dos Sistemas de Saúde. 
PAKER, C., Runnels, V., \& Labonté, R. (2009). Globalization and the Cross-Border Flow of Health Workers. In R. Labonté, T. Schrecker, C. Packer, \& V. Runnels (Eds.), Globalization and Health: Pathways, Evidence and Policy, (pp. 213-234). Nova Iorque: Routledge.

PEIXOTO, J. (2002). The lusophone migration system - the end of a cycle? VII Congresso Luso-Afro-Brasileiro de Ciências Sociais. Rio de Janeiro: Brasil.

PEIXOTO, J. (2004). País de emigração ou país de imigração? Mudança e continuidade no regime migratório em Portugal. Socius Working (Paper n. ${ }^{\circ}$ 2). Lisboa: ISEG).

PEIXOTO, J. (2007). Dinâmicas e regimes migratórios: o caso das migrações internacionais em Portugal. Análise Social, 42(183), 445-469.

PIORE, M. J. (1979). Birds of Passage. Migrant Labour and Industrial Societies. Cambridge: Cambridge University Press.

PIRES, R. P. (coord.), (2010). Portugal: Atlas das Migrações Internacionais. Lisboa: Tinta da China e Fundação Calouste Gulbenkian.

PIRES, R. P., Pereira, C., Azevedo, J., Espírito Santo, I., Vidigal, I., \& Ribeiro, A. C. (2015). Emigração Portuguesa. Relatório Estatístico 2015. Lisboa: Observatório da Emigração e Rede Migra, CIES-IUL, ISCTE-IUL, e DGACCP.

RIBEIRO, J. S. (2015). Beyond the Portuguese Nursing Labour Market: Towards a Crisis of Professionalism?. In T. Carvalho, \& R. Santiago (Org.), Professionalism, Managerialism and Reform in Higher Education and the Health Services: the European welfare state and the rise of the knowledge society, (pp. 146-168). Londres: Palgrave.

RIBEIRO, J. S., Conceição, C., Pereira, J., Leone, C., Mendonça, P., Temido, M., Vieira, C. P., \& Dussault, G. (2014). Health professionals moving to... and from Portugal. Health Policy, 114(2-3), 97-108.

SANTOS, B. S. (1993). Portugal: Retrato Singular. Porto: Edições Afrontamento.

TAKENOUCHI, M. (2001). International Division of Labour and Migration as a Global Labour Supply - a Theoretical Perspective of Study. (CIRJE Discussion Paper No. F-110). Tokyo: CIRJE, Faculty of Economics, University of Tokyo.

TODARO, M. P. (1969). A model of labour migration and urban unemployment in lessdeveloped countries. American Economic Review, 59(1), 138-148.

WALlERSTEIN, I. (1974). The Modern World-System I: Capitalist Agriculture and the Origins of the European World-Economy in the Sixteenth Century. Nova Iorque: Academic Press. 
WiSMAR, M., Maier, C. B., Glinos, I., Dussault, G., \& Figueras, J. (Eds.) (2011). Health Professional Mobility and Health Systems: Evidence from 17 European Countries, Copenhaga, OMS/Observatório Europeu de Sistemas e Políticas de Saúde.

ZLOTNICK, H. (1992). Empirical identification of international migration systems. In M. M. Kritz, L. L. Lim, \& H. Zlotnick (Eds.), International Migration Systems: A Global Approach, (pp. 19-40). Oxford: Clarendon Press. 
(Página deixada propositadamente em branco) 
Rui Machado Gomes é Professor catedrático e investigador do CES da Universidade de Coimbra. Tem investigado temas das áreas da educação e das políticas educativas, incluindo a análise dos processos de mobilidade académica e de emigração qualificada. Além de outros trabalhos nos domínios da Educação e dos Estudos Culturais, publicou O governo da educação em Portugal (2005), Olhares sobre o lazer (2007) e O corpo e a política da vida (2009). Publicou também várias dezenas de artigos em revistas nacionais e internacionais dando conta dos resultados dos projetos de investigação em que participou. Foi o investigador responsável da pesquisa que deu origem a este livro. 
Série Investigação

Imprensa da Universidade de Coimbra

Coimbra University Press

2019

$\begin{array}{lll}12 & 2 & 0 \\ \text { UNIVERSIDADE }\end{array}$

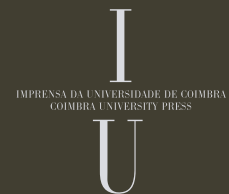

